SERGIO SERINO

\title{
Dinâmica e estabilidade em um modelo para populações de ostras
}

São Paulo 
SERGIO SERINO

\section{Dinâmica e estabilidade em um modelo para populações de ostras}

Versão original

Dissertação apresentada à Escola de Artes, Ciências e Humanidades da Universidade de São Paulo para obtenção do título de Mestre em Ciências pelo Programa de Pós-graduação em Modelagem de Sistemas Complexos.

Área de concentração: Sistemas Complexos

Orientador: Prof. Dr. José Ricardo Gonçalves de Mendonça

São Paulo

2016 
Autorizo a reprodução e divulgação total ou parcial deste trabalho, por qualquer meio convencional ou eletrônico, para fins de estudo e pesquisa, desde que citada a fonte.

Dinâmica e estabilidade em um modelo para populações de ostras / Sergio Serino ; orientador, José Ricardo Gonçalves de Mendonça. - São Paulo, 2016

$82 \mathrm{f}$. : il

Dissertação (Mestrado em Ciências) - Programa de PósGraduação em Modelagem de Sistemas Complexos, Escola de Artes, Ciências e Humanidades, Universidade de São Paulo

Versão original

1. Ostra. 2. Sistemas dinâmicos. 3. Cálculo diferencial e integral. 4. Dinâmica de populações. I. Mendonça, José Ricardo Gonçalves de, orient. II. Título

CDD 22.ed. -594.4 
Dissertação de autoria de Sergio Serino, sob o título "Dinâmica e estabilidade em um modelo para populações de ostras", apresentada à Escola de Artes, Ciências e Humanidades da Universidade de São Paulo, para obtenção do título de Mestre em Ciências pelo Programa de Pós-graduação em Modelagem de Sistemas Complexos, na área de concentração Fundamentos de Sistemas Complexos, aprovada em de de pela comissão julgadora constituída pelos doutores:

$\operatorname{Prof}(\mathbf{a}) . \operatorname{Dr}(\mathbf{a})$.

Presidente

Instituição:

$\operatorname{Prof(a).~Dr(a).~}$

Instituição:

$\operatorname{Prof(a).} \operatorname{Dr}(a)$.

Instituição:

$\operatorname{Prof(a).~Dr(a).~}$

Instituição: 


\section{Agradecimentos}

Agradeço ao meu orientador, Prof. Dr. José Ricardo Gonçalves de Mendonça, pelo seu apoio, foco e determinação na construção deste trabalho.

Agradeço aos professores doutores Alexandre Ferreira Ramos e Carla Morsello, que participaram de minha banca de qualificação com contribuições diretas e muito importantes para este estudo.

Agradeço aos professores doutores Andrea Leite Rodrigues, Camilo Rodrigues Neto, Carlos de Brito Pereira, Fernando Coelho, Fernando F. Ferreira, Flávia Mori Sarti, Francisco J. S. M. Alvarez, Joyce da Silva Bevilacqua, Masayuki O. Hase e Paulo Sinisgalli, cujas aulas, seminários e opiniões foram muito importantes para a realização deste trabalho.

Finalmente, agradeço a todos os meus colegas de mestrado, em especial aos meus amigos Gustavo Antonio Freitas de Mendonça e Willian Wagner Lautenschläger pelas importantes sugestões proferidas. 


\section{Resumo}

SERINO, Sergio. Dinâmica e estabilidade em um modelo para populações de ostras: subtítulo do trabalho. 2016. 82 f. Dissertação (Mestrado em Ciências) - Escola de Artes, Ciências e Humanidades, Universidade de São Paulo, São Paulo, 2016.

O objetivo deste trabalho é estudar a ocorrência de mudanças de regime típicas de comportamentos em sistemas complexos, em particular no contexto de sistemas dinâmicos aplicados. Para isso, desenvolvemos um modelo matemático que representa a interação entre uma cultura de ostras utilizadas para consumo humano e os processos de eutrofização e biorremediação do ecossistema que as contém. As interações entre as populações de ostras e do fitoplâncton entre si e com a matéria suspensa, subproduto das relações entre os componentes do meio e seu processo de eutrofização, alteram os níveis de oxigenação e a consequente qualidade da água devido à realização de maior ou menor quantidade de fotossíntese pelas vegetações mais profundas do meio. Neste trabalho propomos um sistema dinâmico de três variáveis para modelar esse sistema e analisamos seus pontos de equilíbrio usando duas técnicas, método de Quirk-Ruppert e os critérios de Routh-Hurwitz, além de resolvê-lo numericamente para um conjunto de parâmetros realísticos (fenomenológicos) obtidos a partir da literatura especializada. Nossos resultados indicam que o limite de extração diária de ostras que pode ser realizado sem levar a cultura ao colapso gira em torno de $4.8 \%$ da população.

Palavras-chaves: Sistemas dinâmicos. Sistemas complexos. Dinâmica de populações. Método de Quirk-Ruppert. Critérios de Routh-Hurwitz. 


\begin{abstract}
SERINO, Sergio. Dynamics and stability in a model for oyster populations: work subtitle. 2016. 82 p. Dissertation (Master of Science) - School of Arts, Sciences and Humanities, University of São Paulo, São Paulo, 2016.

The objective of this work is to study the occurrence of regime shifts that are typical in the behavior of complex systems, in particular in the context of applied dynamical systems. Accordingly, we have developed a mathematical model that represents the interaction between a culture of oysters used for human consumption and the eutrophication and bioremediation processes of the ecosystem containing the culture. The interactions between the oyster populations and the phytoplankton between themselves and with the suspended matter, that appears as a by-product of the relationship between the components of the medium and its eutrophication process, change the oxygenation levels and the resulting water quality due to the realization of a greater or lesser amount of photosynthesis by the vegetation of the deeper levels. In this paper we propose a dynamical system of three variables to model the system and analyze its points of equilibrium using two techniques, the Quirk-Ruppert method and the Routh-Hurwitz criteria, besides solving the equations numerically for a realistic (phenomenological) set of parameters obtained from the literature. Our results indicate that the daily extraction threshold that can be achieved without collapsing the culture of oysters amounts to approximately $4.8 \%$ of the total population.
\end{abstract}

Keywords: Dynamical systems. Complex systems. Population dynamics. Method of QuirkRuppert. Routh-Hurwitz criteria. 


\section{Lista de figuras}

Figura 1 - Diagrama do sistema dinâmico de Lotka-Volterra . . . . . . . . . . . 13

Figura 2 - Soluções para o sistema Lotka-Volterra . . . . . . . . . . . . 15

Figura 3 - Retrato de Fase para o sistema de Lotka-Volterra . . . . . . . . . . 15

Figura 4 - Nutrient Loading . . . . . . . . . . . . . . . 17

Figura 5 - Modelo "c" de Scheffer . . . . . . . . . . . . . . . 20

Figura 6 - Grafo orientado do sistema dinâmico proposto . . . . . . . . . 23

Figura 7 - Grafo de Sistema Dinâmico com 3 espécies . . . . . . . . . . 27

Figura 8 - Grafo de Sistema Dinâmico com 3 espécies . . . . . . . . . . 28

Figura 9 - Grafo de Sistema Dinâmico com 6 espécies . . . . . . . . . . . . 29

Figura 10 - Grafo de Sistema Dinâmico com 8 espécies ～. . . . . . . . . . . . 29

Figura 11 - Color test aplicado a um grafo de Sistema Dinâmico com 3 espécies . . . 31

Figura 12 - Color test aplicado a um grafo de Sistema Dinâmico com 5 espécies . . . . 31

Figura 13 - Grafo orientado - Exemplo de aplicação dos critérios de Routh-Hurwitz . 34

Figura 14 - Condições I e II para método de Quirk-Ruppert aplicadas no ponto de equilíbrio $P_{4}$, elemento $a_{11} \ldots \ldots \ldots \ldots$

Figura 15 - Condições I e II para método de Quirk-Ruppert aplicadas no ponto de equilíbrio $P_{4}$, elemento $a_{22} \ldots \ldots \ldots \ldots \ldots$

Figura 16 - Condições I e II para método de Quirk-Ruppert aplicadas no ponto de equilíbrio $P_{4}$, elemento $a_{33} \ldots \ldots \ldots \ldots$. . . . . . . . . 40

Figura 17 - Condição III para método de Quirk-Ruppert aplicadas no ponto de equilíbrio $P_{4}$, elemento $a_{12}$ e $a_{21} \ldots \ldots \ldots \ldots \ldots$

Figura 18 - Condição III para método de Quirk-Ruppert aplicadas no ponto de equilíbrio $P_{4}$, elemento $a_{13}$ e $a_{31} \ldots \ldots \ldots \ldots \ldots$

Figura 19 - Condição V para método de Quirk-Ruppert aplicadas no ponto de equilíbrio $P_{4}, \operatorname{det} A \ldots \ldots \ldots \ldots \ldots \ldots \ldots$

Figura 20 - Estudo de sinal para o método de Quirk-Ruppert no ponto de equilíbrio $P_{4} \quad$. 42

Figura 21 - Condição V para método de Quirk-Ruppert aplicadas nos pontos de equilíbrio $P_{1}$ e $P_{2}, \operatorname{det} A \ldots \ldots \ldots \ldots \ldots \ldots$

Figura 22 - Condição I para método de Quirk-Ruppert aplicada no ponto de equilíbrio $P_{3}$, elemento $a_{11} \ldots \ldots \ldots \ldots \ldots \ldots$

Figura 23 - Condição $a_{1}$ para o ponto de equilíbrio $P_{1} \ldots \ldots \ldots \ldots$. . . . . 44 
Figura 24 - Condição $a_{3}$ para o ponto de equilíbrio $P_{1} \ldots \ldots \ldots \ldots$

Figura 25 - Condição $a_{1} a_{2}$ para o ponto de equilíbrio $P_{1} \ldots \ldots \ldots \ldots$

Figura 26 - Estudo de sinal para os critérios de Routh-Hurwitz no ponto de equilíbrio $P_{1} \quad 46$

Figura 27 - Soluções para o sistema dinâmico na vizinhança do ponto de equilíbrio $P_{1}$ perturbado na variável $P(t), P_{1}=(\delta, 0,0), \delta=1 \cdot 10^{-6}, h=0.0005 \ldots$. .

Figura 28 - Soluções para o sistema dinâmico na vizinhança do ponto de equilíbrio $P_{1}$ perturbado na variável $O(t), P_{1}=(0, \delta, 0), \delta=1 \cdot 10^{-6}, h=0.0005 \ldots \ldots$

Figura 29 - Soluções para o sistema dinâmico na vizinhança do ponto de equilíbrio $P_{1}$ perturbado na variável $M(t), P_{1}=(0,0, \delta), \delta=1 \cdot 10^{-6}, h=0.0005 \ldots$.

Figura 30 - Condição $a_{1}$ para o ponto de equilíbrio $P_{2} \ldots \ldots \ldots \ldots$

Figura 31 - Condição $a_{3}$ para o ponto de equilíbrio $P_{2} \ldots \ldots \ldots \ldots$

Figura 32 - Condição $a_{1} a_{2}$ para o ponto de equilíbrio $P_{2} \ldots \ldots \ldots \ldots$

Figura 33 - Estudo de sinal para os critérios de Routh-Hurwitz no ponto de equilíbrio $P_{2} \quad 51$

Figura 34 - Soluções para o sistema dinâmico na vizinhança do ponto de equilíbrio $P_{2}$ perturbado na variável $P(t), P_{2}=(\delta, 0,1), \delta=1 \cdot 10^{-6}, h=0.05 \ldots 52$

Figura 35 - Soluções para o sistema dinâmico na vizinhança do ponto de equilíbrio $P_{2}$ perturbado na variável $O(t), P_{2}=(0, \delta, 1), \delta=1 \cdot 10^{-6}, h=0.05 \ldots 53$

Figura 36 - Soluções para o sistema dinâmico na vizinhança do ponto de equilíbrio $P_{2}$ perturbado na variável $M(t), P_{2}=(0,0,1+\delta), \delta=1 \cdot 10^{-6}, h=0.05 \ldots 54$

Figura 37 - Condição $a_{3}$ para o ponto de equilíbrio $P_{3} \ldots \ldots \ldots \ldots$

Figura 38 - Condição $a_{1} a_{2}$ para o ponto de equilíbrio $P_{3} \ldots \ldots \ldots$. . . . . . . 56

Figura 39 - Estudo de sinal para os critérios de Routh-Hurwitz no ponto de equilíbrio $P_{3} \quad 57$

Figura 40 - Soluções para o sistema dinâmico na vizinhança do ponto de equilíbrio $P_{3}$ perturbado na variável $P(t), P_{3}=\left(P^{*}+\delta, O^{*}, M^{*}\right), \delta=1 \cdot 10^{-6}, h=0.047 .58$

Figura 41 - Soluções para o sistema dinâmico na vizinhança do ponto de equilíbrio $P_{3}$ perturbado na variável $O(t), P_{3}=\left(P^{*}, O^{*}+\delta, M^{*}\right), \delta=1 \cdot 10^{-6}, h=0.047$.

Figura 42 - Soluções para o sistema dinâmico na vizinhança do ponto de equilíbrio $P_{3}$ perturbado na variável $O(t), P_{3}=\left(P^{*}, O^{*}+\delta, M^{*}\right), \delta=1 \cdot 10^{-6}, h=0.049$.

Figura 43 - Soluções para o sistema dinâmico na vizinhança do ponto de equilíbrio $P_{3}$ perturbado na variável $M(t), P_{3}=\left(P^{*}, O^{*}, M^{*}+\delta\right), \delta=1 \cdot 10^{-6}, h=0.047$

Figura 44 - Condição $a_{3}$ para o ponto de equilíbrio $P_{4} \ldots \ldots \ldots$

Figura 45 - Condição $a_{1} a_{2}$ para o ponto de equilíbrio $P_{4} \ldots \ldots \ldots$

Figura 46 - Estudo de sinal para os critérios de Routh-Hurwitz no ponto de equilíbrio $P_{4} \quad 64$ 
Figura 47 - Soluções para o sistema dinâmico na vizinhança do ponto de equilíbrio $P_{4}$ perturbado na variável $P(t), P_{4}=\left(P^{*}-\delta, O^{*}, M^{*}\right), \delta=5 \cdot 10^{-1}, h=0.047$.

Figura 48 - Soluções para o sistema dinâmico na vizinhança do ponto de equilíbrio $P_{4}$ perturbado na variável $O(t), P_{4}=\left(P^{*}, O^{*}+\delta, M^{*}\right), \delta=5 \cdot 10^{-1}, h=0.047 .66$

Figura 49 - Soluções para o sistema dinâmico na vizinhança do ponto de equilíbrio $P_{4}$ perturbado na variável $M(t), P_{4}=\left(P^{*}, O^{*}, M^{*}+\delta\right), \delta=5 \cdot 10^{-1}, h=0.047$

Figura 50 - Soluções para o sistema dinâmico na vizinhança do ponto de equilíbrio $P_{4}$ perturbado na variável $P(t), P_{4}=\left(P^{*}-\delta, O^{*}, M^{*}\right), \delta=1 \cdot 10^{-6}, h=0.049$.

Figura 51 - Soluções para o sistema dinâmico na vizinhança do ponto de equilíbrio $P_{4}$ perturbado na variável $O(t), P_{4}=\left(P^{*}, O^{*}+\delta, M^{*}\right), \delta=1 \cdot 10^{-6}, h=0.049$.

Figura 52 - Soluções para o sistema dinâmico na vizinhança do ponto de equilíbrio $P_{4}$ perturbado na variável $M(t), P_{4}=\left(P^{*}, O^{*}, M^{*}+\delta\right), \delta=1 \cdot 10^{-6}, h=0.049$

Figura 53 - Resumo geral da classificação dos pontos de equilíbrio em função do parâmetro

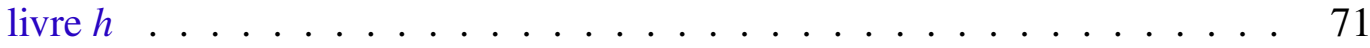

Figura 54 - Condição $a_{1}$ para o ponto de equilíbrio $P_{4}$ com os parâmetros $h$ e $r_{p}$ livres $\quad 72$

Figura 55 - Condição $a_{3}$ para o ponto de equilíbrio $P_{4}$ com os parâmetros $h$ e $r_{p}$ livres $\quad 73$

Figura 56 - Condição $a_{1} a_{2}$ para o ponto de equilíbrio $P_{4}$ com os parâmetros $h$ e $r_{p}$ livres 73

Figura 57 - Estudo de sinal para os critérios de Routh-Hurwitz no ponto de equilíbrio $P_{4}$ com os parâmetros $h$ e $r_{p}$ livres . . . . . . . . . . . . . 74

Figura 58 - Diagrama de fase para variável $P$ em função parâmetro $h \ldots \ldots$

Figura 59 - Diagrama de fase para a variável $O$ em função parâmetro $h \ldots \ldots$

Figura 60 - Diagrama de fase para variável $M$ em função parâmetro $h \ldots$. . . . . . . 76 


\section{Sumário}

$1 \quad$ Introdução $\ldots \ldots \ldots \ldots \ldots \ldots \ldots \ldots \ldots \ldots \ldots$

1.1 Sistemas marinhos costeiros $\ldots \ldots \ldots \ldots$

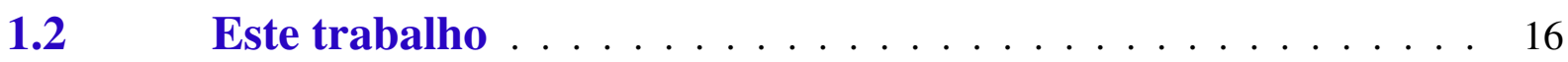

2 Dinâmica de populações de ostras . . . . . . . . . . . . . 19

$2.1 \quad$ O processo de eutrofização de estuários . . . . . . . . . . . . . . 19

2.2 Um modelo para populações de ostras em estuários . . . . . . 20

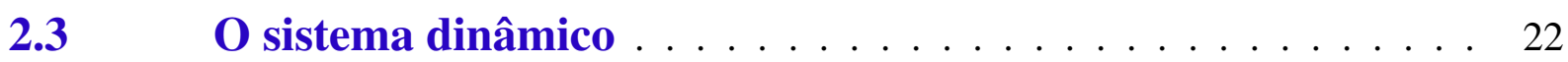

3 Análise de estabilidade e dinâmica do modelo . . . . . . . . 25

3.1 O método de estabilidade qualitativa de Quirk-Ruppert . . . 26

3.2 Os critérios de Routh-Hurwitz para estabilidade de Lyapunov 31

3.3 Simulações do sistema dinâmico . . . . . . . . . . . . . . . . 36

3.4 Análise do ponto de equilíbrio $P_{4}$ do sistema dinâmico pelo método de Quirk-Ruppert . . . . . . . . . . . . . . . . . 38

3.5 Análise dos pontos de equilíbrio do sistema dinâmico pelos critérios de Routh-Hurwitz . . . . . . . . . . . . . . . . . . . . . 43

3.5.1 Estabilidade do ponto de equilíbrio $P_{1}$ com o parâmetro $h$ livre . . 44

3.5.2 Estabilidade do ponto equilíbrio $P_{2}$ com o parâmetro $h$ livre . . . 49

3.5.3 Estabilidade do ponto equilíbrio $P_{3}$ com o parâmetro $h$ livre . . 55

3.5.4 Estabilidade do ponto de equilíbrio $P_{4}$ com o parâmetro $h$ livre . . 61

3.5.5 Estabilidade do ponto de equilíbrio $P_{4}$ com dois parâmetros livres

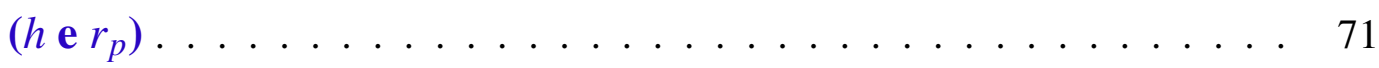

3.6 Diagramas de fase em função do parâmetro livre $h \ldots 74$

4 Conclusões e perspectivas . . . . . . . . . . . 77

Referências $^{1} \ldots \ldots \ldots \ldots \ldots$. . . . . . . . 79

Apêndice A - Código em Matlab para solução de EDOs. . 81 


\section{Introdução}

Dinâmica de populações é uma área de estudo que utiliza ferramentas matemáticas para tentar explicar variações de tamanho e composição de populações no decorrer do tempo. Trata-se de uma área interdisciplinar que conta com a união de esforços em áreas científicas bem distintas tais como a biologia (genética populacional e ecologia), a matemática, ciências sociais e medicina (epidemiologia). O ferramental matemático empregado é relativamente extenso e foi construído principalmente pela adaptação de técnicas originárias de outras áreas de aplicação, como a física e a engenharia, no estudo de populações em biologia (BACAËR, 2011). O uso de teorias e métodos da linguagem matemática na modelagem das interações entre indivíduos e espécies e o meio ambiente em que vivem constitui o objeto da ecologia matemática, que é considerada um ramo da ecologia (PASTOR, 2008).

Thomas Robert Malthus (1766-1834) foi um economista que se dedicou, entre outrs coisas, ao estudo do crescimento de populações BacaËr (2011), Cappuccino e Price (1995). Malthus ganhou notoriedade pela publicação em 1798 de seu livro intitulado An Essay on the Principle of Population, as It Affects the Future Improvement of Society, no qual ele anunciou a iminência de uma catástrofe para a humanidade em decorrência da sua interpretação matemática para o crescimento exponencial e ilimitado da população mundial, que traria, segundo o seu modelo, problemas futuros de sustentabilidade pela falta de um nível de produção de alimentos adequado à condição de sobrevivência da população para enfrentar este crescimento populacional rápido e ilimitado. A simplicidade de equação de seu modelo pode ser vista a seguir:

$$
\frac{d P}{d t}=r P
$$

onde $P$ é a densidade da população e $r$ é a taxa de crescimento populacional.

Pierre-François Verhulst (1804-1849), nascido em Bruxelas, foi professor de matemática na universidade de sua cidade e um importante pesquisador que sucedeu Malthus ao considerar o crescimento de uma população como limitado pelas condições de fertilidade e tamanho do território que pode ocupar (BACAËR, 2011). Sua equação que modela o crescimento de uma determinada população é dada por

$$
\frac{d P}{d t}=r P\left(1-\frac{P}{K}\right)
$$

na qual as grandezas $P$ e $r$ são como antes e $K$ representa a "capacidade de suporte" da população.

Alfred J. Lotka (1880-1949), que foi um matemático e biofísico norte-americano, e Vito Volterra (1860-1940), um matemático italiano, criaram de maneira independente um modo 
diferente de se enxergar o inter-relacionamento entre espécies que convivem em uma determinada comunidade. Em seu modelo, os elementos que simbolizam as espécies estão interconectados de maneira a formar um corpo único, o que é comumente definido como sistema, descrito por um conjunto de equações que regem o comportamento destes elementos. O sistema por eles idealizado se popularizou pelo nome de sistema predador-presa, que na sua versão original representava a interação entre duas espécies, se aproximando de maneira mais fiel ao que hoje se utiliza como modelos dinâmicos para estudo da dinâmica de populações e comunidades (BOCCARA, 2005; MONTEIRO, 2011).

Um sistema dinâmico pode ser definido como um aparato matemático para análise representado por um conjunto específico de elementos, que incluem: um espaço de fase, que representa todas as possibilidades de estado que o compõe; uma variável temporal, que é o seu relógio; e uma lei de evolução, formada por um conjunto de equações com que se permite determinar o estado atual do sistema em função do tempo pelo intermédio do conhecimento de seus estados anteriores (BOCCARA, 2005).

Um modelo construído com base em um sistema dinâmico representa a realidade de um fenômeno que se quer estudar. Sua estrutura é formada por componentes, agentes ou entidades, que se inter-relacionam por intermédio de uma rede que os interconectam conforme o grau da força de influência que exercem entre si. O resultado deste estudo é o registro do comportamento dos componentes do sistema conforme ocorre a passagem do tempo. Apesar da simplicidade das influências que, na maioria das vezes, os componentes exercem entre si, podem ocorrer determinadas condições, em que envolvendo a multiplicidade das conexões e os graus de influência, levam ao registro de padrões de comportamentos complexos. Em linguagem matemática, os componentes de um sistema dinâmico são representados por variáveis que compõe o seu conjunto de equações diferenciais, as interconexões são representadas pela forma de como as variáveis ficam dispostas em suas respectivas equações e o grau de influência é dado pelos valores de seus parâmetros. Uma mudança repentina de comportamento na dinâmica de crescimento dos componentes do sistema indica uma complexidade que pode ser avaliada por uma modificação no padrão de comportamento das soluções do sistema dinâmico, a qual é representada por uma transição de fase do sistema.

O ferramental principal na análise de sistemas dinâmicos é o conjunto de técnicas matemáticas que estudam a estabilidade de sistemas dinâmicos, com o qual se pode estudar as propriedades de um sistema dinâmico tais como as características dos diferentes estados de fase, 
suas transições e a determinação do comportamento das soluções em torno de seus pontos de equilíbrio (PASTOR, 2008).

O comportamento das soluções pode variar, dada as condições iniciais de operação de um sistema, ou seja, um ponto de partida e o conjunto de valores para os seus respectivos parâmetros. O padrão de comportamento do conjunto de soluções determina a classificação de seu estado de fase, que se divide em duas possíveis, a estável e a instável. A classificação de estável ocorre quando esse comportamento se perpetua independentemente da passagem do tempo, ela ainda se subdivide em dois tipos, o primeiro chamado de estabilidade assintótica, que ocorre quando as soluções do sistema se estabilizam em valores fixos localizados em um determinado ponto de equilíbrio; e um segundo tipo de estabilidade, chamada de não assintótica, que é caracterizada pelo surgimento de ciclo limites, em que há um equilíbrio dinâmico de convivência entre espécies com o aparecimento de uma trajetória fixa no comportamento das soluções do sistema, a qual circunda um determinado ponto de equilíbrio; por último, tem-se a classificação de estado de fase instável, em que o comportamento das soluções do sistema não converge para nenhum conjunto de pontos fixos (trajetória fixa), neste estado se denota em geral a extinção de uma ou mais espécies (EDELSTEIN-KESHET, 2005; PASTOR, 2008).

A figura 1 representa uma comunidade simples formada por apenas duas populações em uma dinâmica do tipo predador-presa idealizado por Lotka e Volterra por volta dos anos 1920. Naquela figura, $N_{1}$ representa a densidade da população de presas, $N_{2}$ a densidade da população de predadores, $\beta$ é o parâmetro que representa a eficiência metabólica da conversão da biomassa da presa ingerida pelo predador, $h$ representa o índice sucesso no abate da presa, $m$ representa a probabilidade de morte espontânea do predador e $r$ é o parâmetro que representa a taxa de crescimento da população de presas.

Figura 1 - Diagrama do sistema dinâmico de Lotka-Volterra

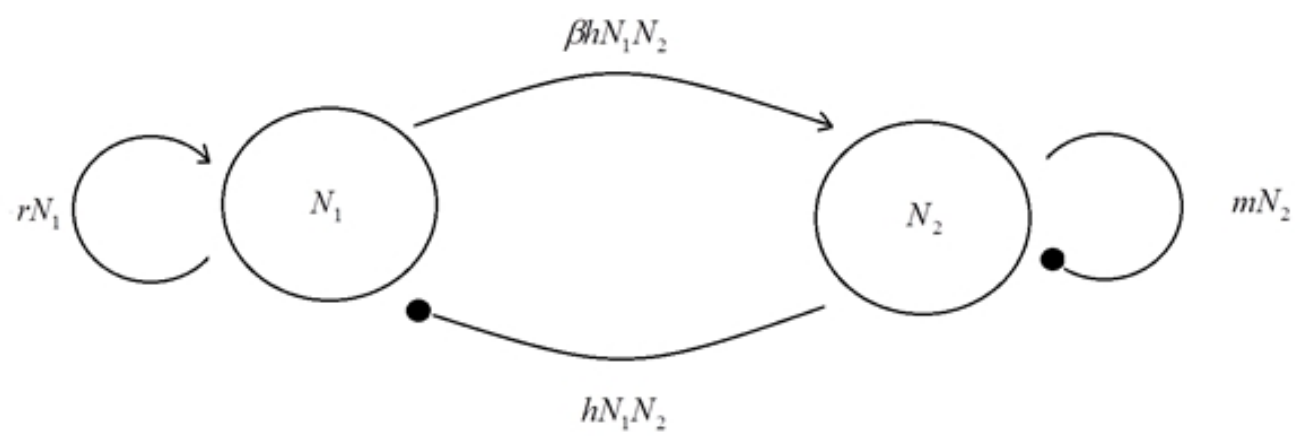

Fonte: Sergio Serino, 2016 
O sistema de equações que governa a evolução temporal das interações entre as espécies segundo o modelo descrito na figura 1 é dado por

$$
\begin{aligned}
& \frac{d N_{1}}{d t}=r N_{1}-h N_{1} N_{2} \\
& \frac{d N_{2}}{d t}=\beta h N_{1} N_{2}-m N_{2}
\end{aligned}
$$

A equação (3) do sistema ilustra o crescimento da primeira população representada pelo conjunto de presas $\left(N_{1}\right)$, ela indica que esta população aumenta em função de um parâmetro $r$, e decresce em função do abate da presa indicado pelo parâmetro $h$, que é a probabilidade de se ocorrer o encontro entre presa e predador, $N_{1} N_{2}$. A equação (4) deste sistema fornece o comportamento temporal da segunda população formada pelos predadores desta comunidade $\left(N_{2}\right)$, que cresce ao mesmo tempo em que a quantidade de abates com sucesso fortalece a população de predadores $\left(\beta h N_{2}\right)$ e decresce em função da taxa de morte natural do predador dada por $m N_{2}$ (PASTOR, 2008).

Estudar a evolução de uma comunidade como essa é determinar o comportamento das soluções $N_{1}(t)$ e $N_{2}(t)$ para o sistema de equações que governa, (3) e (4); em relação a um dado conjunto de valores formado por parâmetros, $r, h, \beta, m$; e as respectivas condições iniciais, $N_{1}(0)$ e $N_{2}(0)$, que o compõem. (BOYCE; PRIMA, 2005; BRAUN, 1983; EDELSTEIN-KESHET, 2005; MONTEIRO, 2011).

Pode-se ver na figura 2 o gráfico que representa um conjunto possível de funções que são as soluções para este sistema, as quais evidenciam um estado de convivência entre as duas espécies formando um ciclo-limite, ou seja, um estado de fase estável não assintótico que é representado de forma mais clara em seu retrato de fase (figura 3), dados os seguintes valores de parâmetros: $r=1.5, h=0.10, \beta=0.05, m=0.05$; e as condições iniciais $N_{1}(0)=30$ e $N_{2}(0)=12$. 
Figura 2 - Soluções para o sistema Lotka-Volterra

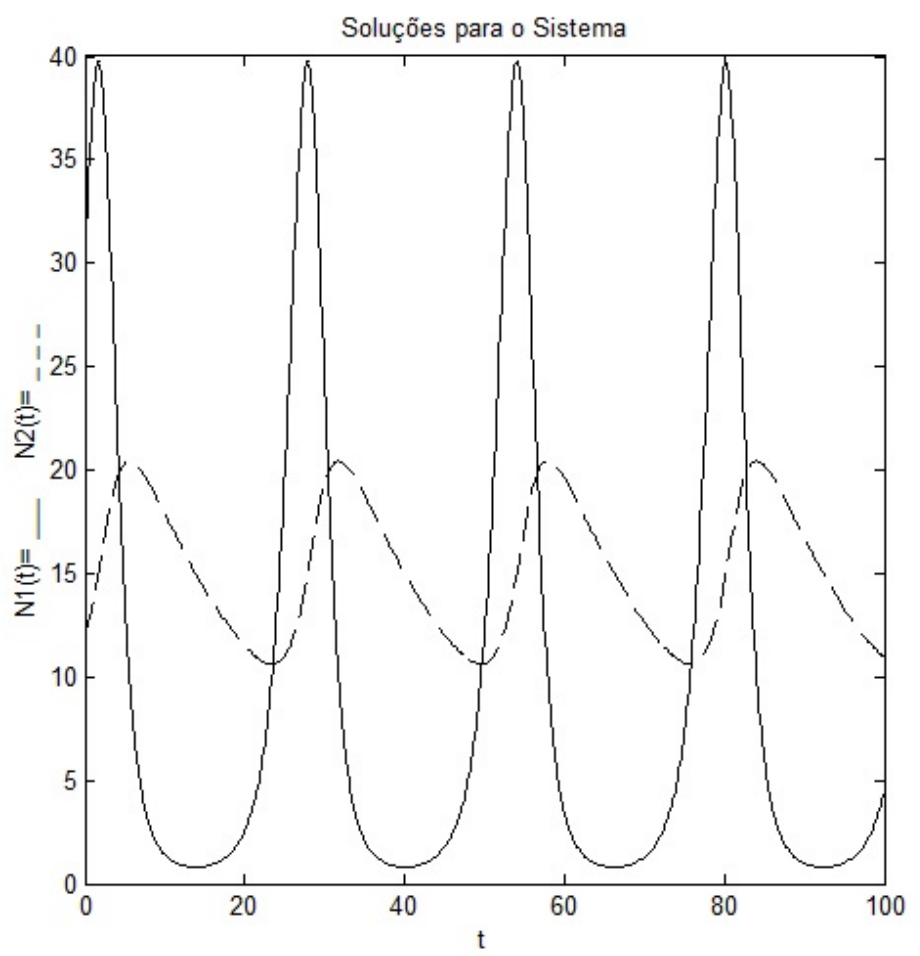

Fonte: Sergio Serino, 2016

Figura 3 - Retrato de Fase para o sistema de Lotka-Volterra

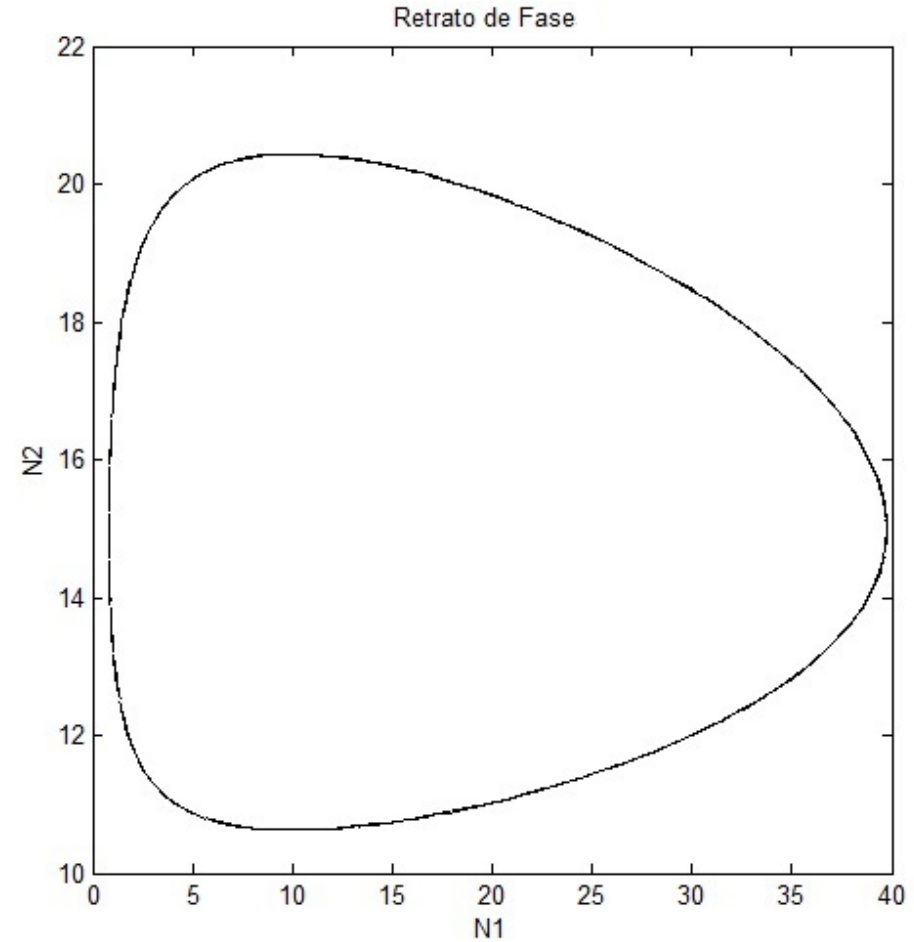

Fonte: Sergio Serino, 2016 


\subsection{Sistemas marinhos costeiros}

Uma zona costeira constitui, em princípio, uma região de transição ecológica que desempenha um importante papel no desenvolvimento e reprodução de várias espécies que ocorrem entre os ecossistemas terrestres e marinhos. As condições oceanográficas e climatológicas próprias de uma determinada região costeira conferem traços distintos à sua biodiversidade em geral, o que dá suporte a uma grande variedade de ecossistemas que incluem banhados, dunas, praias, estuários, restingas, manguezais, costões rochosos, lagunas e marismas, os quais abrigam inúmeras espécies da flora e da fauna. A concentração de nutrientes, flutuações térmicas e salinas, além da forma estrutural destas regiões determinam a biodiversidade do meio (MMA, 2010).

Mudanças abruptas têm sido documentadas em zonas costeiras com evidência de importantes ciclos de retroalimentação que envolvem a interferência humana por meio da prática da pesca e de abate de animais marinhos, que provocam efeitos em cascata com sérias implicações. O aumento do processo de eutrofização e a destruição destes habitats marinhos têm levado ao colapso muitos desses sistemas. Alguns desses sistemas marinhos demonstram certo grau de recuperação quando a pressão exploratória é diminuída ou cessada, enquanto outros sistemas jamais se recuperam. Isso alerta para a existência de limiares que evidenciam uma complexidade no comportamento das populações desses sistemas, notada pelo surgimento de variações repentinas no total de indivíduos que compõem as populações, causando ora um aumento excessivo, ora a extinção local de uma determinada espécie, influenciando diretamente todo o ecossistema (SCHEFFER, 2009).

\subsection{Este trabalho}

O objetivo deste estudo é criar um modelo que represente a dinâmica populacional de ostras em estuários e estudar a estabilidade desses ecossistemas.

Define-se estuário como sendo um corpo de água costeiro, de circulação relativamente restrita, que possui ligação com o mar aberto, e no qual a água do mar é diluída com água doce oriunda de drenagem do continente trazida por rios (PRITCHARD, 1967). Estuários são representados pelas bocas de marés de rios, têm-se tornados carregados de sedimentos, nutrientes e poluentes na maior parte do mundo. Normalmente são situados próximos a regiões densamente habitadas pelo homem que ainda explora de forma intensa as atividades de pesca e extração de 
mariscos, moluscos e crustáceos em geral. Tudo isto coloca estes ecossistemas entre aqueles que mais sofrem da degradação ambiental no mundo (SCHEFFER, 2009).

Do ponto de vista da estabilidade deste ecossistema, é interessante notar a existência de linhas de realimentação positiva entre a biota e as condições do meio físico, o que pode conduzir a situações de descontrole em determinadas situações. Ainda segundo Scheffer (2009), historicamente, tem-se o registro de situações como esta, por exemplo, o ocorrido na costa oeste dos Estados Unidos, na baia de Chesapeake, no início do século XX ilustrado na figura 4.

Figura 4 - Nutrient Loading

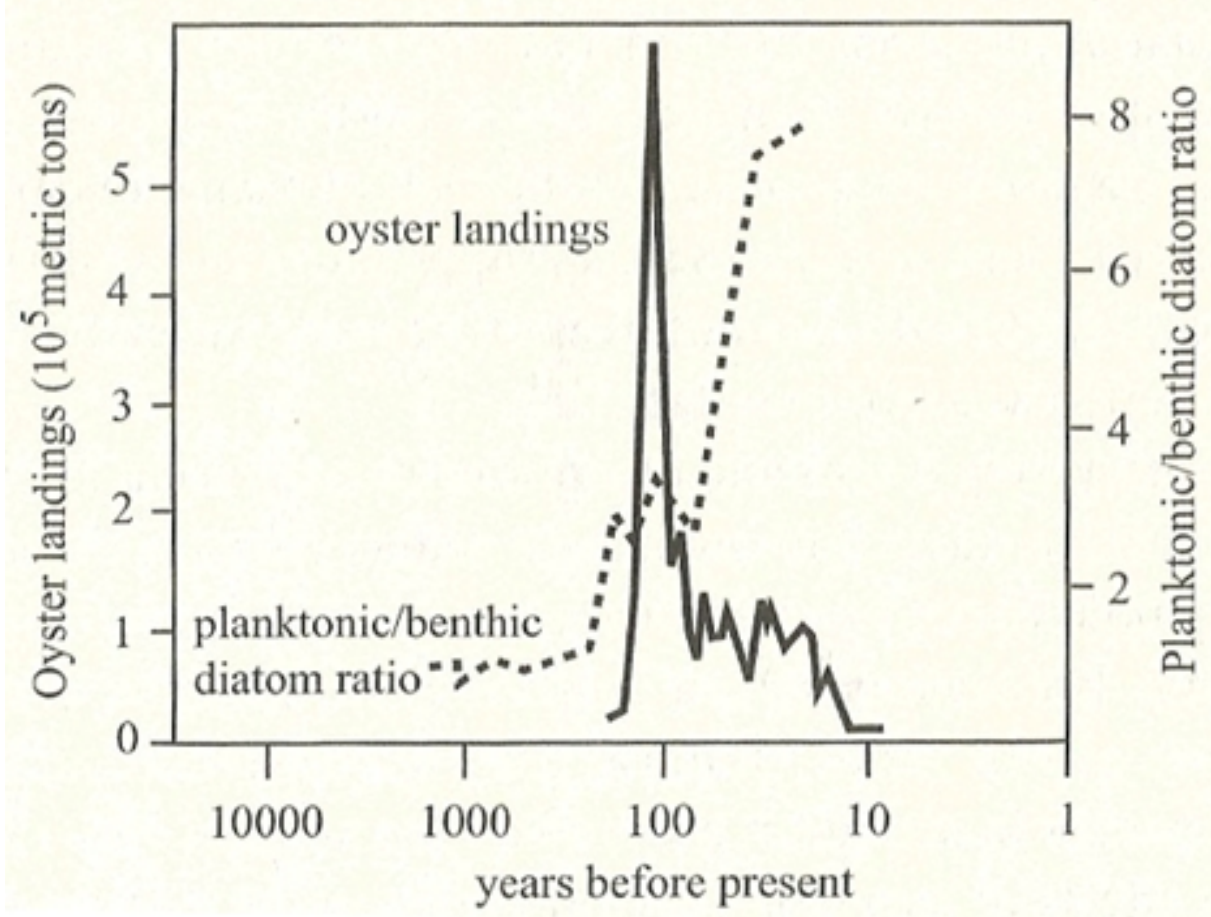

Fonte: Sheffer, 2009, p. 209

Nessa bacia, com o colapso da indústria pesqueira da ostra, o ecossistema se modificou profundamente, provavelmente por causa da ausência destes filtros naturais, que são as ostras, houve um aumento da biomassa do fitoplâncton, o que ocasionou um excessivo processo de decomposição do material orgânico que sobrou culminando em um processo de anoxia. Neste novo cenário tornou mais comum o aparecimento de doenças nas ostras remanescentes. Assim, a recuperação da população de ostras parecia agora depender destes fatores. Experimentos feitos em Pamlinco Sound, um estuário similar, mostraram que uma população de ostras crescia bem e não era afetada por doenças se fosse transportada para uma zona acima de água menos profunda, onde normalmente ocorria a hipofixia no verão, isso indica que se uma densa população de ostras e outros bivalves tiver a chance se alimentar de fitoplâncton de maneira mais eficiente o seu 
contingente populacional crescerá a taxas mais elevadas o que previne os efeitos da eutrofização, como por exemplo a hipofixia, pelo intermédio da filtragem que esses seres fazem da água, melhorando a sua qualidade, esse fato sugere que a interferência nestes elos de realimentação positiva do ecossistema podem melhorar as condições ambientais. Portanto, a excessiva coleta de ostras e outros bivalves desses estuários podem conduzir a uma mudança repentina de fase mudando o estado de equilíbrio do sistema e alterando a dinâmica de crescimento populacional em uma determinada comunidade. Conhecer os limites desta transição é importante, pois torna viável a exploração destes elementos dentro de condições de segurança e manutenção ambiental saudável para o ecossistema (SCHEFFER, 2009). 


\section{Dinâmica de populações de ostras}

Neste capítulo se verá parte dos conceitos de ecologia que foram a motivação deste trabalho e culminaram na criação do modelo de sistema dinâmico proposto.

\subsection{O processo de eutrofização de estuários}

O processo de eutrofização é o enriquecimento da água por nutrientes, em especial compostos de nitrogênio e fósforo. O papel que tem os nutrientes dissolvidos na água ainda é objeto de muita pesquisa, seu impacto afeta o funcionamento de estuários e habitats associados. Uma das principais preocupações é a suscetibilidade que os estuários têm à eutrofização, o que causa um acelerado crescimento do fitoplâncton e produz indesejáveis distúrbios no equilíbrio populacional entre as espécies e na qualidade da água de um ecossistema. Existem vários fatores que contribuem para a eutrofização de um estuário, fatores naturais como aqueles associados à abundância de luz e chuva em determinadas épocas do ano, ou ainda fatores artificiais como aqueles ocasionados pela poluição proveniente das atividades humanas carreada pelos rios. Entre os vários aspectos capazes de mensurar o processo de eutrofização se destaca o aumento excessivo de fitoplâncton na água (PAINTING et al., 2007).

Pesquisas realizadas com cultivo de ostras mostram que elas e outros bivalves atuam como eficientes filtradores, pois se alimentam do fitoplâncton e da matéria orgânica, reduzindo a carga de nutrientes e por consequência a eutrofização de um ecossistema. Experiências realizadas indicam que um cultivo com 200 mil ostras que ocupam uma área de $2000 \mathrm{~m}^{2}$ podem filtrar até 2 milhões de litros de água por hora. Portanto, a manutenção da população de ostras em um ecossistema é uma alternativa de combate ao desequilíbrio provocado pelo processo de eutrofização (PEREIRA et al., 2007).

A eutrofização da água tornou-se um enorme problema nos recentes anos e o entendimento de seu mecanismo de funcionamento ajudará a enfrentá-la e a manter mais saudáveis os estuários, os ecossistemas marinhos e consequentemente a diversidade da vida no planeta (YANG et al., 2008). 


\subsection{Um modelo para populações de ostras em estuários}

O modelo inicialmente proposto para estudo da dinâmica de uma população de ostras em um estuário neste trabalho é uma adaptação do modelo "c" sugerido por Scheffer (2009) na p. 214 de sua obra Critical Transitions in Nature and Society, conforme ilustra a figura 5.

Figura 5 - Modelo "c" de Scheffer

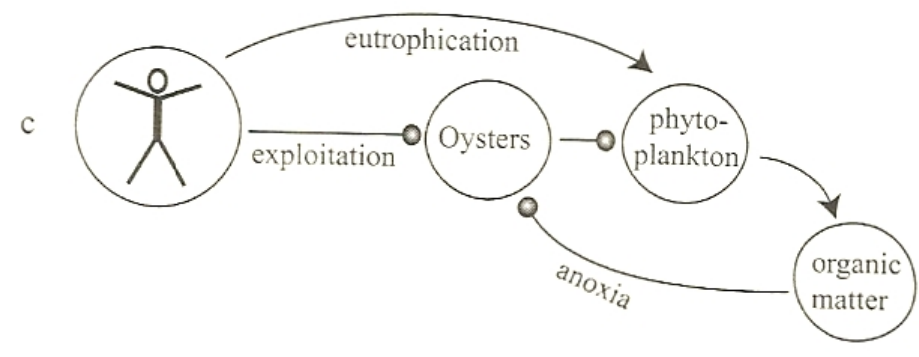

Fonte: Sheffer, 2009, p. 214

Neste modelo, as influências que cada componente tem sobre os outros são as seguintes:

1. A população humana atua diretamente no aumento do processo de eutrofização sendo fator facilitador do crescimento da população de fitoplâncton;

2. A população humana atua diretamente na diminuição da densidade populacional de ostras pelo processo de extração para consumo;

3. A população de ostras atua diretamente na diminuição da população de fitoplâncton por intermédio do processo de alimentação/filtragem;

4. A população de fitoplâncton atua diretamente no aumento da produção de matéria orgânica pelo processo de decomposição;

5. A matéria orgânica atua diretamente na diminuição da população de ostras pelo processo de anoxia.

Em princípio, construimos o seguinte conjunto com quatro equações diferenciais para simular essas influências:

$$
\begin{aligned}
\frac{d P}{d t} & =p P(k-P)+e H-f O P-m P \\
\frac{d O}{d t} & =o P O-a M-c H O-n O \\
\frac{d M}{d t} & =d m P \\
\frac{d H}{d t} & =h H
\end{aligned}
$$


onde os termos possuem os seguintes significados:

- $H$ : densidade da população humana;

- $O$ : densidade da população de ostras;

- $P$ : densidade da população de fitoplâncton;

- $M$ : densidade da matéria orgânica;

- $p$ : taxa de crescimento da população $P$;

- $h$ : taxa de crescimento da população $H$;

- $o$ : probabilidade de predação da população $P$ pela $O$;

- $a$ : taxa de anoxia;

- $c$ : taxa de consumo;

- $e$ : taxa de eutrofização;

- $f$ : taxa de filtragem/alimentação;

- $d$ : taxa de decomposição;

- $m$ : taxa de mortalidade da população $P$;

- $n$ : taxa de mortalidade da população $O$;

- $k$ : capacidade de suporte da população $P$.

Ao nos aprofundarmos no estudo das influências entre os elementos que compõe esse sistema dinâmico, no entanto, notamos que seria interessante evidenciar que o processo de alimentação das ostras tem efeito de redução na poluição ambiental, pois a filtragem que esses moluscos fazem para obter o fitoplâncton, que é seu alimento natural, remove o excesso do material suspenso na água, o que facilita a passagem de luz para os estratos mais profundos do meio aquoso, aumentando assim a eficiência da fotossíntese realizada pela vegetação destas camadas, que por consequência eleva o nível de oxigênio, aumentando a qualidade da água. Esta técnica é chamada biorremediação e tem aplicação na cultura comercial de ostras (PEREIRA et al., 2007). Assim, readaptou-se o sistema dinâmico inicialmente proposto para se poder simular este importante fenômeno, estipulou-se um parâmetro chamado de $b$ para se quantificar a influência das ostras na biorremediação no sistema, e o que era chamada de densidade de matéria orgânica passou a ser chamada de densidade de matéria suspensa, pois contempla de forma mais geral a composição dos corpos suspensos na água. Essas mudanças exigiram o acréscimo do termo $b O M$ na equação (7) do sistema inicial para funcionar como fator de redução da poluição, parâmetro que diminui a quantidade de matéria suspensa em função da alimentação das ostras. Deste modo, 
depois dessa adequação e da renomeação de seus parâmetros, a equação (7) passou a ser escrita da seguinte maneira:

$$
\frac{d M}{d t}=r_{m} P-b O M
$$

Outra mudança no sistema inicial proposto ocorreu pela avaliação da real necessidade de se representar a densidade populacional humana no sistema, uma vez que indiretamente a influência humana na poluição ambiental pode ser devidamente representada pelo crescimento populacional do fitoplâncton, que tem principalmente nos resíduos de fósforo e nitrogênio lançados nas águas seu fator de proliferação. Desta maneira, o sistema dinâmico em estudo passou a representar uma cultura de ostras realizada pelo homem destinada a seu consumo, e a influência direta que ele tem sobre essa população passou a ser a quantidade de ostras extraída, representada por um simples parâmetro chamado de $h$, que significa a quantidade relativa da coleta realizada para este consumo. Matematicamente isto simplificou o sistema com a eliminação da equação (8) e a reescrita da equação (6), que após uma adequação na nomenclatura de seus parâmetros assumiu a forma

$$
\frac{d O}{d t}=r_{o} P O-a M O-h O-m_{o} O
$$

Por último, considerou-se que o parâmetro $m$, que no sistema inicialmente proposto indicava a taxa de mortalidade do fitoplâncton, é desprezível em um ambiente composto por ostras dada a sua voracidade de predação. Optou-se então por eliminar o termo que ilustrava esta taxa reescrevendo a equação (5) deste sistema como

$$
\frac{d P}{d t}=r_{p} P(k-P)-f O P
$$

Depois de todas essas modificações tem-se um novo modelo, representado pelo sistema dinâmico descrito a seguir.

\subsection{O sistema dinâmico}

Pelas considerações da seção anterior obteve-se, então, o seguinte sistema dinâmico para estudo: 
Figura 6 - Grafo orientado do sistema dinâmico proposto

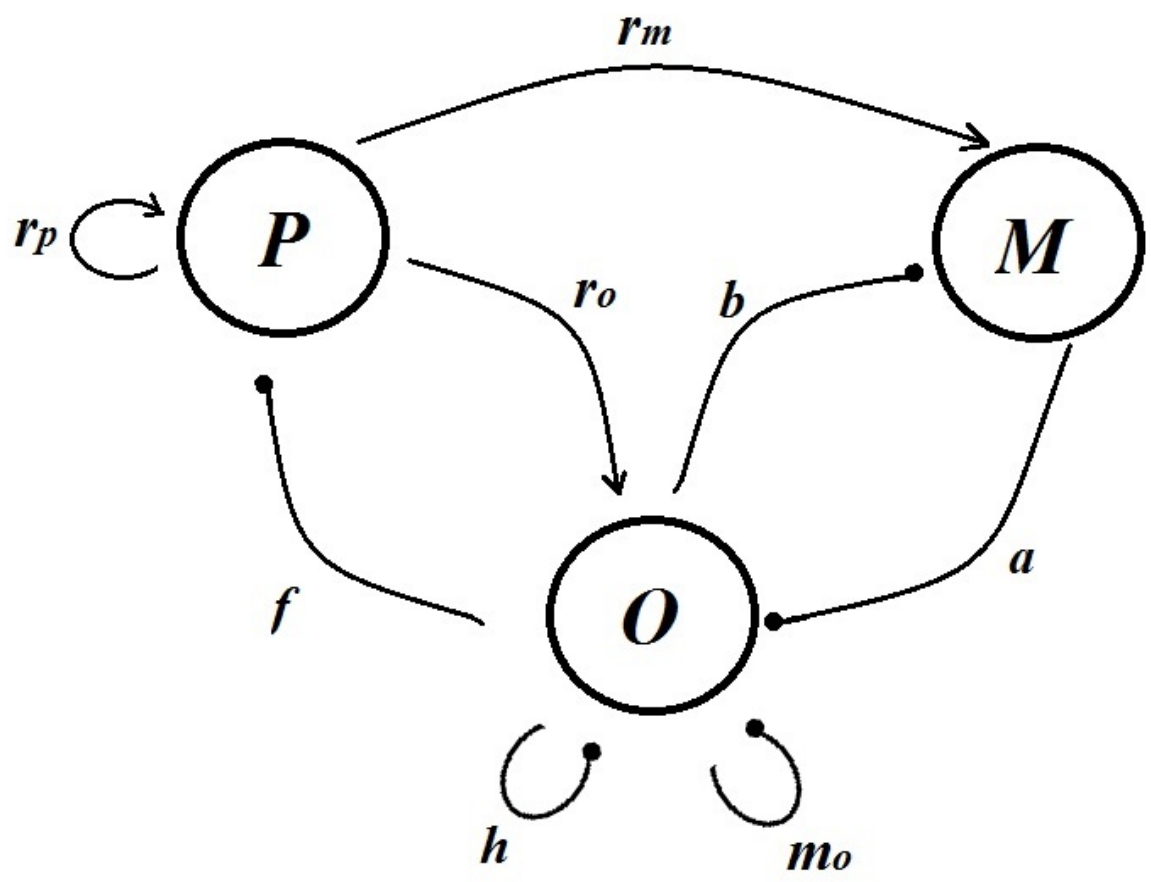

Fonte: Sergio Serino, 2016

As equações que regem as interações de nosso modelo são dadas por

$$
\begin{aligned}
\frac{d P}{d t} & =r_{p} P(k-P)-f O P \\
\frac{d O}{d t} & =r_{o} P O-a M O-h O-m_{o} O \\
\frac{d M}{d t} & =r_{m} P-b O M
\end{aligned}
$$

onde agora os termos possuem os seguintes significados ( $g$ : grama, $m$ : metro, $d$ : dia):

- $P$ : densidade da população de fitoplâncton, medida pela quantidade de clorofila-a $(\mu g$. $\left.m^{-3}\right)$

- $O$ : densidade da população de ostras $\left(m^{-3}\right)$;

- $M$ : densidade de matéria suspensa $\left(m g \cdot m^{-3}\right)$;

- $a$ : taxa de anoxia $\left(m^{3} \cdot m g^{-1} \cdot d^{-1}\right)$;

- $b$ : taxa de biorremediação $\left(m^{-3} \cdot d^{-1}\right)$;

- $f$ : taxa de filtragem/alimentação da população de $P$ pela $O\left(m^{-3} \cdot d^{-1}\right)$;

- $h$ : taxa de coleta de ostras para consumo humano $\left(d^{-1}\right)$;

- $k$ : capacidade de suporte da população $P\left(\mu g \cdot m^{-3}\right)$;

- $m_{o}$ : probabilidade de mortalidade da população $O\left(d^{-1}\right)$; 
- $r_{m}$ : taxa de crescimento da matéria suspensa $\left(m g \cdot \mu g^{-1} \cdot d^{-1}\right)$;

- $r_{o}$ : taxa de crescimento da população $O$ pelo consumo de $P\left(m^{3} \cdot \mu g^{-1} \cdot d^{-1}\right)$;

- $r_{p}$ : taxa de crescimento da população $P\left(m^{3} \cdot \mu g^{-1} \cdot d^{-1}\right)$.

- O termo $r_{p} P(k-P)$ da equação (9) representa equação logística que ilustra o crescimento da população $P$;

- - $f O P$, da equação (9), representa a mortalidade da população $P$ de ser devorada pela população de ostras $O$;

- $r_{o} P O$, da equação (10), representa o crescimento da população de predadores $O$ por devorar membros da população de presas $P$;

- $-a M O$, da equação (10), representa a mortalidade da população $O$ pelo processo de anoxia provocada por $M$;

- $-h O$, da equação (10), representa a parcela de elementos da população $O$ coletada para consumo humano;

- $-m_{o} O$, da equação (10), representa probabilidade de morte do predador $O$;

- $r_{m} P$, da equação (11), representa a contribuição que a população do fitoplâncton $(P)$ dá para o aumento da matéria suspensa $(M)$;

- $-b O M$, da equação (11), representa a parcela da matéria suspensa $(M)$ que é suprimida pela população $O$. 


\section{Análise de estabilidade e dinâmica do modelo}

Neste capítulo apresentamos duas técnicas para a análise da estabilidade das soluções de sistemas dinâmicos: o método qualitativo de Quirk-Ruppert e os critérios de Routh-Hurwitz. Ambos serão posteriormente aplicados ao estudo do sistema dinâmico proposto neste trabalho.

De forma geral, um sistema de equações diferenciais que compreende a interação entre $k$ espécies pode ser dado por:

$$
\begin{aligned}
\frac{d N_{1}}{d t} & =F_{1}\left(N_{1}, N_{2}, \ldots, N_{k}\right) \\
\frac{d N_{2}}{d t} & =F_{2}\left(N_{1}, N_{2}, \ldots, N_{k}\right) \\
& \vdots \\
\frac{d N_{k}}{d t} & =F_{k}\left(N_{1}, N_{2}, \ldots, N_{k}\right)
\end{aligned}
$$

Esse sistema pode ser escrito em notação vetorial como

$$
\frac{d N}{d t}=\boldsymbol{F}(\boldsymbol{N})
$$

onde $\boldsymbol{N}=\left(N_{1}, N_{2}, \ldots, N_{k}\right), \boldsymbol{F}=\left(F_{1}, F_{2}, \ldots, F_{k}\right)$, e cada uma das funções $F_{1}, F_{2}, \ldots, F_{k}$ pode depender de uma ou mais espécies de população $N_{1}, N_{2}, \ldots, N_{k}$. Supondo que exista soluções para este sistema, então é possível solucioná-lo impondo-se $\boldsymbol{F}(\boldsymbol{N})=0$ para se identificar seus possíveis pontos de equilíbrio, $\boldsymbol{N}^{*}=\left(N_{1}^{*}, N_{2}^{*}, \ldots, N_{k}^{*}\right)$. Para prosseguir-se a análise do sistema descrito pelo conjunto de equações (12) se faz necessário determinar as propriedades de estabilidade das suas soluções em seus respectivos pontos de equilíbrio, o que é realizado pela linearização do sistema encontrando-se a matriz jacobiana de $F(N)$ pelo intermédio da resolução da equação

$$
J=\frac{d N}{d t}\left(N^{*}\right)
$$

onde

$$
J=\left[\begin{array}{cccc}
\frac{\partial F_{1}}{\partial N_{1}} & \frac{\partial F_{1}}{\partial N_{2}} & \cdots & \frac{\partial F_{1}}{\partial N_{k}} \\
\vdots & \vdots & \ddots & \vdots \\
\frac{\partial F_{k}}{\partial N_{1}} & \frac{\partial F_{k}}{\partial N_{2}} & \cdots & \frac{\partial F_{k}}{\partial N_{k}}
\end{array}\right]
$$


A matriz jacobiana empregada desta forma é chamada pelos biólogos de matriz comunidade (LEVINS, 1968). Partindo-se dela se faz necessária a resolução da equação (15)

$$
\operatorname{det}(J-\lambda I)=0
$$

Esse cálculo resultará na equação característica, aqui genericamente expressa pelo polinômio

$$
\lambda^{k}+a_{1} \lambda^{k-1}+a_{2}^{k-2}+\cdots+a_{k}=0
$$

O próximo passo deveria ser o cálculo das raízes do polinômio descrito na equação (16), autovalores $(\lambda)$, para a determinação do comportamento das soluções deste sistema, se para um determinado ponto de equilíbrio forem encontrados valores reais menores do que zero para os autovalores, tem-se a indicação de um comportamento estável do sistema na vizinhança desses pontos, no entanto, esta tarefa se torna deveras complicada de se realizar quanto maior for o número de espécies contidas na comunidade, pois o grau do polinômio da equação característica aumenta consideravelmente, o que dificulta a obtenção das raízes. Para enfrentar esta dificuldade se apresentará adiante a primeira das técnicas que trabalhará este polinômio característico para determinar o comportamento do sistema dinâmico sem a necessidade de se determinar seus autovalores.

\subsection{O método de estabilidade qualitativa de Quirk-Ruppert}

A construção de modelos práticos que representem ecossistemas origina modelos dinâmicos com uma quantidade grande de estágios que retratam o comportamento de seus componentes. Estudar a estabilidade nestes sistemas pode se tornar uma tarefa bastante incômoda, quando, por exemplo, o número de espécies envolvidas ultrapassa a quantidade de cinco (EDELSTEINKESHET, 2005).

Para lidar com sistemas com muitas espécies, existe um processo prático de análise conhecido pelo nome de método Quirk-Ruppert.

Este processo consiste em uma análise qualitativa de um sistema dinâmico, que envolve muito pouco cálculo. O método foi criado por dois economistas Quirk e Ruppert, mas ganhou notoriedade após as aplicações realizadas em ecologia por May, Levins e Jeffries (EDELSTEINKESHET, 2005; JEFFRIES, 1974; LEVINS, 1974; MAY, 1973).

Esta técnica de análise se baseia na verificação de determinadas condições de influência entre espécies de uma comunidade representadas por uma matriz construída a partir da jacobiana 
mencionada na equação (14), em que os elementos desta têm apenas sinais positivos (+), negativos (-) e nulos (0) que ilustram a influência qualitativa que um determinado nó ou estágio (espécie) recebe de seu vizinho se houver uma conexão entre eles. Antes da aplicação do método, é necessário se construir a matriz que retrata esta influência. Acompanhe o exemplo a seguir.

Seja um sistema dinâmico, em que um determinado ponto de equilíbrio a ser classificado possui em sua jacobiana as interações entre três espécies que estão representadas no grafo a seguir:

Figura 7 - Grafo de Sistema Dinâmico com 3 espécies

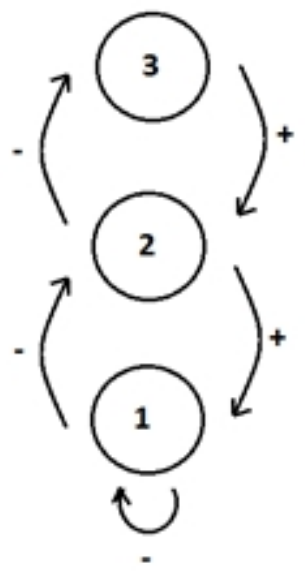

Fonte: Adaptado de Pastor, 2008, p.182

A matriz A que ilustra a qualidade das conexões é dada por:

$$
(\text { sinais de } J)=A=\left[\begin{array}{ccc}
- & - & 0 \\
+ & 0 & - \\
0 & + & 0
\end{array}\right]
$$

As influências em cada nó são apresentadas pelo conteúdo das respectivas colunas que o representam. Assim, na coluna um, que representa as conexões para o nó de mesmo número, encontra-se o elemento $a_{11}$, cujo sinal negativo (-) representa a realimentação negativa que este nó recebe de si mesmo. O elemento $a_{21}$ da mesma coluna com sinal positivo (+) representa a influência que o nó um recebe do nó dois, ilustrado devidamente no grafo ilustrado na figura 7 pela seta orientada que aponta para o nó um com o sinal positivo. No elemento $a_{31}$ encontra-se registrado zero (0), pois nenhuma conexão e influência o nó um recebe do nó três, conforme mostra o grafo. Os demais elementos da matriz seguem o mesmo padrão de representação para a conexão dos nós que suas colunas representam com seus respectivos vizinhos (PASTOR, 2008). O estudo da 
estabilidade de um sistema dinâmico pelo método de Quirk-Ruppert envolve a verificação das seguintes condições na matriz A que o representa:

I - Todos os elementos $a_{i i} \leq 0$.

II - Existência de pelo menos um elemento tal que $a_{i i}<0$.

III - Todo $a_{i j} a_{j i} \leq 0$ para todo $i \neq j$.

IV - Para toda sequência dada por: $a_{i j} a_{j k} \cdots a_{q r} a_{q i}=0$ para qualquer sequência de três ou mais nós que compõe o grafo que representa um sistema dinâmico.

$\mathrm{V}$ - Determinante de $A \neq 0$.

Edelstein-Keshet (2005) ainda reinterpreta essas mesmas condições com um olhar da ecologia:

I - Não existem espécies que exercem uma realimentação positiva em si mesma.

II - Há no mínimo, uma espécie capaz de se autorregular.

III - Dada uma interação entre duas espécies (conexão dupla formada por duas setas de sentidos contrários), sempre haverá efeitos opostos entre elas (+) e (-).

IV - Não existem cadeias de interação que conectem três ou mais espécies.

V - Não existem espécies que não são afetadas por interações com outras espécies ou consigo mesmas.

Se um sistema dinâmico analisado cumprir todas estas cinco premissas obtendo o conceito de verdadeiro para todas elas será considerado como um sistema qualitativamente estável, estas condições são necessárias para garantir a estabilidade do sistema, contudo, não são suficientes para declarar um sistema como sendo estável em qualquer situação, sendo assim, a recíproca não é verdadeira. Portanto, um sistema poderá ainda ser ou não estável caso falhe no teste.

Abaixo se observa três exemplos de aplicação do método em sistemas distintos:

Sistema 1:

Figura 8 - Grafo de Sistema Dinâmico com 3 espécies

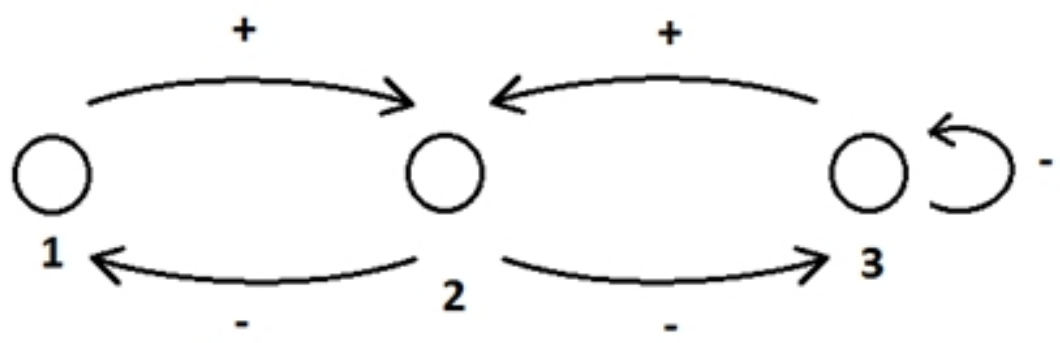

Fonte: Adaptado de Edelstein-Keshet, 2005, p. 238

Sistema 2: 
Figura 9 - Grafo de Sistema Dinâmico com 6 espécies

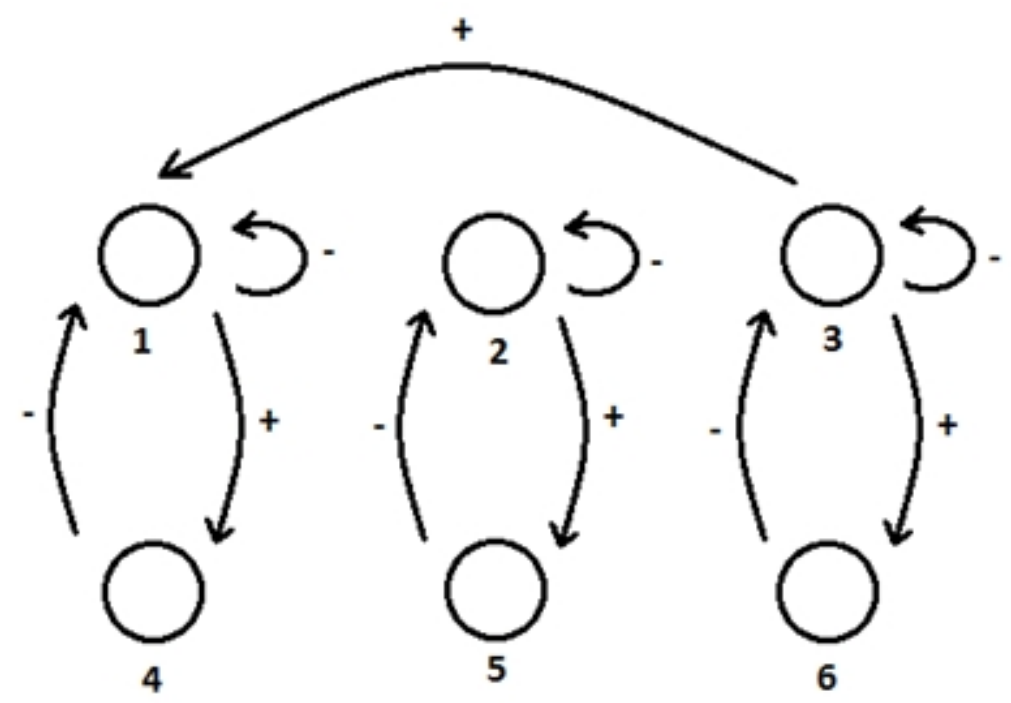

Fonte: Adaptado de Edelstein-Keshet, 2005, p. 238

Sistema 3:

Figura 10 - Grafo de Sistema Dinâmico com 8 espécies

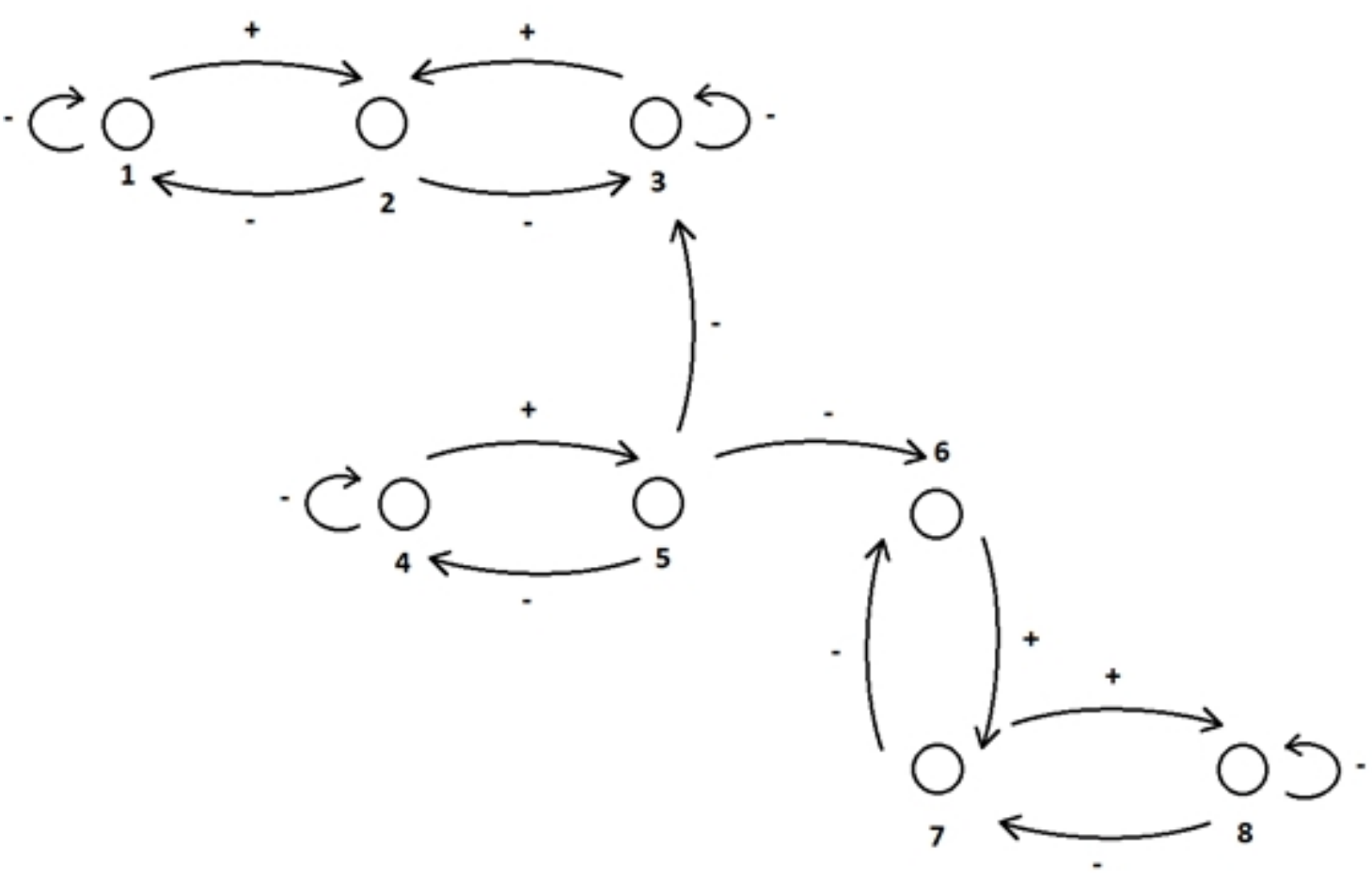

Fonte: Adaptado de Edelstein-Keshet, 2005, p. 238

Aplicando o método de Quirk-Ruppert aos sistemas ilustrados pelos grafos das figuras 8, 9, e 10 se obtém a seguinte avaliação das cinco condições testadas para cada um dos três grafos conforme ilustra a tabela 1 : 
Tabela 1 - Aplicação das Condições de Quirk-Ruppert

\begin{tabular}{cccc}
\hline Condição & Sistema 1 & Sistema 2 & Sistema 3 \\
\hline I & Sim & Sim & Sim \\
II & Sim & Sim & Sim \\
III & Sim & Sim & Sim \\
IV & Sim & Não & Sim \\
V & Sim & Sim & Sim \\
\hline
\end{tabular}

Fonte: Adaptado de Edelstein-Keshet, 2005, p. 240

Portanto, dada esta análise compreende-se que apenas os sistemas 1 e 3 são estáveis, já o sistema 2 pode ser ou não estável dependendo das formas de interações e dos valores dos parâmetros que possui, assim, para determinar sua condição de estabilidade é necessária a aplicação de algum outro método, como por exemplo, os critérios de Routh-Hurwitz (EDELSTEIN-KESHET, 2005; PASTOR, 2008).

Para aqueles sistemas que passam no teste de estabilidade de Quirk-Ruppert ainda existe a indagação se a estabilidade encontrada pelo método é neutra (não assintótica) ou assintótica, onde o estado estacionário da solução do sistema pode ser um nó estável ou em espiral. EdelsteinKeshet (2005), cita que Jeffries (1974) idealizou um conjunto auxiliar de condições, que substitui a condição II do método de Quirk-Ruppert pelo chamado de color test, capaz de determinar o tipo da estabilidade que exerce o sistema em estudo. Em primeiro lugar, antes de aplicá-lo, são necessárias mais duas definições a respeito dos grafos que compõe o sistema em análise:

i-) Um link de predação é um par de espécies conectadas pelo intermédio de duas setas, uma positiva (+) e outra negativa (-);

ii-) Uma comunidade de predação é um subgrafo consistindo de todos os links de predação interconectados.

Pode-se identificar exemplos destes links de predação nos sistemas 1 e 3 que anteriormente passaram nas cinco condições de Quirk-Ruppert como sendo os links que interconectam o conjunto de vértices: $\{1,2,3\}$ para o sistema 1 e $\{1,2,3\},\{4,5\}$ e $\{6,7,8\}$ para o sistema 3 .

A seguir é aplicado o color test, que é dito falhar se alguma das quatro condições a seguir não puderem ser satisfeitas ao se colorir qualquer subgrafo que representa uma determinada comunidade de predação

1 - Cada nó que se autorregula (auto realimenta) é pintado de preto;

2 - Há no mínimo um nó branco (sem pintar) no sistema;

3 - Todo nó branco está conectado a um link de predação e a no mínimo outro nó branco; 
4 - Todo nó pintado de preto conectado por um link de predação a um nó branco também está conectado a outro nó branco.

Somente quando o sistema em estudo falha, ou seja, não satisfaz alguma das quatro condições anteriores e passa nos condições I, III, IV e V de Quirk-Ruppert é dito possuir estabilidade assintótica (EDELSTEIN-KESHET, 2005).

A seguir se vê o color test aplicado aos sistemas anteriores 1 e 2:

Sistema 1:

Figura 11 - Color test aplicado a um grafo de Sistema Dinâmico com 3 espécies

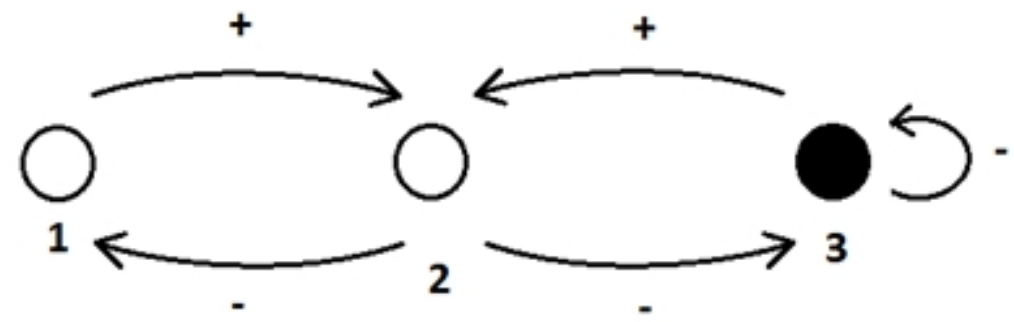

Fonte: Adaptado de Edelstein-Keshet, 2005, p. 238

Sistema 2:

Figura 12 - Color test aplicado a um grafo de Sistema Dinâmico com 5 espécies

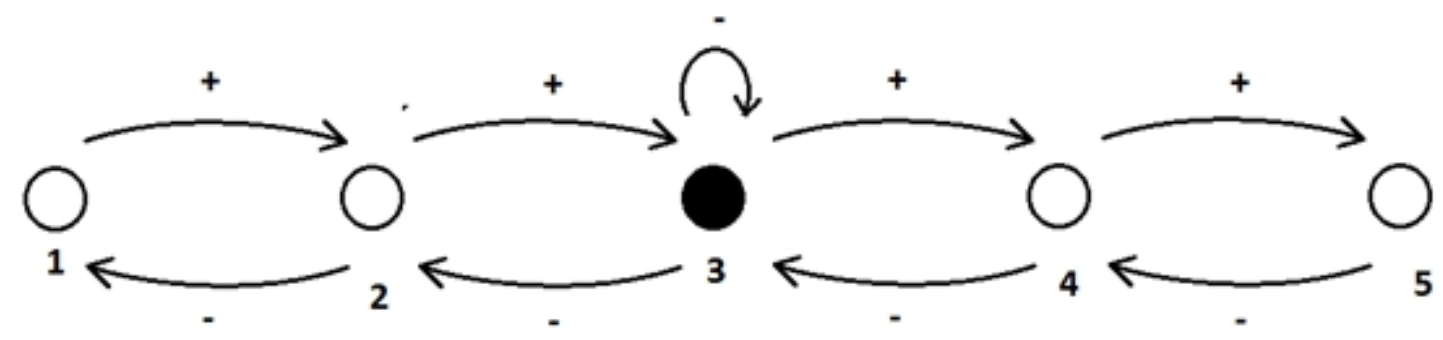

Fonte: Adaptado de Edelstein-Keshet, 2005, p. 238

Logo, vê-se que o sistema 1 na figura 11 possui estabilidade assintótica, pois falha no teste, enquanto, o sistema 2 na figura 12, que não falha no color test, possui estabilidade neutra ou não assintótica.

\subsection{Os critérios de Routh-Hurwitz para estabilidade de Lyapunov}

Não é toda solução de um sistema de equações diferenciais que pode ser expressa como um conjunto de funções elementares, deduzidas por um processo analítico. Em muitos desses problemas, nem sempre o mais importante é conhecer valores específicos de uma determinada 
solução, mas sim se saber quais os comportamentos que têm uma solução em relação à variação dos parâmetros de seu sistema, e quais são as fronteiras que separam um comportamento do outro. Consequentemente, dado um conjunto de condições iniciais, às vezes é suficiente conhecer que uma determinada solução é periódica e, por outras, que pode ser aproximada a uma função que tem comportamento assintótico. Alguns desses problemas básicos são estudados pela teoria qualitativa de equações diferenciais, e um dos principais conceitos estudados é o de estabilidade de uma solução. A. M. Lyapunov (1857-1918) foi um notável matemático russo que estudou este conceito em detalhes (PISKUNOV, 1964). Dado um sistema formado por duas equações diferenciais:

$$
\begin{aligned}
& \frac{d x}{d t}=f_{1}(t, x, y) \\
& \frac{d y}{d t}=f_{2}(t, x, y)
\end{aligned}
$$

Sejam $x=x(t)$ e $y=y(t)$ soluções do sistema que satisfaçam às seguintes condições iniciais:

$$
\begin{aligned}
& x_{t=0}=x_{0} \\
& y_{t=0}=y_{0} \\
& \bar{x}_{t=0}=\bar{x}_{0} \\
& \bar{y}_{t=0}=\bar{y}_{0}
\end{aligned}
$$

As soluções $x=x(t)$ e $y=y(t)$ que satisfazem o sistema de equações diferenciais representado pelas equações (17) e ((18) são chamadas de estáveis por Lyapunov, se para cada pequeno e arbitrário $\varepsilon>0$, existe um $\delta>0$ tal que todos os valores das soluções do sistema para sempre satisfazem às seguintes inequações:

$$
\begin{aligned}
& |\bar{x}(t) \quad-\quad x(t)|<\varepsilon \\
& |\bar{y}(t)-y(t)|<\varepsilon
\end{aligned}
$$

se as condições iniciais obedecerem as seguintes condições:

$$
\begin{aligned}
& \left|\bar{x}_{0}-x_{0}\right|<\delta \\
& \left|\bar{y}_{0}-y_{0}\right|<\delta
\end{aligned}
$$

Os valores iniciais adicionais $\left(\bar{x}_{0}\right.$ e $\left.\bar{y}_{0}\right)$ podem interpretados como uma pequena perturbação em torno das condições iniciais das funções de solução do sistema dada por $x_{0}$ e $y_{0}$ que é dito possuir 
uma solução estável pelo conceito de Lyapunov, se mesmo quando $t \rightarrow \infty$, os valores calculados para as funções de solução do sistema se aproximam novamente de $x=x(t)$ e $y=y(t)$.

A modelagem de sistemas dinâmicos que representam as interações entre espécies de um ecossistema podem em sua aplicação prática romper a barreira de duas espécies analisadas por modelo, o que envolve a construção de sistemas com mais equações, cada qual representando uma espécie em estudo. A procura das características de uma determinada solução para o sistema originado, como por exemplo, a estabilidade pelo método da análise linear, envolve o cálculo dos autovalores associados a este sistema de equações diferenciais, o que se torna bastante difícil, pois o polinômio característico gerado por seu respectivo sistema de equações lineares atinge grau muito elevado em função do maior número de espécies estudadas. Para contornar esta situação pode-se utilizar os critérios de Routh-Hurwitz (EDELSTEIN-KESHET, 2005).

Pelos critérios de Routh-Hurwitz se pode determinar a estabilidade dos pontos de equilíbrio associados a este polinômio sem resolvê-lo, apenas avaliando determinadas condições em uma nova matriz montada a partir dos coeficientes $a_{1}, a_{2}, \ldots, a_{k}$ do respectivo polinômio oriundo do sistema original de equações. Dada uma equação característica, tal como a equação (16), definem-se as seguintes $H_{k}$ matrizes em relação à quantidade $k$ de espécies que compõem a comunidade (EDELSTEIN-KESHET, 2005):

$$
\begin{gathered}
H_{1}=a_{1}, \quad H_{2}=\left[\begin{array}{cc}
a_{1} & 1 \\
a_{3} & a_{2}
\end{array}\right], \quad H_{3}=\left[\begin{array}{ccc}
a_{1} & 1 & 0 \\
a_{3} & a_{2} & a_{1} \\
a_{5} & a_{4} & a_{3}
\end{array}\right], \quad \cdots, \\
H_{j}=\left[\begin{array}{cccccc}
a_{1} & 1 & 0 & 0 & \cdots & 0 \\
a_{3} & a_{2} & a_{1} & 1 & \cdots & 0 \\
a_{5} & a_{4} & a_{3} & a_{2} & \cdots & 0 \\
\vdots & \vdots & \vdots & \vdots & \ddots & \vdots \\
a_{2 j-1} & a_{2 j-2} & a_{2 j-3} & a_{2 j-4} & \cdots & a_{j}
\end{array}\right]
\end{gathered}
$$

onde um termo $a_{l m}$ na matriz $H_{j}$ é dado por $a_{2 l-m}$ se $0<2 l-m<k, 1$ se $2 l=m$ e 0 se $2 l<m$ ou $2 l>k+m$.

Pelos critérios de Routh-Hurwitz, as matrizes $H_{j}$ montadas desta maneira implicarão que o sistema em estudo terá todos os seus autovalores com partes reais negativas se e somente se os 
seus determinantes forem maiores que zero $\left(H_{j}>0\right.$, para $\left.j=1,2, \ldots k\right)$, o que indicará que os pontos de equilíbrio $N^{*}$ são estáveis (EDELSTEIN-KESHET, 2005).

May (1973) sintetiza os critérios de Routh-Hurwitz para a condição de estabilidade para os casos em que $\mathrm{k}=2,3$ e 4 :

$$
\begin{aligned}
& k=2: \quad a_{1}>0, a_{2}>0 ; \\
& k=3: \quad a_{1}>0, a_{2}>0, a_{1} a_{2}>a_{3} ; \\
& k=4: \quad a_{1}>0, a_{3}>0, a_{4}>0, a_{1} a_{2} a_{3}>a_{3}^{2}+a_{1}^{2} a_{4} .
\end{aligned}
$$

Podemos exemplificar esses critérios com a seguinte aplicação: suponha que N1 representa uma população de predadores e N2 e N3 populações de presas de N1, conforme o diagrama da figura 13.

Figura 13 - Grafo orientado - Exemplo de aplicação dos critérios de Routh-Hurwitz

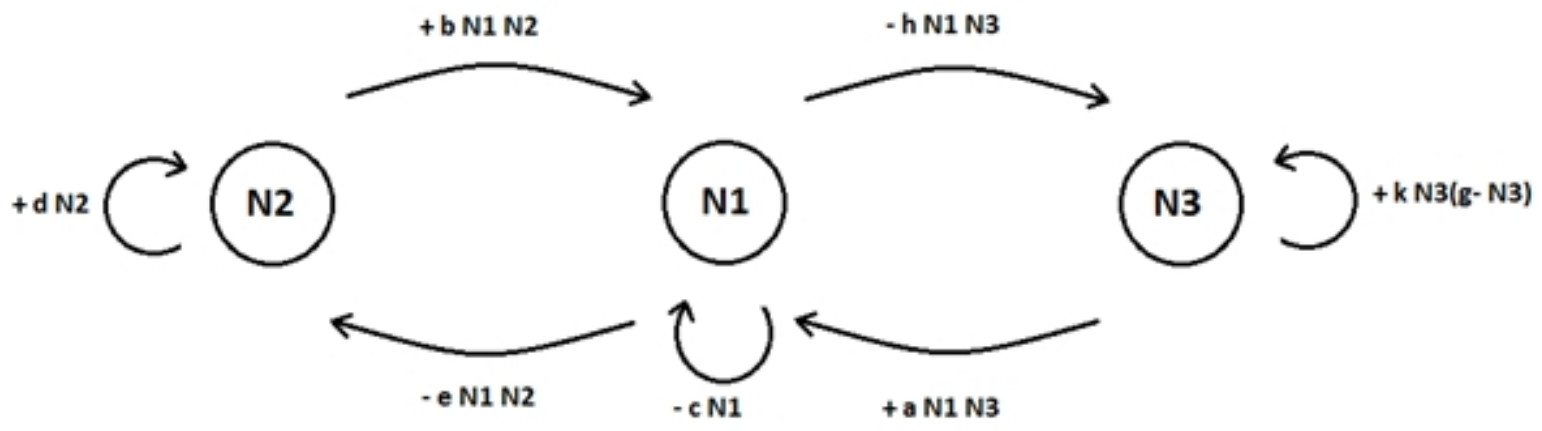

Fonte: Adaptado para Edelstein-Keshet, 2005, p. 234

Nesta figura 13, as grandezas significam:

- $c N_{1}$ : probabilidade de morte do predador;

- $a N_{1} N_{3}$ : crescimento da população N1 pela predação por membros da população N3;

- $b N_{1} N_{2}$ : crescimento da população N1 pela predação por membros da população N2;

- $d N_{2}$ : crescimento da população N2 quando o seu predador não está presente;

- $e N_{1} N_{2}$ : mortalidade da população $\mathrm{N} 2$ pela predação por membros da população de presas $\mathrm{N} 1$;

- $h N_{1} N_{3}$ : representa a mortalidade da população N3 pela predação por membros da população N1;

- $k N_{3}\left(g-N_{3}\right)$ : equação logística que ilustra o crescimento da população N3. 
As equações para este sistema são dadas por

$$
\begin{aligned}
\frac{d N_{1}}{d t} & =a N_{1} N_{3}+b N_{1} N_{2}-c N_{1} \\
\frac{d N_{2}}{d t} & =d N_{2}-e N_{1} N_{2} \\
\frac{d N_{3}}{d t} & =k N_{3}\left(g-N_{3}\right)-h N_{1} N_{3}
\end{aligned}
$$

Ao se impor as derivadas das equações (19), (20) e (21) como sendo iguais a zero, resolve-se o sistema para encontrar os valores dos pontos de equilíbrio $N_{1}^{*}, N_{2}^{*}$ e $N_{3}^{*}$ :

$$
\begin{gathered}
a N_{1} N_{3}+b N_{1} N_{2}+c N_{1}=0 \Longrightarrow a N_{3}^{*}+b N_{2}^{*}=c, \text { ou } N_{1}^{*}=0 \\
d N_{2}-e N_{1} N_{3}=0 \Longrightarrow N_{1}^{*}=\frac{d}{e}, \quad \text { ou } \quad N_{2}^{*}=0 \\
k N_{3}\left(g-N_{3}\right)-h N_{1} N_{3}=0 \Longrightarrow k g-k N_{3}^{*}-h N_{1}^{*}=0
\end{gathered}
$$

Portanto, tem-se os seguintes pontos de equilíbrio para o sistema:

$$
N_{1}^{*}=\frac{d}{e} \quad N_{2}^{*}=\frac{c-a N_{2}}{b} \quad N_{3}^{*}=g-\frac{h}{k} N_{1}^{*}
$$

Calculando a matriz jacobiana deste sistema obtém-se

$$
J=\left[\begin{array}{ccc}
a N_{3}^{*}+b N_{2}^{*}-c & b N_{1}^{*} & a N_{1}^{*} \\
-e N_{2}^{*} & d-e N_{1}^{*} & 0 \\
-h N_{3}^{*} & 0 & k g-2 k N_{3}^{*}-h N_{1}^{*}
\end{array}\right]
$$

Inserindo-se os valores encontrados como pontos de equilíbrio, pode-se simplificar os conteúdos da diagonal principal da matriz,

$$
J=\left[\begin{array}{ccc}
0 & b N_{1}^{*} & a N_{1}^{*} \\
-e N_{2}^{*} & 0 & 0 \\
-h N_{3}^{*} & 0 & -k N_{3}^{*}
\end{array}\right]
$$

e então calcular sua equação característica

$$
\operatorname{det}\left[\begin{array}{ccc}
0-\lambda & b N_{1}^{*} & a N_{1}^{*} \\
-e N_{2}^{*} & 0-\lambda & 0 \\
-h N_{3}^{*} & 0 & -k N_{3}^{*}-\lambda
\end{array}\right]=0
$$


que fornece a equação

$$
-\lambda^{3}+\lambda^{2} k N_{3}^{*}+\lambda\left(-e N_{2}^{*} b N_{1}^{*}-h N_{3}^{*} a N_{1}^{*}\right)+\left(k N_{3}^{*} e N_{2}^{*} b N_{1}^{*}\right)=0 .
$$

Multiplicando todos os termos da equação por -1 obtém-se os termos da equação na sua forma geral que interessam ao método (a saber, com o coeficiente da maior potência de $\lambda$ positivo)

$$
\lambda^{3}+a_{1} \lambda^{2}+a_{2} \lambda+a_{3}=0
$$

onde

$$
\begin{aligned}
& a_{1}=k N_{3}, \\
& a_{2}=e b N_{1}^{*} N_{2}^{*}+h a N_{1}^{*} N_{3}^{*}, \\
& a_{3}=k e b N_{1}^{*} N_{2}^{*} N_{3}^{*} .
\end{aligned}
$$

Nesta etapa se avaliam as condições dos critérios de Routh-Hurwitz, que neste exemplo com três espécies $(k=3)$ implica em

$$
a_{1}>0, \quad a_{3}>0, \quad a_{1} a_{2}>a_{3},
$$

Nota-se que a condição $a_{1}>0$ é satisfeita uma vez $k N_{3}^{*}$ é um valor positivo. A condição $a_{3}>0$ é verdadeira pela mesma razão. Verificando a condição $a_{1} a_{2}>a_{3}$, tem-se que $a_{1} a_{2}=$ $k N_{3}^{*}\left(e b N_{1}^{*} N_{2}^{*}+h a N_{1}^{*} N_{3}^{*}\right)$, que é claramente maior que $a_{3}=k e b N_{1}^{*} N_{2}^{*} N_{3}^{*}$, uma vez que $h a k N_{1}^{*}\left(N_{3}^{*}\right)^{2}$ é um valor positivo. Portanto, conclui-se que o ponto de equilíbrio formado por $N_{1}^{*}, N_{2}^{*}$ e $N_{3}^{*}$ é sempre estável, não importando quais os valores que podem assumir os parâmetros do sistema dinâmico que o originou.

\subsection{Simulações do sistema dinâmico}

Nesta seção se fará a análise da estabilidade dos pontos de equilíbrio no modelo proposto para uma população de ostras, conforme o conjunto formado pelas equações diferenciais (9), (10) e (11), novamente exibidas abaixo, tal como enunciadas na seção 2.3:

$$
\begin{aligned}
\frac{d P}{d t} & =r_{p} P(k-P)-f O P \\
\frac{d O}{d t} & =r_{o} P O-a M O-h O-m_{o} O \\
\frac{d M}{d t} & =r_{m} P-b O M
\end{aligned}
$$


O primeiro passo é obtenção dos pontos de equilíbrio, que se consegue por intermédio das soluções possíveis do sistema de equações anteriores submetido à seguinte imposição:

$$
\begin{aligned}
0 & =r_{p} P(k-P)-f O P \\
0 & =r_{o} P O-a M O-h O-m_{o} O \\
0 & =r_{m} P-b O M
\end{aligned}
$$

A solução desse sistema de equações origina quatro pontos de equilíbrio $\left(P^{*}, O^{*}, M^{*}\right)$ nomeados e listados abaixo:

- $P_{1}=(0,0,0)$;

- $P_{2}=(0,0, M)$;

- $P_{3}=\left(\frac{-a f r_{m}+b h r_{p}+b m_{o} r_{p}+b r_{o} r_{p}+\Delta}{2 b r_{o} r_{p}}, \frac{\frac{a f r_{m}}{2 b r_{o}}+\frac{r_{p}}{2}-\frac{h r_{p}}{2 r_{o}}-\frac{m_{o} r_{p}}{2 r_{o}}-\frac{\Delta}{2 b r_{o}}}{f}, \frac{-h-m_{o}+r_{o}-\frac{a f r_{m}}{b r_{p}}+\frac{\Delta}{b r_{p}}}{2 a}\right)$;

- $P_{4}=\left(\frac{-a f r_{m}+b h r_{p}+b m_{o} r_{p}+b r_{o} r_{p}-\Delta}{2 b r_{o} r_{p}}, \frac{\frac{a f r_{m}}{2 b r_{o}}+\frac{r_{p}}{2}-\frac{h r_{p}}{2 r_{o}}-\frac{m_{o} r_{p}}{2 r_{o}}+\frac{\Delta}{2 b r_{o}}}{f}, \frac{-h-m_{o}+r_{o}-\frac{a f r_{m}}{b r_{p}}-\frac{\Delta}{b r_{p}}}{2 a}\right)$,

onde

$$
\Delta=\sqrt{4 b^{2}\left(-h-m_{o}\right) r_{o} r_{p}^{2}+\left(a f r_{m}-b h r_{p}-b m_{o} r_{p}-b r_{o} r_{p}\right)^{2}} .
$$

O passo seguinte é construir a matriz jacobiana, que demostra a dinâmica que tem cada variável com as demais, calculada em seus respectivos pontos de equilíbrio,

$$
J=\left[\begin{array}{ccc}
-f O^{*}+\left(1-2 P^{*}\right) r_{p} & -f P^{*} & 0 \\
O^{*} r_{o} & -h-a M^{*}-m_{o}+P^{*} r_{o} & -a O^{*} \\
r_{m} & -b M^{*} & -b O^{*}
\end{array}\right]
$$

e então obter a equação característica pelo intermédio do cálculo da expressão

$$
\operatorname{det}(J-\lambda I)=0,
$$

o que resulta em

$$
\begin{aligned}
& -b f h O^{* 2}-b f m_{o} O^{* 2}+a f O^{*} P^{*} r_{m}+b h O^{*} r_{p}+b m_{o} O^{*} r_{p}-2 b h O^{*} P^{*} r_{p}-2 b m_{o} O^{*} P^{*} r_{p} \\
& -b O^{*} P^{*} r_{o} r_{p}+2 b O^{*} P^{* 2} r_{o} r_{p}-b h O^{*} \lambda-f h O^{*} \lambda-a f M^{*} O^{*} \lambda-b m_{o} O^{*} \lambda-f m_{o} O^{*} \lambda \\
& -b f O^{* 2} \lambda+b O^{*} P^{*} r_{o} \lambda+h r_{p} \lambda+a M^{*} r_{p} \lambda+m_{o} r_{p} \lambda+b O^{*} r_{p} \lambda-2 h P^{*} r_{p} \lambda \\
& -2 a M^{*} P^{*} r_{p} \lambda-2 m_{o} P^{*} r_{p} \lambda-2 b O^{*} P^{*} r_{p} \lambda-P^{*} r_{o} r_{p} \lambda+2 P^{* 2} r_{o} r_{p} \lambda-h \lambda^{2} \\
& -a M^{*} \lambda^{2}-m_{o} \lambda^{2}-b O^{*} \lambda^{2}-f O^{*} \lambda^{2}+P^{*} r_{o} \lambda^{2}+r_{p} \lambda^{2}-2 P^{*} r_{p} \lambda^{2}-\lambda^{3}=0
\end{aligned}
$$


Nessa altura dos cálculos é notório que a quantidade de parâmetros livres na equação (23) impossibilita de se ter uma noção prática de como eles se inter-relacionam, dessa maneira, se torna útil antes da aplicação de qualquer método de análise da estabilidade aos pontos de equilíbrio a substituição de parte dos parâmetros por valores arbitrados ou típicos encontrados em fenômenos assemelhados ao estudado neste trabalho, e assim, se realizar o estudo da estabilidade em função de uma quantidade menor e mais relevante desses parâmetros aplicados de maneira mais específica ao contexto estudado.

Para a realização desta análise foram considerados os parâmetros $f=0.24 m^{-3} \cdot d^{-1} \mathrm{e} b=$ $0.24 m^{-3} \cdot d^{-1}$, valores típicos da taxa de filtragem praticada pelas ostras para sua alimentação e o efeito da biorremediação causado por este ato respectivamente, ambos extraídos de Pereira et al. (2007). Para a taxa de crescimento do fitoplâncton consideramos o valor $r_{p}=0.55 \mathrm{~m}^{3} \cdot \mu \mathrm{g}^{-1} \cdot d^{-1}$, valor aproximado da mediana dos valores típicos encontrados em Sun et al. (2013), enquanto as taxas de crescimento da população de ostras e de sua mortalidade foram estimados a partir de Pereira et al. (2007) em $r_{o}=0.054 m^{3} \cdot \mu g^{-1} \cdot d^{-1}$ e $m_{o}=0.005 d^{-1}$, respectivamente. A taxa de anoxia foi arbitrada em $a=0.001 \mathrm{~m}^{3} \cdot \mathrm{mg}^{-1} \cdot d^{-1}$, considerando conceitos de Vidal e Neto (2013). A taxa de crescimento da matéria suspensa, representada pelo parâmetro $r_{m}$, foi arbitrada em $0.001 \mathrm{mg} \cdot \mu \mathrm{g}^{-1} \cdot d^{-1}$, indicando que toda a população de fitoplâncton surgida passa eventualmente a compor a matéria suspensa. O parâmetro $h$, taxa de coleta da população de ostras para o consumo humano, foi deixado livre.

\subsection{Análise do ponto de equilíbrio $P_{4}$ do sistema dinâmico pelo método de Quirk-Ruppert}

Nesta seção se analisará a aplicação do método de Quirk-Ruppert desenvolvido na seção 3.1 no estudo da estabilidade qualitativa aplicada ao ponto de equilíbrio $P_{4}$ do sistema dinâmico proposto neste trabalho na seção 3.3 segundo a teoria desenvolvida na seção 3 .

Inserindo-se os valores atribuídos aos parâmetros do sistema na equação (23) se obtém a seguinte matriz qualitativa $A$ :

$$
J=A=\left[\begin{array}{ccc}
-0.24 O^{*}+0.55\left(1-2 P^{*}\right) & -0.24 P^{*} & 0 \\
0.054 O^{*} & -0.005-h-0.001 M^{*}+0.054 P^{*} & -0.001 O^{*} \\
0.001 & -0.24 M^{*} & -0.24 O^{*}
\end{array}\right]
$$


Inserindo-se os valores das variáveis do ponto de equilíbrio $P_{4}=\left(P^{*}, O^{*}, M^{*}\right)$ em relação aos valores numéricos atribuídos aos parâmetros arbitrados desenvolvidas na seção 3.3 obtém-se os elementos da matriz $A$ em função do parâmetro livre $h$,

$$
\begin{aligned}
& a_{11}=0.55(1-140.292(0.00778776-\Delta+0.132 h)-1 .(0.249546+38.5802 \Delta-5.09259 h) \\
& a_{12}=-16.835(0.00778776-\Delta+0.132 h) \\
& a_{13}=0 \\
& a_{21}=0.225(0.249546+38.5802 \Delta-5.09259 h) \\
& a_{22}=-0.005-0.5(0.0489982-7.57576 \Delta-h)+3.7879(0.0077878-\Delta+0.132 h)-h \\
& a_{23}=-0.00416667(0.249546+38.5802 \Delta-5.09259 h) \\
& a_{31}=0.001 \\
& a_{32}=-120 .(0.0489982-7.57576 \Delta-h) \\
& a_{33}=-1 .(0.249546+38.5802 \Delta-5.09259 h)
\end{aligned}
$$

onde

$$
\Delta=\sqrt{0.00376358(-0.005-h)+(-0.00778776-0.132 h)^{2}}
$$

No passo seguinte determinamos, pelo intermédio de representações gráficas, os valores numéricos do parâmetro livre $h$ em que as cinco condições propostas pelo método de QuirkRuppert são satisfeitas, conforme descritas na seção 3.1.

Teste da condição I, todos os elementos $a_{i i} \leq 0$ e condição II, $a_{i i}<0$ para pelo menos um elemento $a_{i i}$ :

Figura 14 - Condições I e II para método de Quirk-Ruppert aplicadas no ponto de equilíbrio $P_{4}$, elemento $a_{11}$

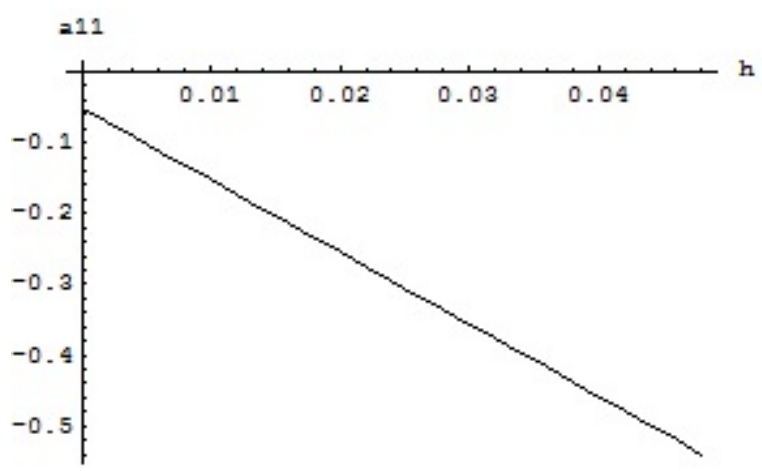

Fonte: Sergio Serino, 2016 
Figura 15 - Condições I e II para método de Quirk-Ruppert aplicadas no ponto de equilíbrio $P_{4}$, elemento $a_{22}$

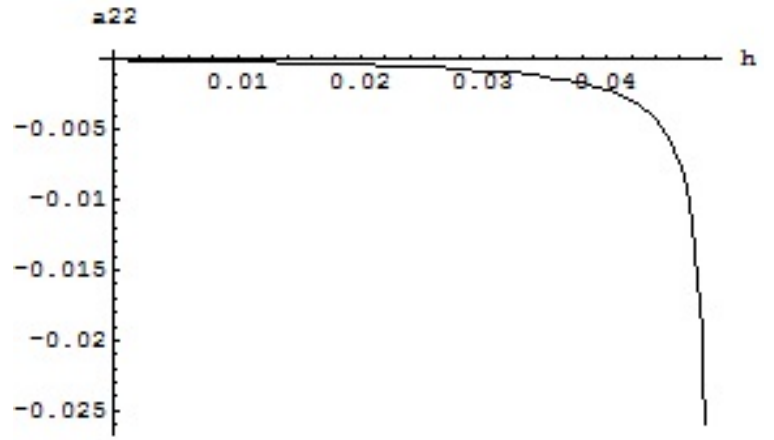

Fonte: Sergio Serino, 2016

Figura 16 - Condições I e II para método de Quirk-Ruppert aplicadas no ponto de equilíbrio $P_{4}$, elemento $a_{33}$

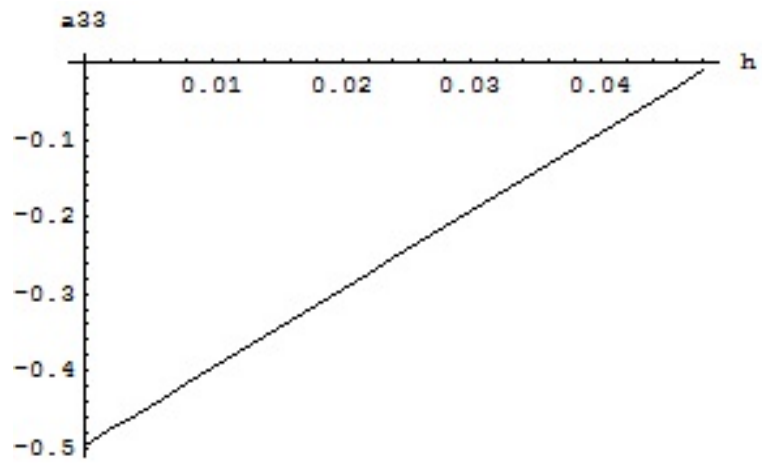

Fonte: Sergio Serino, 2016

Teste da condição III, todo $a_{i j} a_{j i} \leq 0$ para todo $i \neq j$ :

Figura 17 - Condição III para método de Quirk-Ruppert aplicadas no ponto de equilíbrio $P_{4}$, elemento $a_{12}$ e $a_{21}$

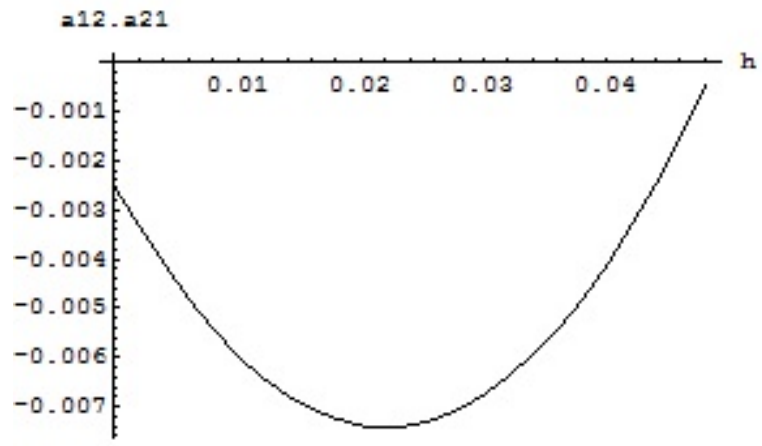

Fonte: Sergio Serino, 2016 
Figura 18 - Condição III para método de Quirk-Ruppert aplicadas no ponto de equilíbrio $P_{4}$, elemento $a_{13}$ e $a_{31}$

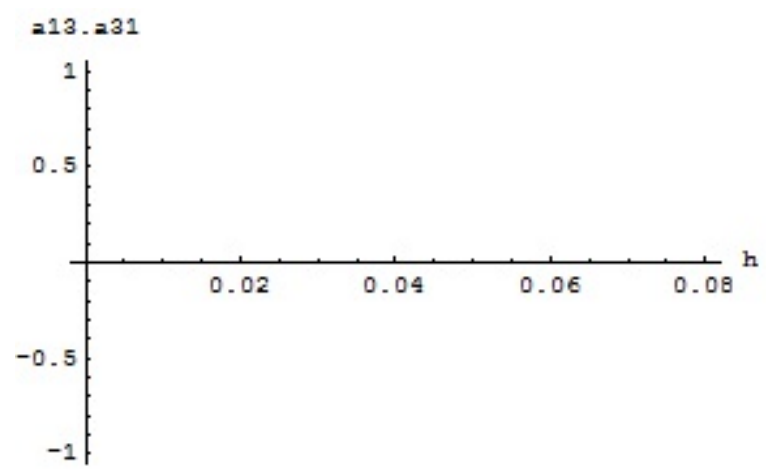

Fonte: Sergio Serino, 2016

Teste da condição IV, para toda sequência dada por: $a_{i j} a_{j k} \cdots a_{q r} a_{q i}=0$ para qualquer sequência de três ou mais nós que compõe o grafo que representa um sistema dinâmico.

Note que a figura 18 ilustra esta condição para efeito de análise.

Teste da condição $\mathrm{V}$, determinante de $A \neq 0$ :

Figura 19 - Condição V para método de Quirk-Ruppert aplicadas no ponto de equilíbrio $P_{4}$, $\operatorname{det} A$

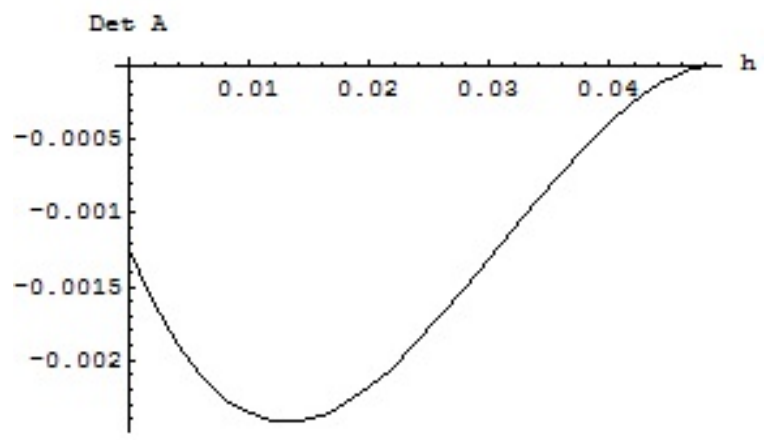

Fonte: Sergio Serino, 2016

Tem-se na figura 20 um resumo da relação de sinais das operações propostas nos testes das cinco condições para o método de Quirk-Ruppert aplicadas ao modelo dinâmico proposto em seu ponto de equilíbrio $P_{4}$. 
Figura 20 - Estudo de sinal para o método de Quirk-Ruppert no ponto de equilíbrio $P_{4}$

\begin{tabular}{llll} 
Condição I & $V$ & $F$ \\
\hline Condição II & $V$ & $F$ \\
\hline Condição III & $V$ & $F$ \\
\hline Condição IV & $V$ & $F$ \\
\hline Condição $V$ & $V$ & & $F$ \\
\hline$I \cap I I \cap I I \cap I V \cap V$ & $V$ & & $F$ \\
\hline$h=0.000$ & & $h=0.048$ &
\end{tabular}

Fonte: Sergio Serino, 2016

Pode-se concluir então, que o ponto de equilíbrio analisado é qualitativamente estável segundo este método desde que o valor do parâmetro $h$ não ultrapasse o limiar numérico de 0.048 .

Os testes das cinco condições do método de Quirk-Ruppert aplicadas aos demais pontos de equilíbrio do sistema dinâmico proposto, $P_{1}, P_{2}$ e $P_{3}$, não possuem valores para o parâmetro livre $h$ de modo a satisfazerem todas as condições simultaneamente.

Para os pontos $P_{1}$ e $P_{2}$, por exemplo, a condição $\mathrm{V}$ é falsa para ambos, pois o determinante da matriz $A$ tem o valor de zero independentemente do valor de $h$, tal como ilustra a figura 21 .

Figura 21 - Condição V para método de Quirk-Ruppert aplicadas nos pontos de equilíbrio $P_{1}$ e $P_{2}, \operatorname{det} A$

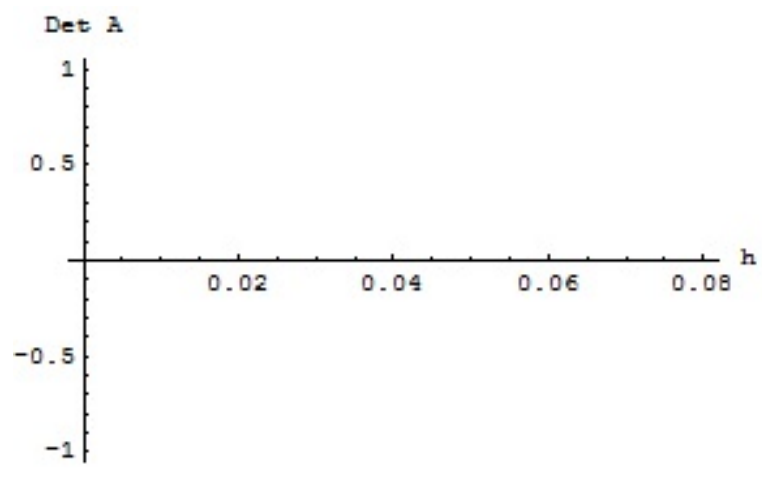

Fonte: Sergio Serino, 2016 
No ponto de equilíbrio $P_{3}$, por exemplo, a condição I é falsa, pois o elemento $a_{11}$ da matriz qualitativa $A$ não possui valores iguais ou menores do que zero independentemente do valor de $h$, conforme é mostrado na figura 22 .

Figura 22 - Condição I para método de Quirk-Ruppert aplicada no ponto de equilíbrio $P_{3}$, elemento $a_{11}$

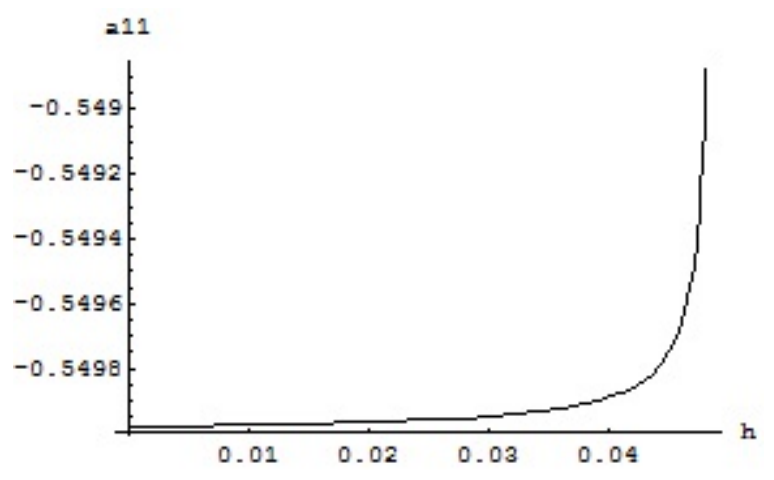

Fonte: Sergio Serino, 2016

Desta maneira, pode-se concluir que os pontos de equilíbrio $P_{1}, P_{2}$ e $P_{3}$ não possuem estabilidade qualitativa, no entanto, a falha em quaisquer condições do teste no método de Quirk-Ruppert não é condição suficiente para estabelecer a não estabilidade de forma ampla para estes pontos, tal como desenvolvido na teoria da seção 3. Deste modo, para ampliar a análise da estabilidade ou não desses pontos se desenvolverá no tópico a seguir a técnica chamada de critérios de Routh-Hurwitz, a qual se mostrará suficientemente capaz de analisar tais pontos, inclusive garantindo a existência da não estabilidade em sentido amplo (sistema instável) quando for o caso.

\subsection{Análise dos pontos de equilíbrio do sistema dinâmico pelos critérios de Routh-Hurwitz}

Nas quatro primeiras secções deste capítulo se estudará, pela aplicação dos critérios de Routh-Hurwitz, o comportamento das possíveis soluções do modelo de sistema dinâmico proposto em função do único parâmetro livre, $h$, em que se classificará os quatro pontos de equilíbrio encontrados no sistema. Na quinta seção se ampliará este estudo para um conjunto de dois parâmetros livres, $h$ e $r_{p}$. 


\subsubsection{Estabilidade do ponto de equilíbrio $P_{1}$ com o parâmetro $h$ livre}

Substituindo os valores do ponto de equilíbrio $P_{1}$ obtidos na seção 3.3 na equação (23) obtemos

$$
h r_{p} \lambda+m_{o} r_{p} \lambda-a r_{p} x \lambda+h \lambda^{2}+m_{o} \lambda^{2}-r_{p} \lambda^{2}+a x \lambda^{2}+\lambda^{3}=0
$$

Inserindo-se os respectivos valores estimados dos parâmetros conforme citado anteriormente na seção 3.3, se obtém a equação caraterística final para um único parâmetro livre $(h)$ :

$$
-0.00275 \lambda-0.55 h \lambda-0.545 \lambda^{2}+h \lambda^{2}+\lambda^{3}
$$

Extraindo-se os termos que compõe a matriz de Hurwitz $\left(H_{3}\right)$, conforme citado na seção 3.2 obtém-se:

$$
\begin{aligned}
& a_{1}=-0.545+h \\
& a_{2}=-0.00275-0.55 h \\
& a_{3}=0
\end{aligned}
$$

Segundo os critérios de Routh-Hurwitz, enunciados na seção 3.2, para se garantir a estabilidade no sistema dinâmico de três variáveis proposto neste trabalho em um determinado ponto de equilíbrio se faz necessário atender às seguintes condições:

$$
a_{1}>0, \quad a_{3}>0, \quad a_{1} a_{2}>a_{3},
$$

que para o ponto de equilíbrio $P_{1}$ podem ser avaliadas respectivamente em função do parâmetro $h$ nos gráficos que ilustram as figuras 23,24 e 25 :

Figura 23 - Condição $a_{1}$ para o ponto de equilíbrio $P_{1}$

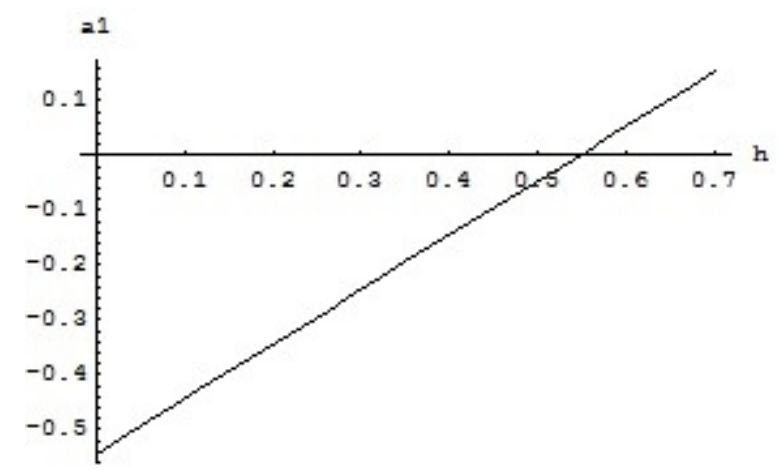

Fonte: Sergio Serino, 2016 
Figura 24 - Condição $a_{3}$ para o ponto de equilíbrio $P_{1}$

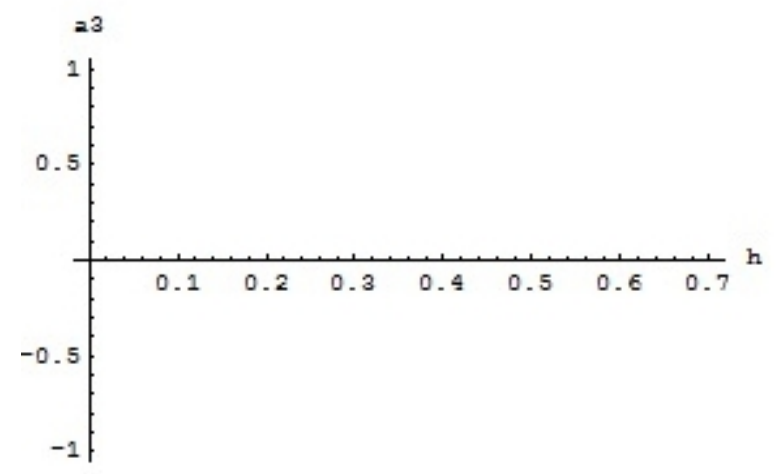

Fonte: Sergio Serino, 2016

Figura 25 - Condição $a_{1} a_{2}$ para o ponto de equilíbrio $P_{1}$

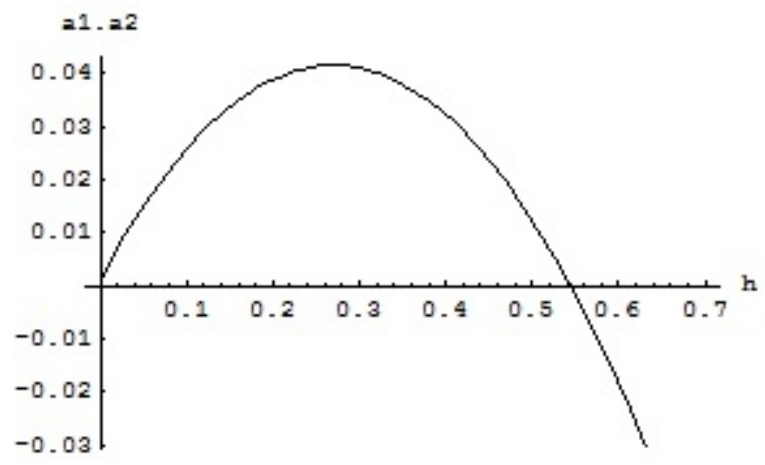

Fonte: Sergio Serino, 2016

Em resumo tem-se no diagrama ilustrado pela figura 26 a avaliação final dos critérios de estabilidade de Routh-Hurwitz para o ponto de equilíbrio $P_{1}$, em que se determina para quais valores de $h$ têm-se $P_{1}$ em equilíbrio estável, ou seja, para quais valores do intervalo de $h$ estão satisfeitas todas as condições: $\left(a_{1}>0\right) \cap\left(a_{1} a_{2}>a_{3}\right) \cap\left(a_{3}>0\right)=V$ (V: verdadeiro). A recíproca também existe, um intervalo de $h$ em $P_{1}$ tem um ponto de equilíbrio não estável quando no mínimo uma dessas condições falha, $\left(a_{1}>0\right) \cap\left(a_{1} a_{2}>a_{3}\right) \cap\left(a_{3}>0\right)=F$ ( $F$ : falso). 
Figura 26 - Estudo de sinal para os critérios de Routh-Hurwitz no ponto de equilíbrio $P_{1}$

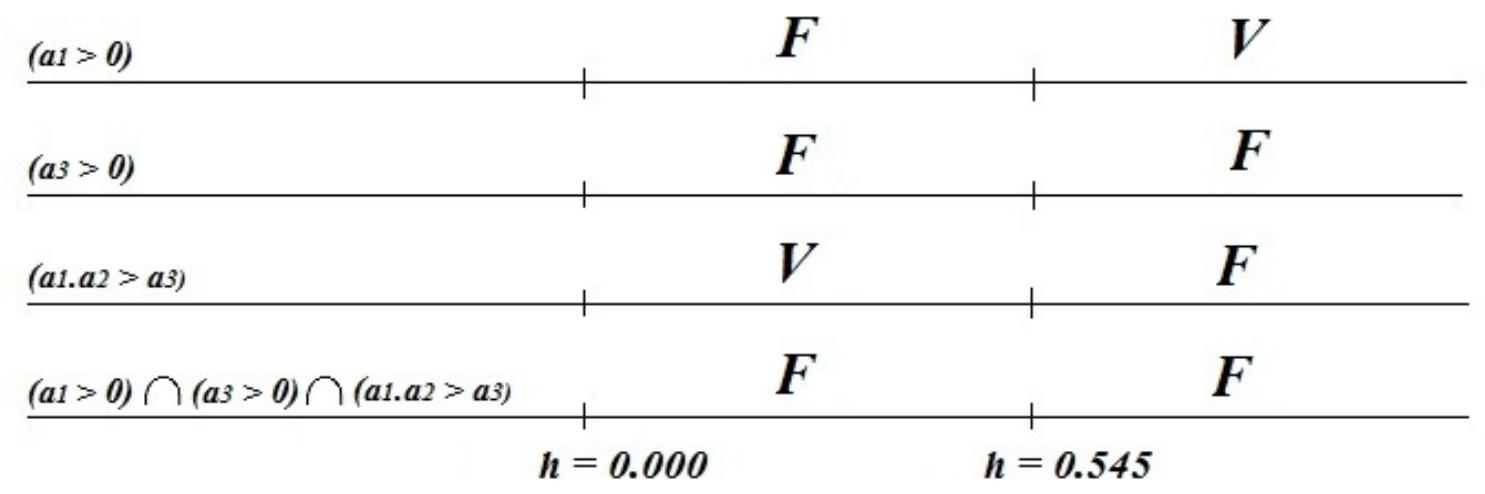

Fonte: Sergio Serino, 2016

Analisando a figura 26 pode-se concluir que as condições que indicam estabilidade na vizinhança do ponto de equilíbrio $P_{1}$ não são satisfeitas independentemente do valor do parâmetro livre $h$. Assim, conforme a definição de estabilidade de Lyapunov, que foi enunciada na seção 3.2, existe pelo menos uma variável que não retornará ao seu ponto de equilíbrio $X^{*}$ quando perturbada por uma diferença $\delta=\left|X^{*}-X\right|<\varepsilon$, esse comportamento caracteriza a condição de não estabilidade para o sistema dinâmico em estudo na vizinhança de $P_{1}$. Para comprovar este comportamento, se fará a simulação das soluções numéricas para este sistema dinâmico com a atribuição de valores para $\delta$ e $h$ contidos no intervalo em estudo para se averiguar o comportamento da evolução de cada uma das variáveis em torno do ponto de equilíbrio, $P_{1}$.

Note na figura 27, que aplicada uma pertubação $\delta$ na variável $P$ em torno do ponto de equilíbrio a simulação da solução numérica realizada por um método de Runge Kutta de quarta ordem mostra um comportamento divergente desta variável, pois a mesma cresce indefinidamente com tendência ao infinito, o que demonstra a instabilidade local na direção da variação imposta na variável $P$. 
Figura 27 - Soluções para o sistema dinâmico na vizinhança do ponto de equilíbrio $P_{1}$ perturbado na variável $P(t), P_{1}=(\delta, 0,0), \delta=1 \cdot 10^{-6}, h=0.0005$
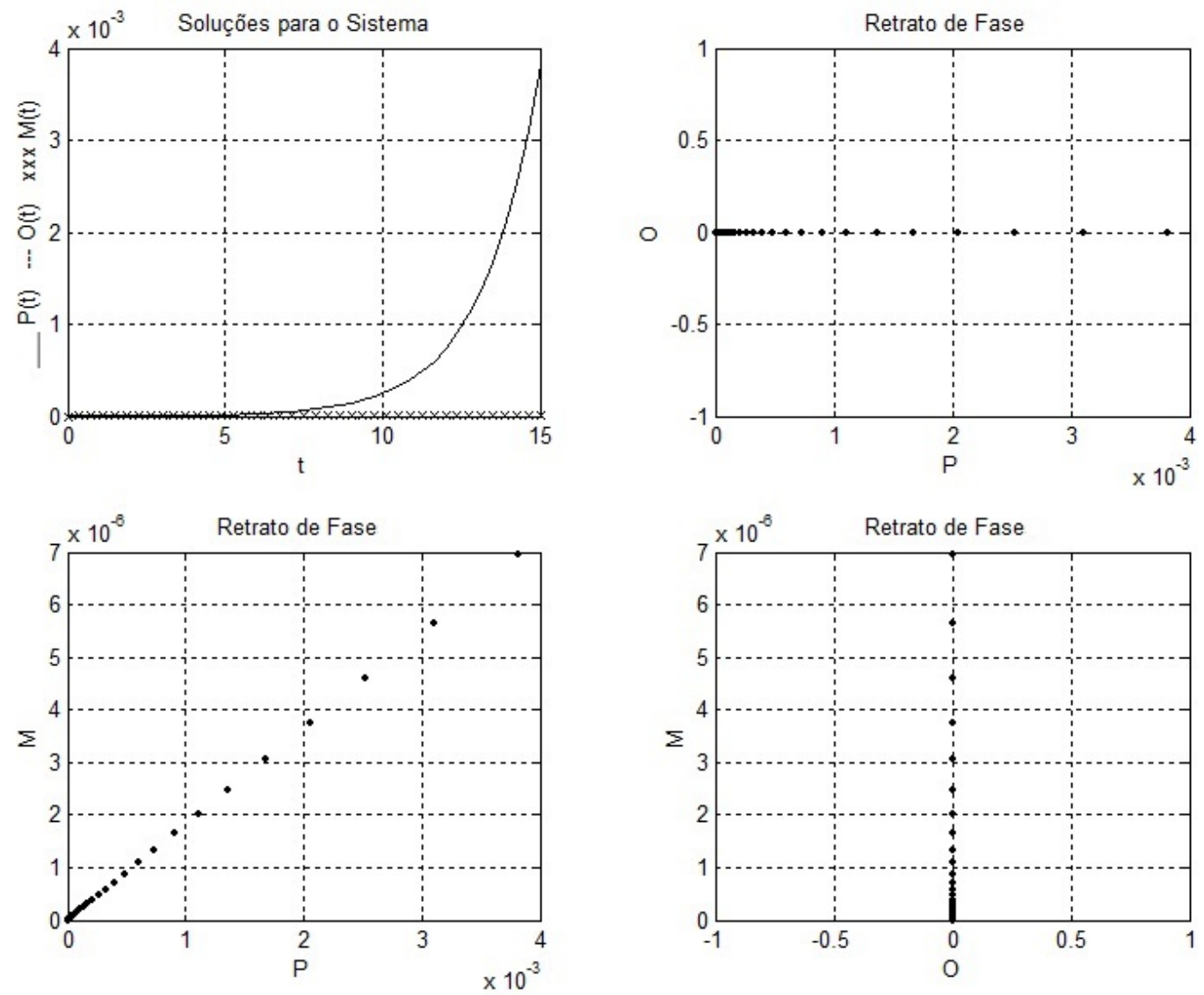

Fonte: Sergio Serino, 2016

Na figura 28, se aplica o procedimento descrito anteriormente na variável $O$ e encontra-se também um comportamento divergente na direção desta variável. 
Figura 28 - Soluções para o sistema dinâmico na vizinhança do ponto de equilíbrio $P_{1}$ perturbado na variável $O(t), P_{1}=(0, \delta, 0), \delta=1 \cdot 10^{-6}, h=0.0005$
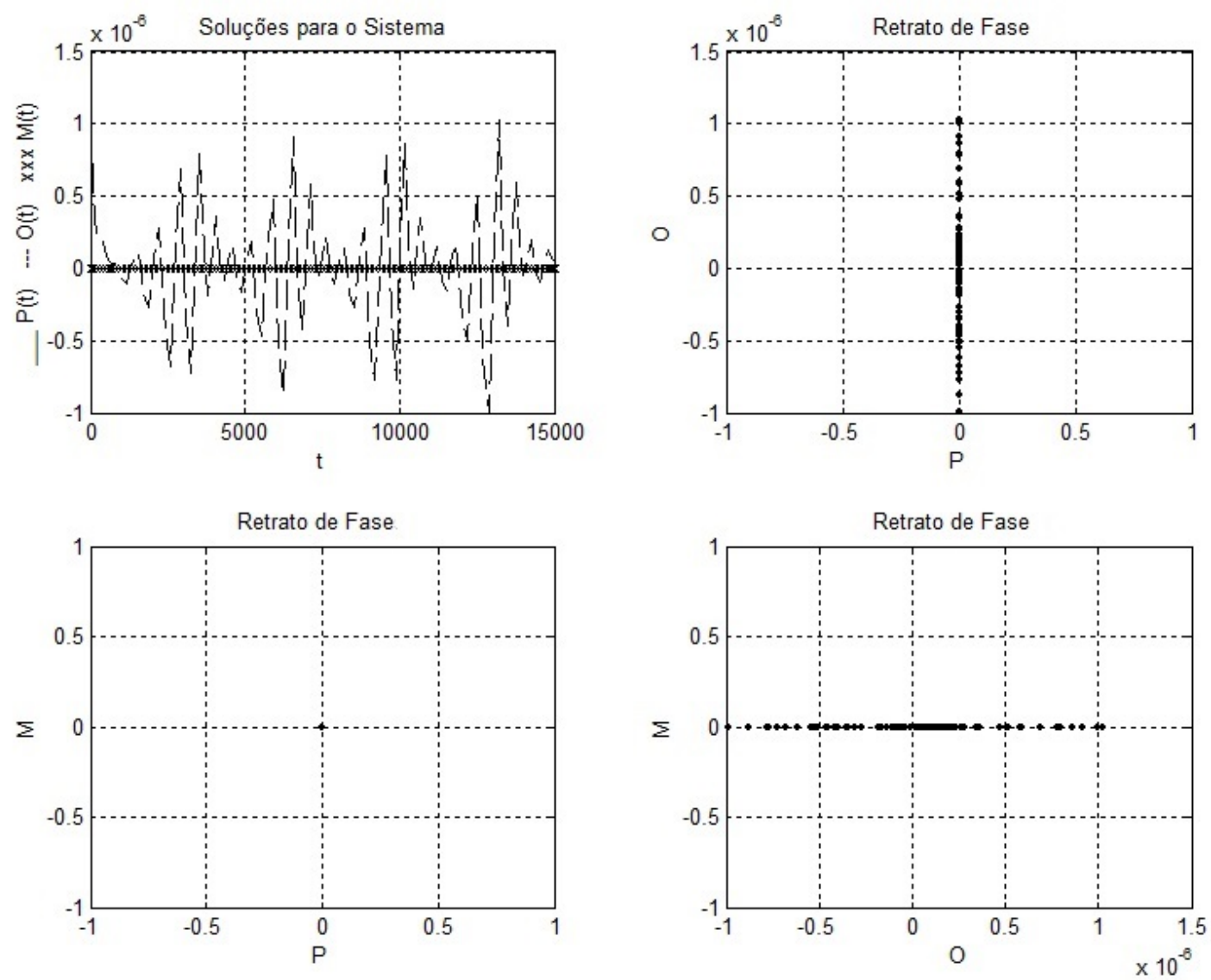

Fonte: Sergio Serino, 2016

Por último, se realiza o mesmo procedimento no sentido da variável $M$, neste caso, se encontra também um comportamento de não estabilidade local em relação a $P_{1}$, a aparente estabilidade vista no gráfico ilustrado na figura 29 indica na verdade o surgimento de um novo ponto de equilíbrio, pois, enquanto as demais variáveis são mantidas em zero e apenas a variável $M$ é perturbada, ocorre que ela assume o valor de $\delta$ e mantém esta situação indefinidamente, não mais retornando a $P_{1}$. Em uma análise futura deste sistema dinâmico verá se tratar de um novo ponto de equilíbrio, o ponto $P_{2}=(0,0, M)$.

Portanto, ao se analisar a simulação das soluções anteriores para cada variável do sistema dinâmico de forma independente, conclui-se, que o sistema dinâmico em estudo é não estável globalmente na vizinhança do ponto de equilíbrio $P_{1}$. 
Figura 29 - Soluções para o sistema dinâmico na vizinhança do ponto de equilíbrio $P_{1}$ perturbado na variável $M(t), P_{1}=(0,0, \delta), \delta=1 \cdot 10^{-6}, h=0.0005$
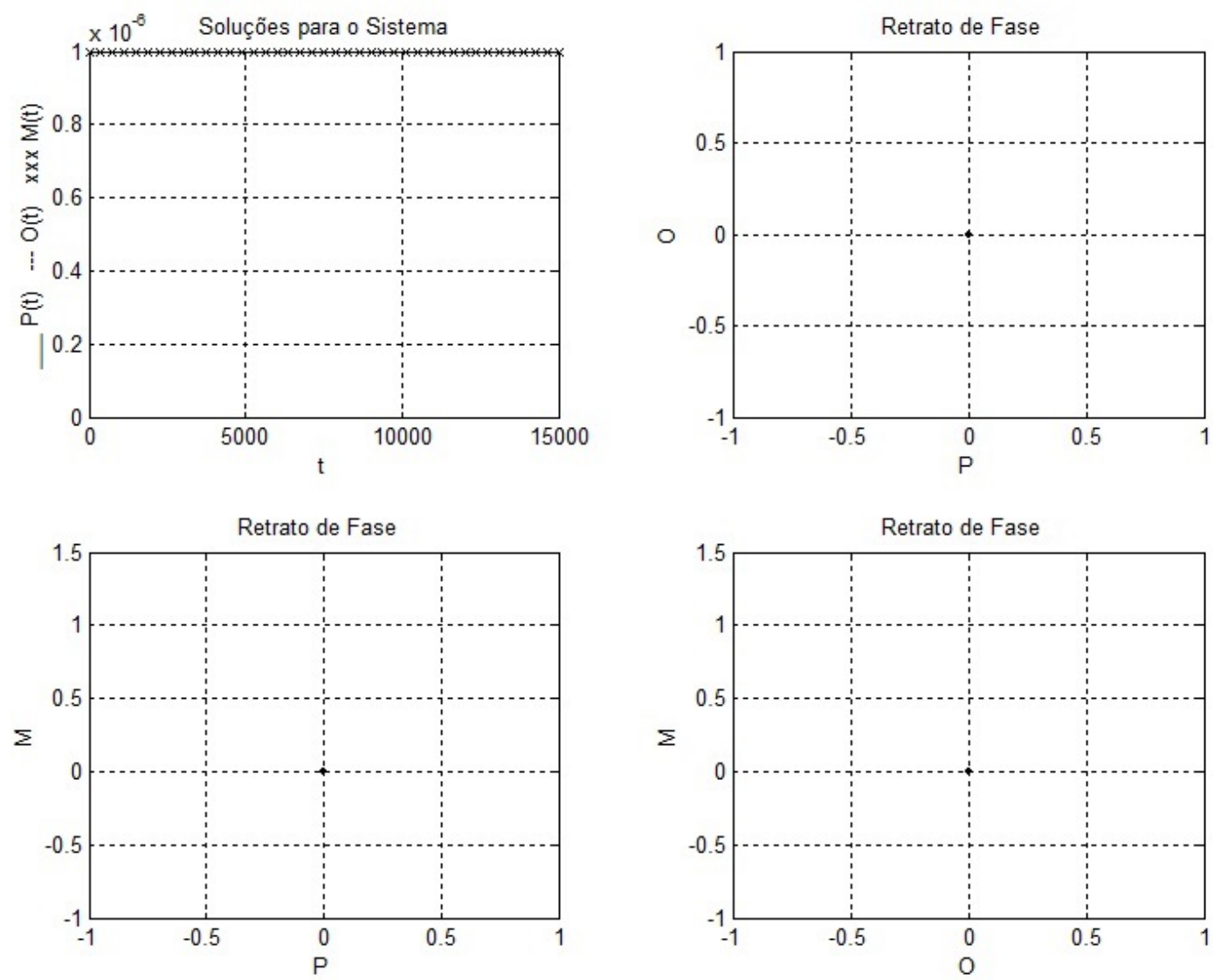

Fonte: Sergio Serino, 2016

\subsubsection{Estabilidade do ponto equilíbrio $P_{2}$ com o parâmetro $h$ livre}

A seguir mostraremos que há pouca diferença na análise de estabilidade do ponto de equilíbrio $P_{2}=(0,0, M)$ em relação à anterior feita em $P_{1}=(0,0,0)$, pois se verá pelos resultados que $P_{1}$ é apenas um caso particular de $P_{2}$ quando $M^{*}=0$.

Substituindo os valores do ponto de equilíbrio $P_{2}$ obtidos na seção 3.3 na equação (23) obtemos a equação característica

$$
-h r_{p} \lambda-m_{o} r_{p} \lambda-a r_{p} x \lambda+h \lambda^{2}+m_{o} \lambda^{2}-r_{p} \lambda^{2}+a x \lambda^{2}+\lambda^{3},
$$


na qual $x$ representa um valor qualquer que a variável $M$ pode assumir. Inserindo os respectivos valores estimados dos parâmetros conforme citado anteriormente ne seção 3.3, obtém-se a equação caraterística final para um único parâmetro livre $(h)$ :

$$
-0.00275 \lambda-0.55 h \lambda-0.00055 x \lambda-0.545 \lambda^{2}+h \lambda^{2}+0.001 x \lambda^{2}+\lambda^{3}
$$

Assim, da equação 31, se extrai parte dos elementos que compõe a matriz de Hurwitz $\left(H_{3}\right)$, conforme citado na seção 3.2:

$$
\begin{aligned}
& a_{1}=-0.545+h+0.001 x \\
& a_{2}=-0.00275-0.55 h-0.00055 x \\
& a_{3}=0
\end{aligned}
$$

Segundo os critérios de Routh-Hurwitz, para garantir a estabilidade deste ponto de equilíbrio se faz necessárias as seguintes condições,

$$
a_{1}>0, \quad a_{3}>0, \quad a_{1} a_{2}>a_{3},
$$

que para $P_{2}$ podem ser avaliadas em função do parâmetro $h$, tal como segue-se respectivamente nos gráficos ilustrados nas figuras (30), (31) e (32):

Figura 30 - Condição $a_{1}$ para o ponto de equilíbrio $P_{2}$

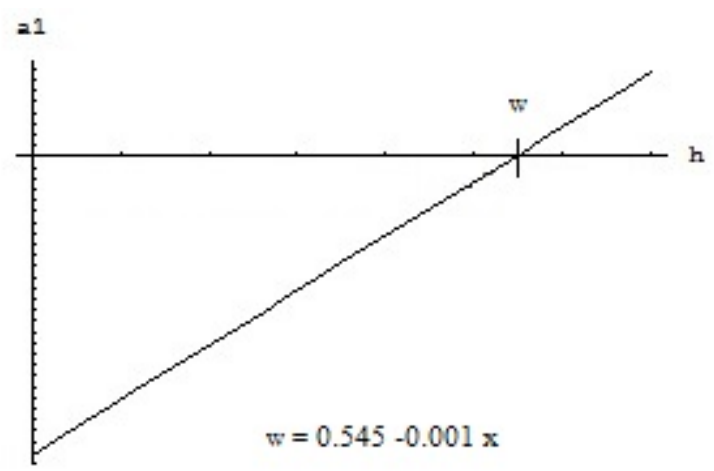

Fonte: Sergio Serino, 2016 
Figura 31 - Condição $a_{3}$ para o ponto de equilíbrio $P_{2}$

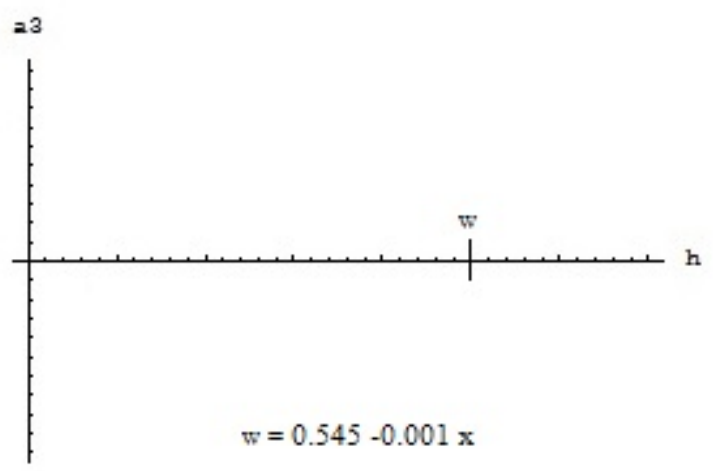

Fonte: Sergio Serino, 2016

Figura 32 - Condição $a_{1} a_{2}$ para o ponto de equilíbrio $P_{2}$

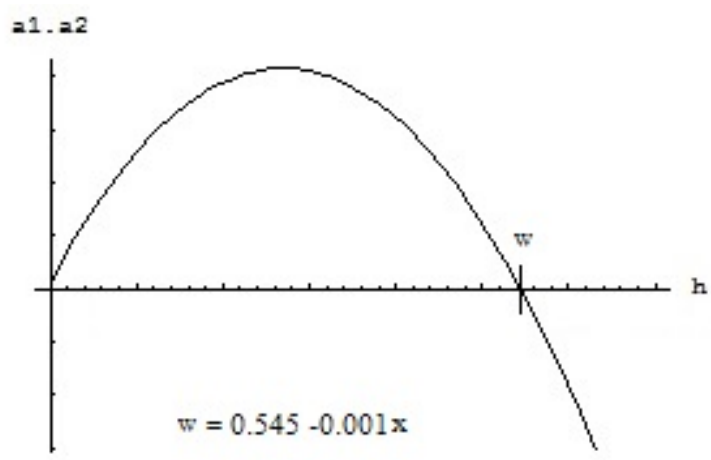

Fonte: Sergio Serino, 2016

Por fim, tem-se o resumo das condições avaliadas representadas na figura 33:

Figura 33 - Estudo de sinal para os critérios de Routh-Hurwitz no ponto de equilíbrio $P_{2}$

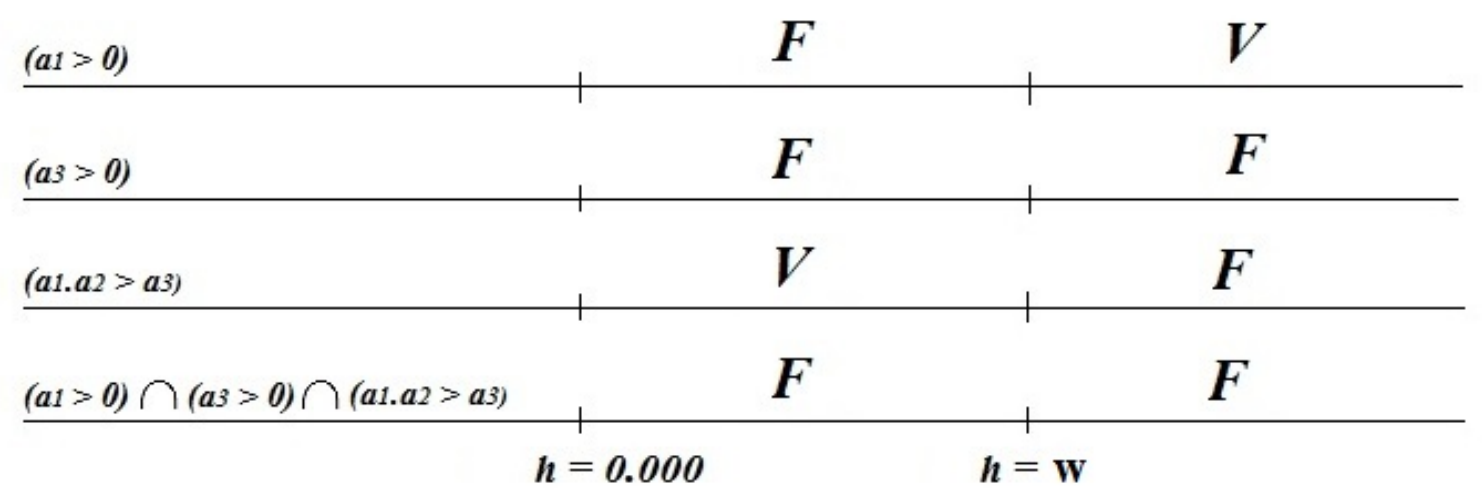

Fonte: Sergio Serino, 2016 
Note que tal como se concluiu em $P_{1}$, o ponto de equilíbrio $P_{2}$ também não é estável qualquer que seja o valor do parâmetro $h$, desse modo, uma determinada pertubação contida na sua vizinhança não terá convergência para $P_{2}$. A principal diferença da análise feita em $P_{1}$ para a de $P_{2}$, é a de que o valor de $h$ pelo qual as curvas encontram seus respectivos zeros de sua função não é mais fixo, o valor de $x$ que assume $M$ em $P_{2}=(0,0, M)$ modifica as raízes das funções que ilustram o comportamento das condições de estabilidade dos critérios de Routh-Hurwitz, sendo agora estas raízes representadas pelo ponto variável chamado oportunamente de $w$ conforme mostraram as figuras 30, 31 e 32 . Acompanhe nas figuras 34, 35 e 36 as simulações das soluções numéricas para o sistema dinâmico proposto na vizinhança de $P_{2}$ com o valor de $M=x=1$ que ilustram a instabilidade do sistema neste ponto de equilíbrio.

Figura 34 - Soluções para o sistema dinâmico na vizinhança do ponto de equilíbrio $P_{2}$ perturbado na variável $P(t), P_{2}=(\delta, 0,1), \delta=1 \cdot 10^{-6}, h=0.05$
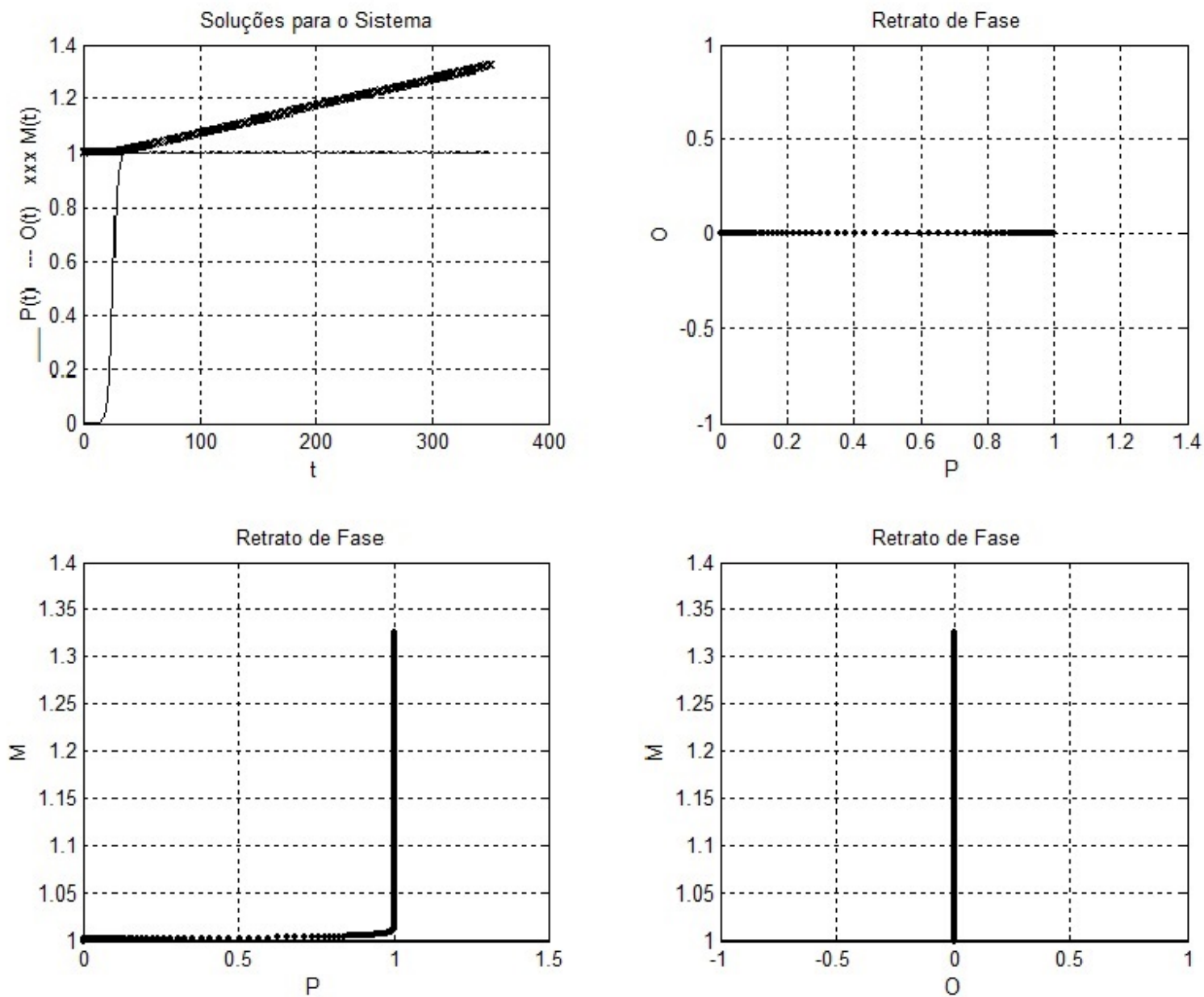

Fonte: Sergio Serino, 2016 
Figura 35 - Soluções para o sistema dinâmico na vizinhança do ponto de equilíbrio $P_{2}$ perturbado na variável $O(t), P_{2}=(0, \delta, 1), \delta=1 \cdot 10^{-6}, h=0.05$
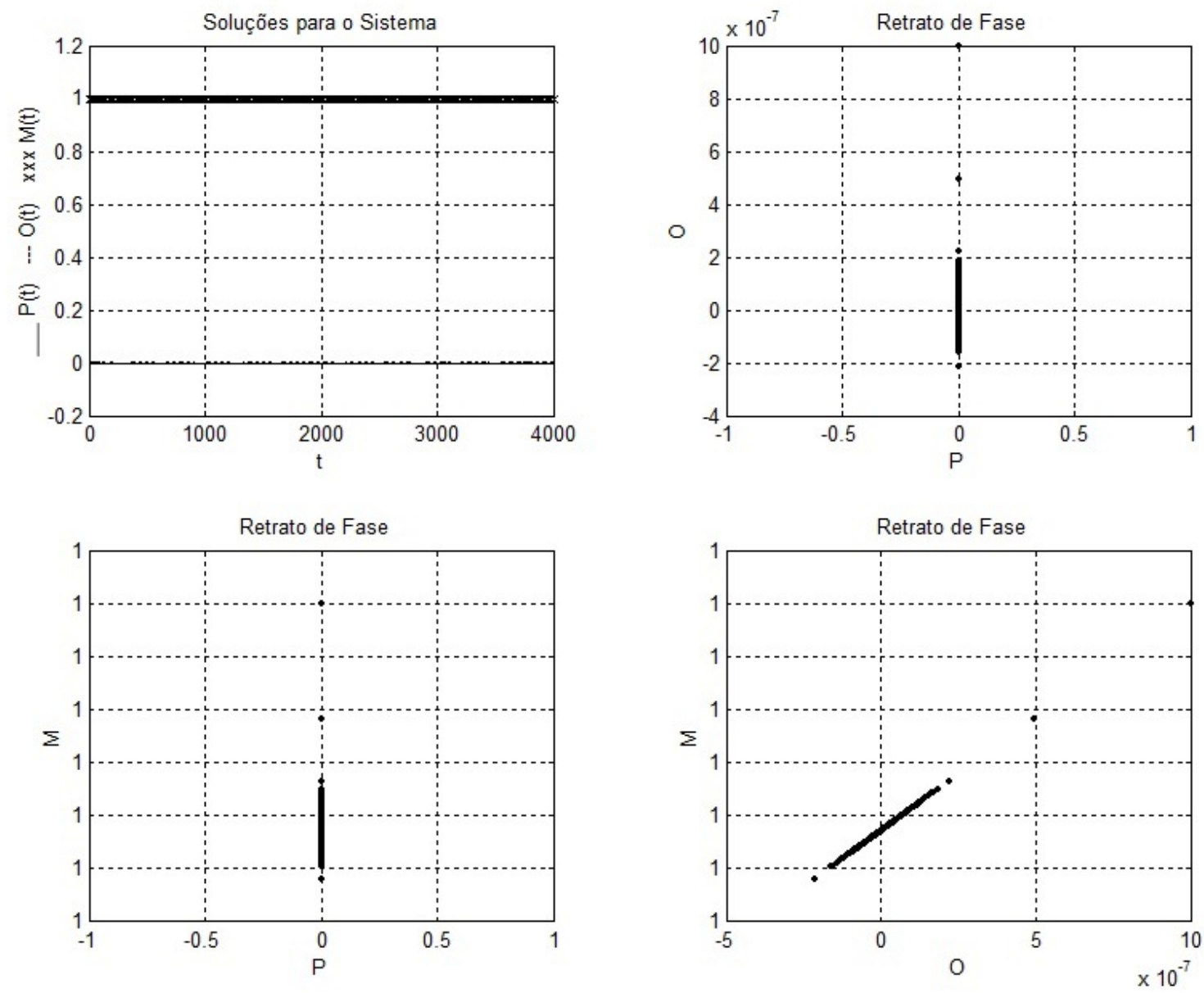

Fonte: Sergio Serino, 2016 
Figura 36 - Soluções para o sistema dinâmico na vizinhança do ponto de equilíbrio $P_{2}$ perturbado na variável $M(t), P_{2}=(0,0,1+\delta), \delta=1 \cdot 10^{-6}, h=0.05$
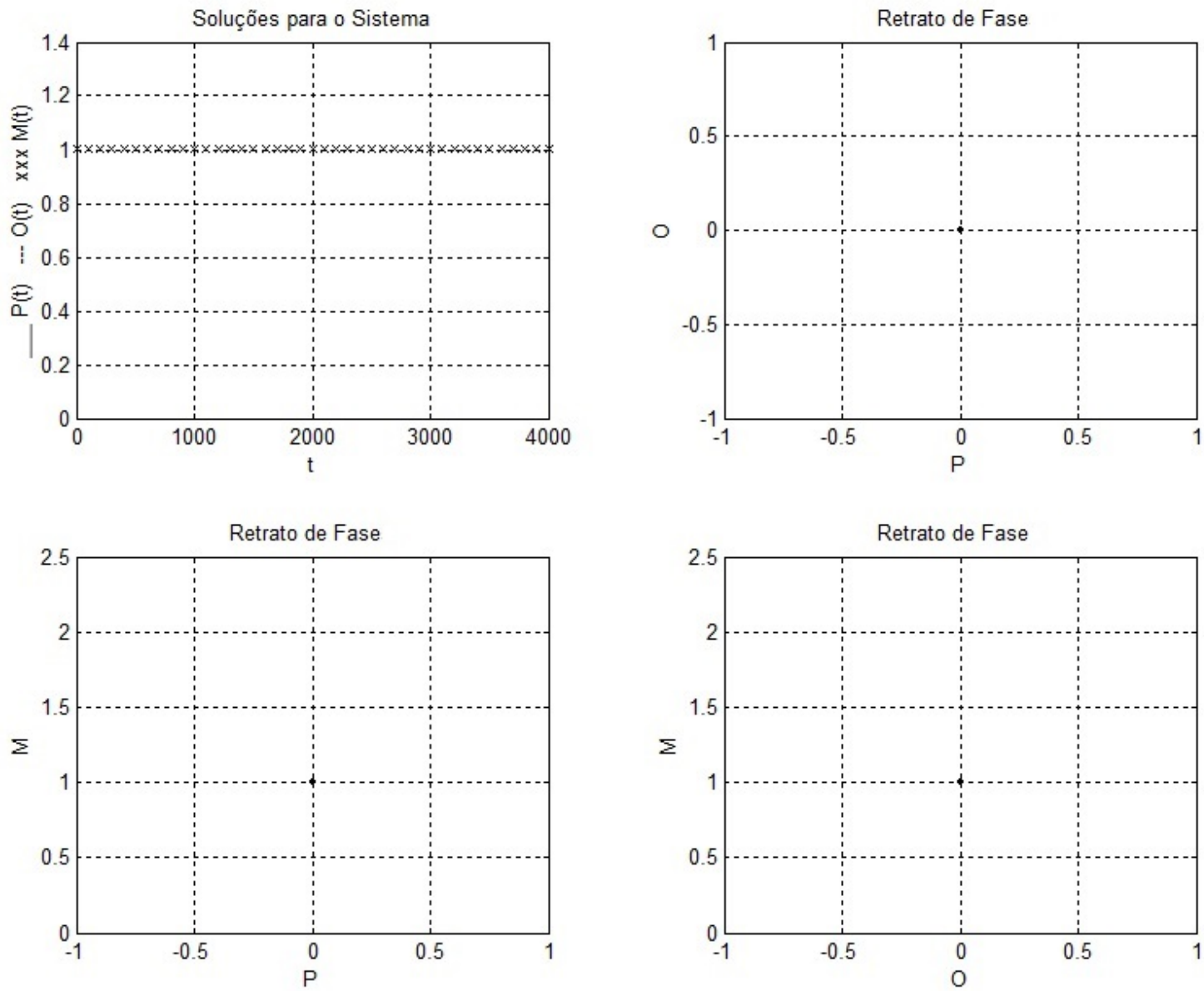

Fonte: Sergio Serino, 2016

As figuras 34, 35 e 36, ilustram um comportamento em que se caracteriza o ponto de equilíbrio $P_{2}$ como sendo de não estabilidade local no sentido da respectiva variável em estudo. Apesar da visualização realizada na figura 36 aparentar um comportamento de relativa estabilidade, isso não ocorre de fato, pois o valor de deslocamento $\delta$ somado a variável $M$ no ponto $P_{2}$ permanece assim, sem mudança, não retornando ao ponto de equilíbrio original $P_{2}=$ $(0,0,1)$, o que denota não ser de comportamento estável, tal como enunciado por Lyapunov em sua definição de estabilidade tratada aqui na seção 3.2 . Portanto, de modo global, $P_{2}=(0,0, M)$ é um ponto de equilíbrio não estável do sistema dinâmico em estudo. 


\subsubsection{Estabilidade do ponto equilíbrio $P_{3}$ com o parâmetro $h$ livre}

Substituindo os valores do ponto de equilíbrio $P_{3}$ obtidos na seção 3.3 na equação (23), obtém-se a equação característica

$$
\begin{gathered}
\quad \frac{3 a^{2} f h r_{m}^{2}}{2 b r_{o}^{2}}+\frac{3 a^{2} f m_{o} r_{m}^{2}}{2 b r_{o}^{2}}+\frac{a^{2} f r_{m}^{2}}{b r_{o}}-\frac{a^{3} f^{2} r_{m}^{3}}{2 b^{2} r_{o}^{2} r_{p}}-\frac{a r_{m} r_{p}}{2}-\frac{3 a h^{2} r_{m} r_{p}}{2 r_{o}^{2}}-\frac{3 a h m_{o} r_{m} r_{p}}{r_{o}^{2}}-\frac{3 a m_{o}^{2} r_{m} r_{p}}{2 r_{o}{ }^{2}}+ \\
\frac{b h r_{p}^{2}}{2 f}+\frac{b m_{o} r_{p}^{2}}{2 f}+\frac{b h^{3} r_{p}^{2}}{2 f r_{o}^{2}}+\frac{3 b h^{2} m_{o} r_{p}^{2}}{2 f r_{o}^{2}}+\frac{3 b h m_{o}^{2} r_{p}^{2}}{2 f r_{o}^{2}}+\frac{b m_{o}^{3} r_{p}^{2}}{2 f r_{o}^{2}}-\frac{b h^{2} r_{p}^{2}}{f r_{o}}-\frac{2 b h m_{o} r_{p}^{2}}{f r_{o}}-\frac{b m_{o}^{2} r_{p}^{2}}{f r_{o}}-\frac{a h r_{m} \Delta}{b r_{o}{ }^{2}}- \\
\frac{a m_{o} r_{m} \Delta}{b r_{o}^{2}}-\frac{a r_{m} \Delta}{2 b r_{o}}+\frac{a^{2} f r_{m}^{2} \Delta}{2 b^{2} r_{o}^{2} r_{p}}+\frac{h^{2} r_{p} \Delta}{2 f r_{o}^{2}}+\frac{h m_{o} r_{p} \Delta}{f r_{o}^{2}}+\frac{m_{o}^{2} r_{p} \Delta}{2 f r_{o}^{2}}-\frac{h r_{p} \Delta}{2 f r_{o}}-\frac{m_{o} r_{p} \Delta}{2 f r_{o}}-\frac{a r_{m} \lambda}{2}+\frac{a f r_{m} \lambda}{2 b}-\frac{a^{2} f r_{m}^{2} \lambda}{2 b r_{o}^{2}}- \\
\frac{a h r_{m} \lambda}{2 r_{o}}+\frac{a f h r_{m} \lambda}{b r_{o}}-\frac{a m_{o} r_{m} \lambda}{2 r_{o}}+\frac{a f m_{o} r_{m} \lambda}{b r_{o}}+\frac{a^{2} f r_{m}^{2} \lambda}{2 b r_{o} r_{p}}-\frac{a^{2} f^{2} r_{m}^{2} \lambda}{2 b^{2} r_{o} r_{p}}+\frac{h r_{p} \lambda}{2}+\frac{m_{o} r_{p} \lambda}{2}+\frac{a h r_{m} r_{p} \lambda}{r_{o}^{2}}+\frac{a m_{o} r_{m} r_{p} \lambda}{r_{o}^{2}}- \\
\frac{h^{2} r_{p} \lambda}{2 r_{o}}-\frac{h m_{o} r_{p} \lambda}{r_{o}}-\frac{m_{o}^{2} r_{p} \lambda}{2 r_{o}}+\frac{a r_{m} r_{p} \lambda}{2 r_{o}}-\frac{b h^{2} r_{p}^{2} \lambda}{2 f r_{o}^{2}}-\frac{b h m_{o} r_{p}^{2} \lambda}{f r_{o}^{2}}-\frac{b m_{o}^{2} r_{p}^{2} \lambda}{2 f r_{o}^{2}}+\frac{b h r_{p}^{2} \lambda}{2 f r_{o}}+\frac{b m_{o} r_{p}^{2} \lambda}{2 f r_{o}}+\frac{a r_{m} \Delta \lambda}{2 b r_{o}^{2}}- \\
\frac{h \Delta \lambda}{2 b r_{o}}-\frac{m_{o} \Delta \lambda}{2 b r_{o}}-\frac{a r_{m} \Delta \lambda}{2 b r_{o} r_{p}}+\frac{a f r_{m} \Delta \lambda}{2 b^{2} r_{o} r_{p}}-\frac{h r_{p} \Delta \lambda}{2 f r_{o}^{2}}-\frac{m_{o} r_{p} \Delta \lambda}{2 f r_{o}^{2}}+\frac{a r_{m} \lambda^{2}}{2 r_{o}}-\frac{a f r_{m} \lambda^{2}}{2 b r_{o}}+\frac{r_{p} \lambda^{2}}{2}+\frac{b r_{p} \lambda^{2}}{2 f}+\frac{h r_{p} \lambda^{2}}{2 r_{o}}- \\
\frac{b h r_{p} \lambda^{2}}{2 f r_{o}}+\frac{m_{o} r_{p} \lambda^{2}}{2 r_{o}}-\frac{b m_{o} r_{p} \lambda^{2}}{2 f r_{o}}+\frac{\Delta \lambda^{2}}{2 b r_{o}}-\frac{\Delta \lambda^{2}}{2 f r_{o}}+\lambda^{3}=0
\end{gathered}
$$

onde

$$
\Delta=\sqrt{4 b^{2}\left(-h-m_{o}\right) r_{o} r_{p}^{2}+\left(a f r_{m}-b h r_{p}-b m_{o} r_{p}-b r_{o} r_{p}\right)^{2}}
$$

Inserindo-se os respectivos valores estimados dos parâmetros na equação (35), conforme citado anteriormente na seção 3.3, se obtém a equação caraterística final para um único parâmetro livre (h) de $P_{3}$ :

$$
0.000622405-0.0963177 \Delta+0.0991188 h-17.2911 \Delta h-4.8241 h^{2}+392.947 \Delta h^{2}+
$$

$51.869 h^{3}+0.0139617 \lambda-2.15692 \Delta \lambda+2.50651 h \lambda-431.527 \Delta h \lambda-56.9616 h^{2} \lambda+0.55 \lambda^{2}+$ $\lambda^{3}=0$

Da equação anterior, se extraem as partes que compõe os elementos que formam a matriz de Hurwitz $\left(H_{3}\right)$, conforme citado na seção 3.2 :

$$
\begin{aligned}
a_{1}= & 0.55, \\
a_{2}= & 0.0139617-2.15692 \Delta+2.50651 h-431.527 \Delta h-56.9616 h^{2}, \\
a_{3}= & 0.000622405-0.0963177 \Delta+0.0991188 h-17.2911 \Delta h \\
& -4.8241 h^{2}+392.947 \Delta h^{2}+4927.55 h^{6},
\end{aligned}
$$

onde

$$
\Delta=\sqrt{0.00376358(-0.005-h)+(-0.00778776-0.132 h)^{2}}
$$


Segundo os critérios de Routh-Hurwitz, para garantir a estabilidade deste ponto de equilíbrio se faz necessário atender simultaneamente as seguintes condições,

$$
a_{1}>0, \quad a_{3}>0, \quad a_{1} a_{2}>a_{3},
$$

que para $P_{3}$ podem ser avaliadas em função do parâmetro $h$, conforme citado na seção 3.2, na representação gráfica ilustrada nas figuras 37 e 38 :

Figura 37 - Condição $a_{3}$ para o ponto de equilíbrio $P_{3}$

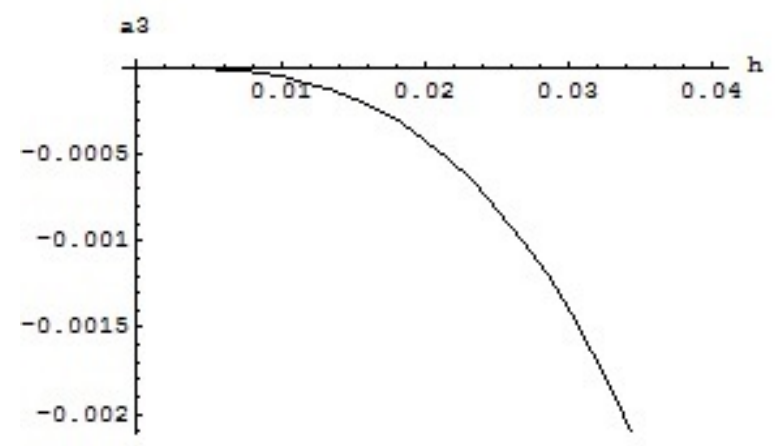

Fonte: Sergio Serino, 2016

Figura 38 - Condição $a_{1} a_{2}$ para o ponto de equilíbrio $P_{3}$

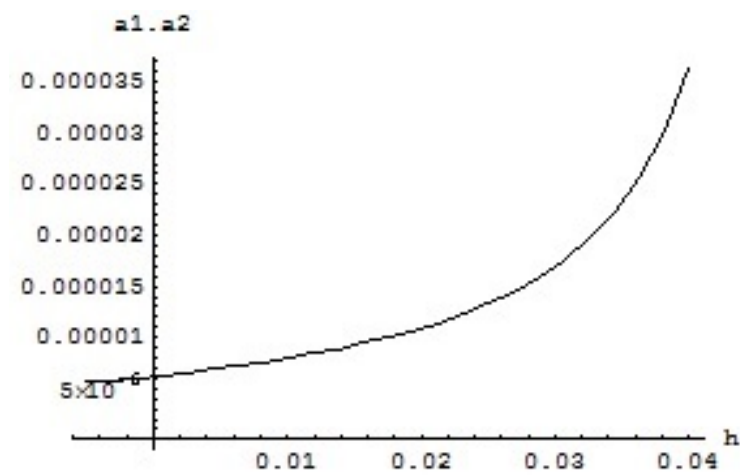

Fonte: Sergio Serino, 2016

Note na figura 39, que o resumo do comportamento ilustrado das três condições anteriores postas numa mesma linha de intervalo $h$ para comparação resultam que ponto de equilíbrio $P_{3}$ também é de não estabilidade independentemente do valor do parâmetro livre $h$, comportamento que é ressaltado na ilustração de que a condição $a_{3}>0$ é falsa. 
Figura 39 - Estudo de sinal para os critérios de Routh-Hurwitz no ponto de equilíbrio $P_{3}$

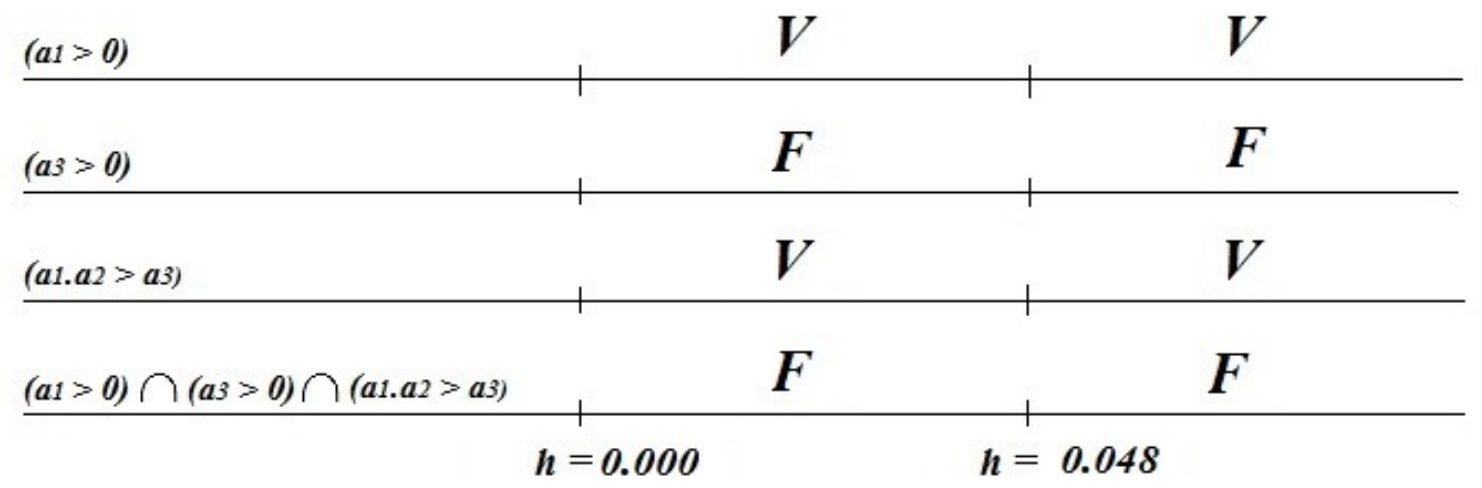

Fonte: Sergio Serino, 2016

A seguir se efetua a simulação das soluções para o conjunto numérico de parâmetros enunciado na seção $3.3 \mathrm{com} h$ livre. Veja na figura 40 que o sistema é não estável localmente quando perturbado na direção da variável $P(t)$. 
Figura 40 - Soluções para o sistema dinâmico na vizinhança do ponto de equilíbrio $P_{3}$ perturbado na variável $P(t), P_{3}=\left(P^{*}+\delta, O^{*}, M^{*}\right), \delta=1 \cdot 10^{-6}, h=0.047$
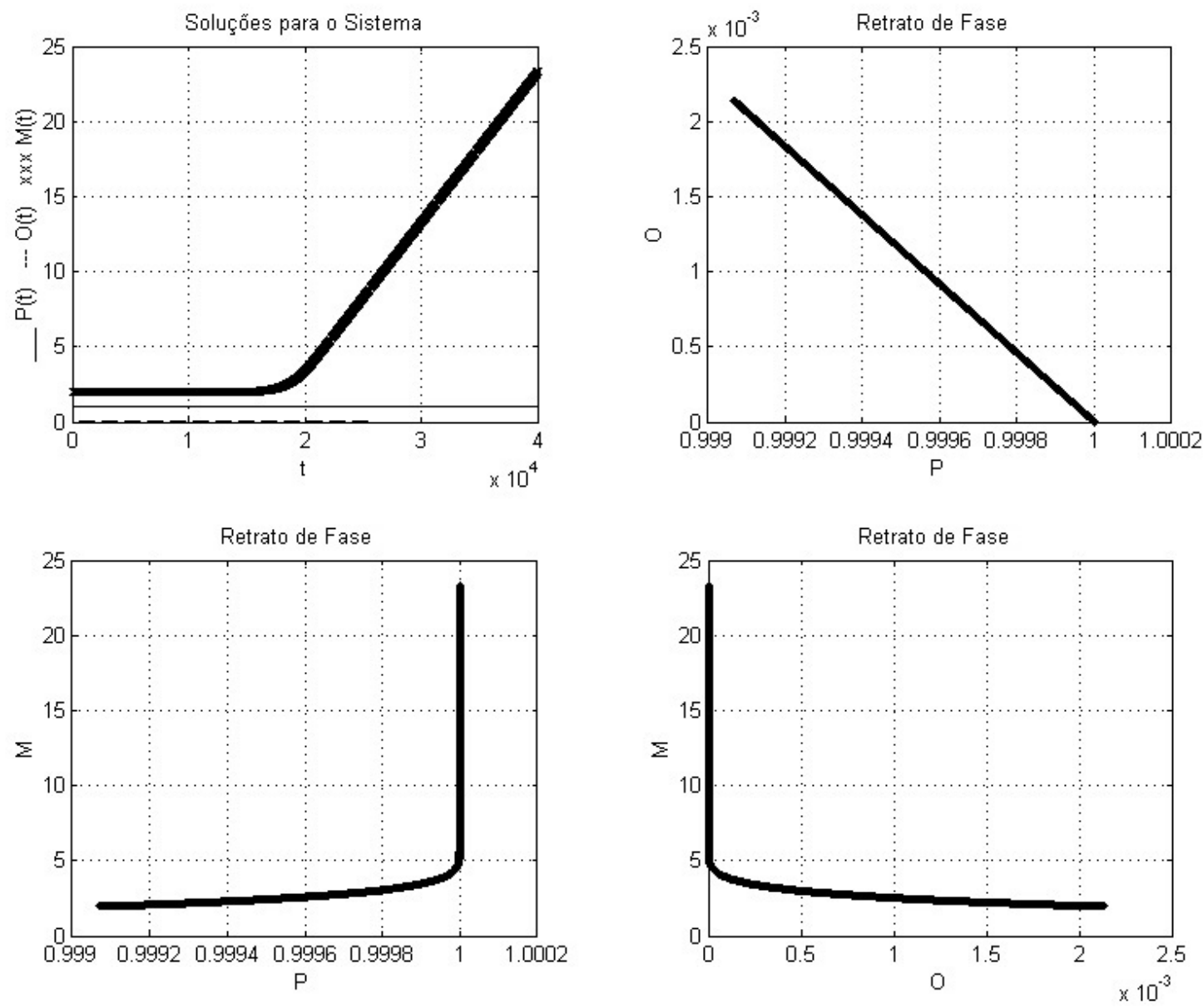

Fonte: Sergio Serino, 2016

Na figura 41 estuda-se apenas a variação no sentido da variável $O(t)$, que representa a densidade da população de ostras, realizado com o parâmetro $h<0.048$, note que na evolução do gráfico existe convergência para todas as variáveis, no entanto, ela não acontece em $P_{3}$ e sim para o ponto de equilíbrio $P_{4}$, que se estudará mais adiante ser ponto estável para este sistema dinâmico. Desta maneira, ainda podemos concluir que o comportamento ilustrado nessa figura é de não estabilidade local em relação a variável $O(t)$, pois uma vez o sistema perturbado na vizinhança de $P_{3}$ no sentido desta variável ocorre uma convergência que não é para próprio ponto inicial, $P_{3}$, e sim para $P_{4}$, porque o parâmetro $h$ se encontra na região de estabilidade para o sistema e $P^{*} \neq 0, O^{*} \neq 0$ e $M^{*} \neq 0$. 
Figura 41 - Soluções para o sistema dinâmico na vizinhança do ponto de equilíbrio $P_{3}$ perturbado na variável $O(t), P_{3}=\left(P^{*}, O^{*}+\delta, M^{*}\right), \delta=1 \cdot 10^{-6}, h=0.047$
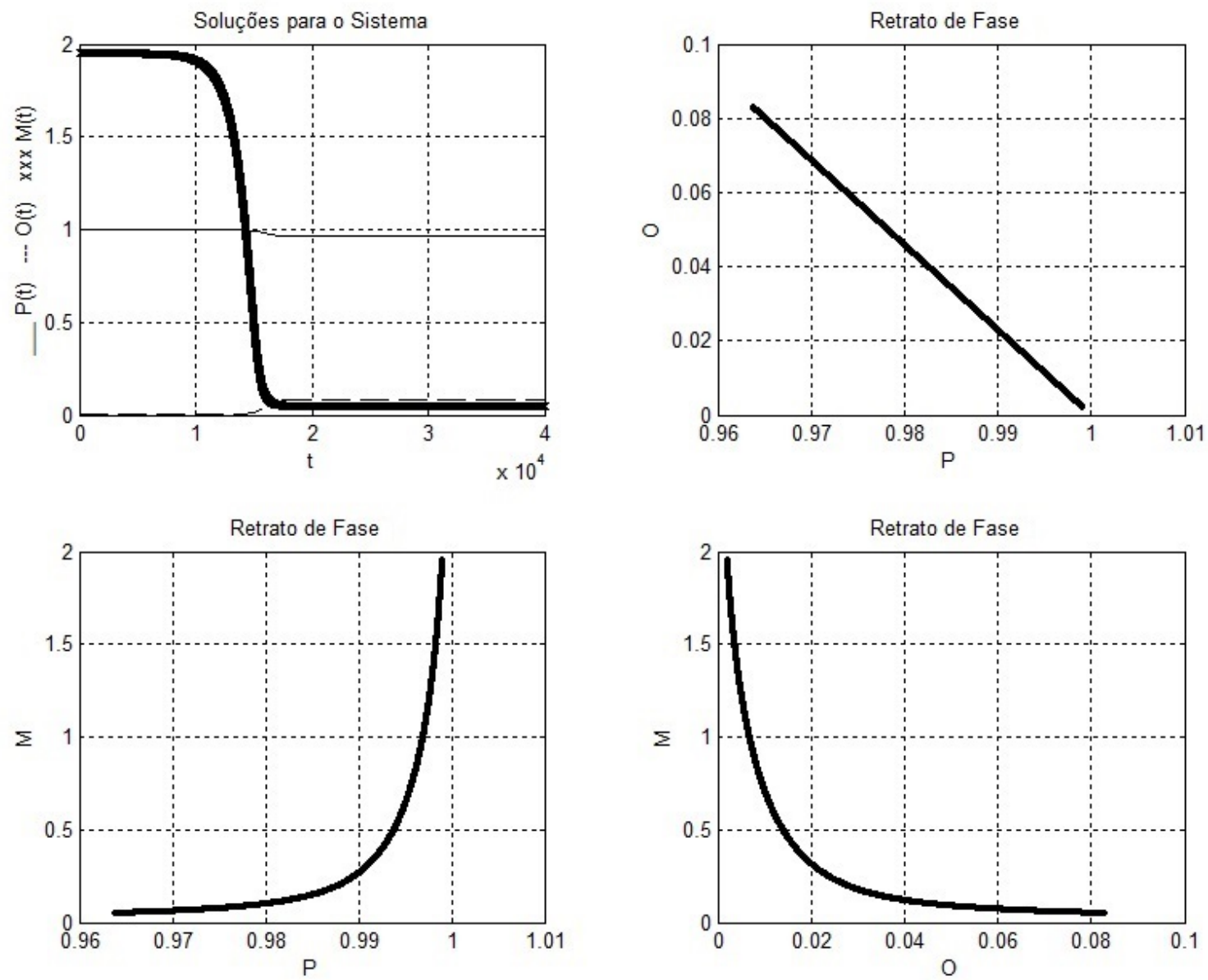

Fonte: Sergio Serino, 2016

Na figura 42, se vê a mesma perturbação em torno de $P_{3}$, mas agora realizada para o parâmetro $h>0.048$, em que se vê um comportamento de não estabilidade local na variável $O(t)$ em relação a $P_{3}$ tal como avaliado anteriormente, no entanto, este comportamento é divergente, ou seja, não há convergência para $P_{4}$ como visto anteriormente na figura 41 . 
Figura 42 - Soluções para o sistema dinâmico na vizinhança do ponto de equilíbrio $P_{3}$ perturbado na variável $O(t), P_{3}=\left(P^{*}, O^{*}+\delta, M^{*}\right), \delta=1 \cdot 10^{-6}, h=0.049$
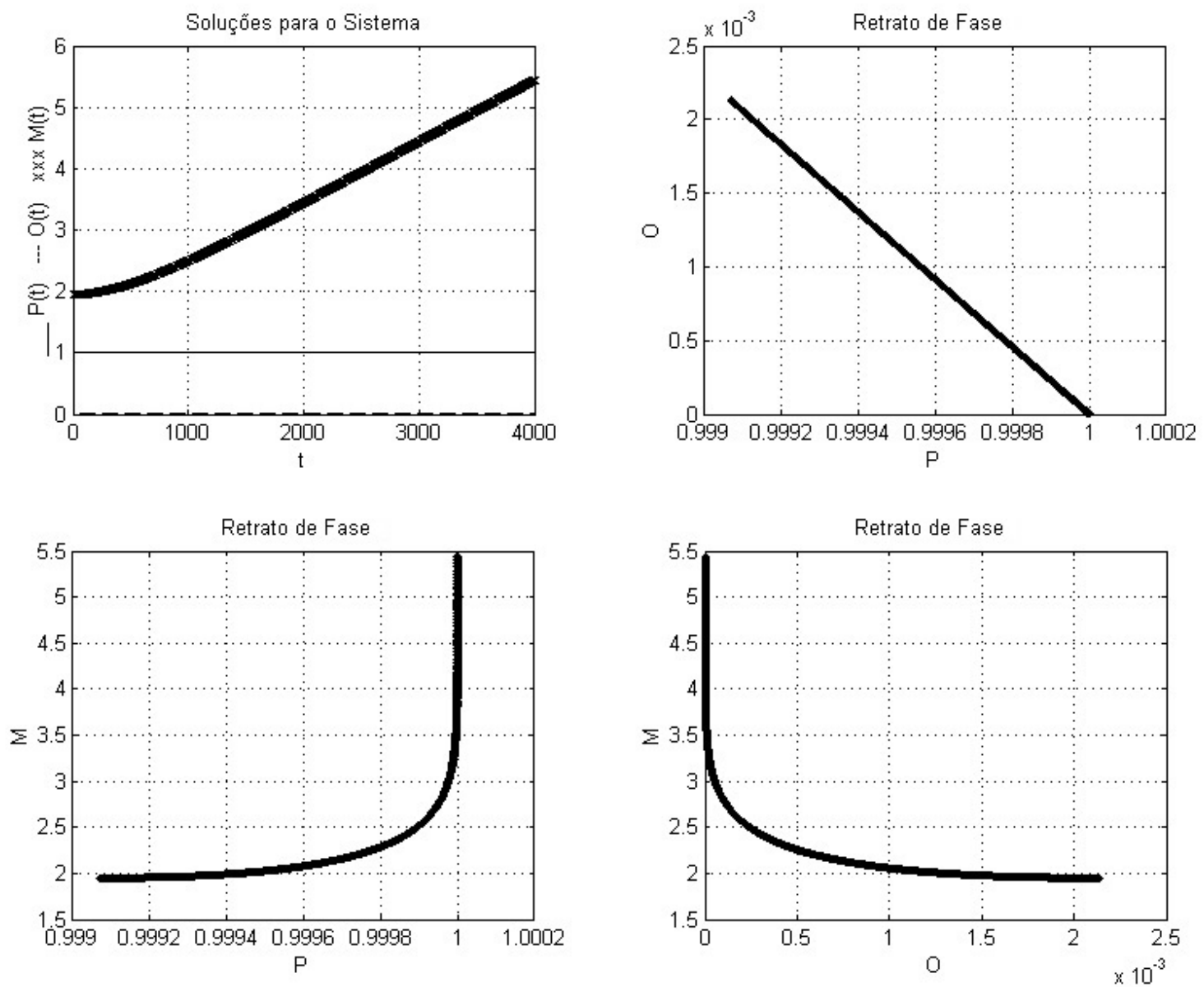

Fonte: Sergio Serino, 2016

Na figura 43 se vê a perturbação em direção a $M(t)$ para $P_{3}$. 
Figura 43 - Soluções para o sistema dinâmico na vizinhança do ponto de equilíbrio $P_{3}$ perturbado na variável $M(t), P_{3}=\left(P^{*}, O^{*}, M^{*}+\delta\right), \delta=1 \cdot 10^{-6}, h=0.047$
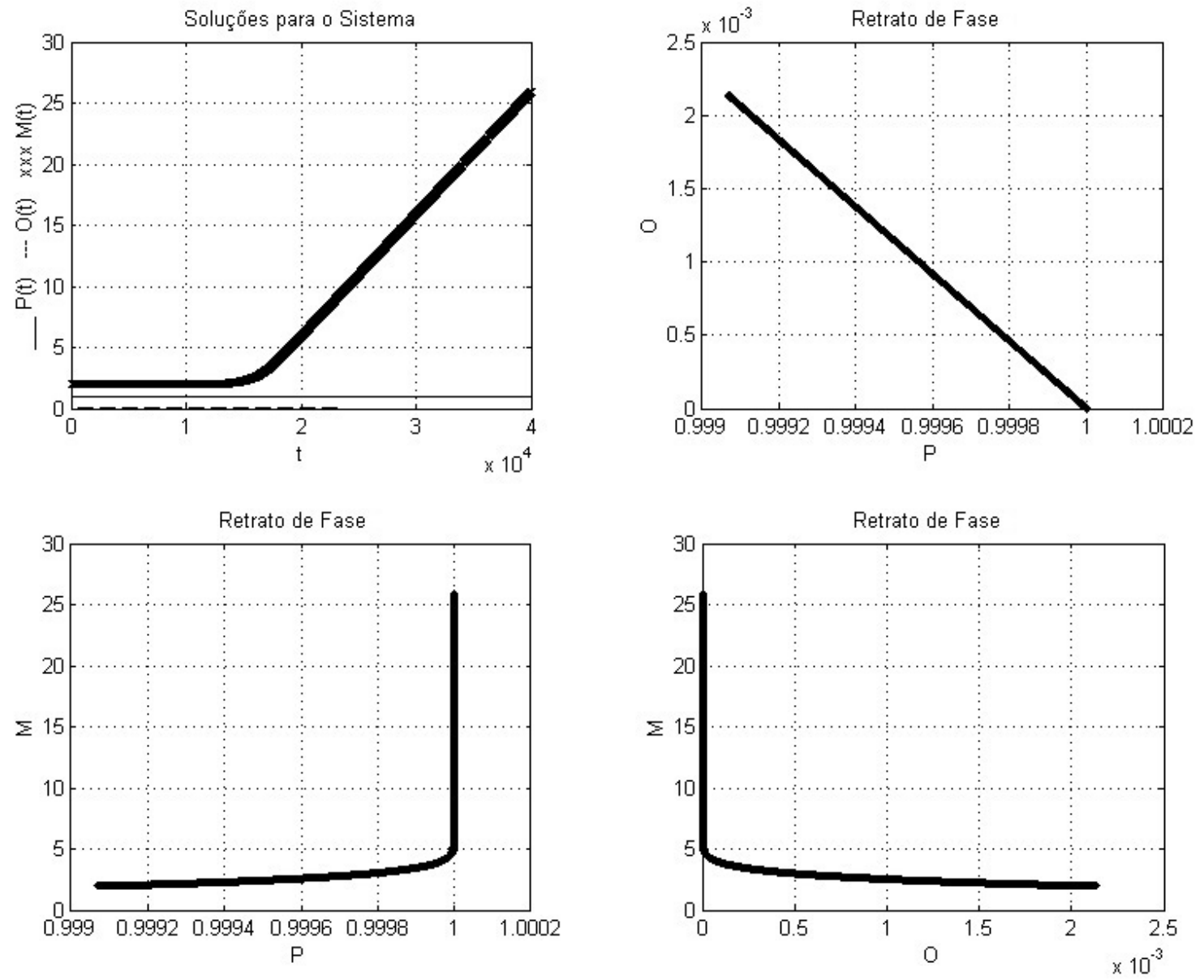

Fonte: Sergio Serino, 2016

Portanto, dado que existe não estabilidade local simultaneamente para todas variáveis, pode-se afirmar que o ponto de equilíbrio $P_{3}$ do sistema dinâmico em estudo não tem estabilidade global segundo os critérios de Routh-Hurwitz.

\subsubsection{Estabilidade do ponto de equilíbrio $P_{4}$ com o parâmetro $h$ livre}

Substituindo os valores do ponto de equilíbrio $P_{4}$ obtidos na seção 3.3 na equação (23) obtém-se a equação característica

$$
\begin{array}{r}
\frac{3 a^{2} f h r_{m}^{2}}{2 b r_{o}^{2}}+\frac{3 a^{2} f m_{o} r_{m}^{2}}{2 b r_{o}^{2}}+\frac{a^{2} f r_{m}^{2}}{b r_{o}}-\frac{a^{3} f^{2} r_{m}^{3}}{2 b^{2} r_{o}^{2} r_{p}}-\frac{a r_{m} r_{p}}{2}-\frac{3 a h^{2} r_{m} r_{p}}{2 r_{o}^{2}}-\frac{3 a h m_{o} r_{m} r_{p}}{r_{o}^{2}}-\frac{3 a m_{o}^{2} r_{m} r_{p}}{2 r_{o}^{2}}+ \\
\frac{b h r_{p}^{2}}{2 f}+\frac{b m_{o} r_{p}^{2}}{2 f}+\frac{b h^{3} r_{p}^{2}}{2 f r_{o}^{2}}+\frac{3 b h^{2} m_{o} r_{p}^{2}}{2 f r_{o}^{2}}+\frac{3 b h m_{o}^{2} r_{p}^{2}}{2 f r_{o}^{2}}+\frac{b m_{o}{ }^{2} r_{p}^{2}}{2 f r_{o}^{2}}-\frac{b h^{2} r_{p}^{2}}{f r_{o}}-\frac{2 b h m_{o} r_{p}^{2}}{f r_{o}}-\frac{b m_{o}{ }^{2} r_{p}^{2}}{f r_{o}}+\frac{a h r_{m} \Delta}{b r_{o}^{2}}+ \\
\frac{a m_{o} r_{m} \Delta}{b r_{o}^{2}}+\frac{a r_{m} \Delta}{2 b r_{o}}-\frac{a^{2} f r_{m}^{2} \Delta}{2 b^{2} r_{o}^{2} r_{p}}-\frac{h^{2} r_{p} \Delta}{2 f r_{o}^{2}}-\frac{h m_{o} r_{p} \Delta}{f r_{o}^{2}}-\frac{m_{o}^{2} r_{p} \Delta}{2 f r_{o}^{2}}+\frac{h r_{p} \Delta}{2 f r_{o}}+\frac{m_{o} r_{p} \Delta}{2 f r_{o}}-\frac{a r_{m} \lambda}{2}+\frac{a f r_{m} \lambda}{2 b}-\frac{a^{2} f r_{m}^{2} \lambda}{2 b r_{o}^{2}}-
\end{array}
$$


$\frac{a h r_{m} \lambda}{2 r_{o}}+\frac{a f h r_{m} \lambda}{b r_{o}}-\frac{a m_{o} r_{m} \lambda}{2 r_{o}}+\frac{a f m_{o} r_{m} \lambda}{b r_{o}}+\frac{a^{2} f r_{m}^{2} \lambda}{2 b r_{o} r_{p}}-\frac{a^{2} f^{2} r_{m}^{2} \lambda}{2 b^{2} r_{o} r_{p}}+\frac{h r_{p} \lambda}{2}+\frac{m_{o} r_{p} \lambda}{2}+\frac{a h r_{m} r_{p} \lambda}{r_{o}^{2}}+\frac{a m_{o} r_{m} r_{p} \lambda}{r_{o}^{2}}-$ $\frac{h^{2} r_{p} \lambda}{2 r_{o}}-\frac{h m_{o} r_{p} \lambda}{r_{o}}-\frac{m_{o}^{2} r_{p} \lambda}{2 r_{o}}+\frac{a r_{m} r_{p} \lambda}{2 r_{o}}-\frac{b h^{2} r_{p}^{2} \lambda}{2 f r_{o}^{2}}-\frac{b h m_{o} r_{p}{ }^{2} \lambda}{f r_{o}{ }^{2}}-\frac{b m_{o}{ }^{2} r_{p}^{2} \lambda}{2 f r_{o}{ }^{2}}+\frac{b h r_{p}{ }^{2} \lambda}{2 f r_{o}}+\frac{b m_{o} r_{p}{ }^{2} \lambda}{2 f r_{o}}-\frac{a r_{m} \Delta \lambda}{2 b r_{o}{ }^{2}}+$ $\frac{h \Delta \lambda}{2 b r_{o}}+\frac{m_{o} \Delta \lambda}{2 b r_{o}}+\frac{a r_{m} \Delta \lambda}{2 b r_{o} r_{p}}-\frac{a f r_{m} \Delta \lambda}{2 b^{2} r_{o} r_{p}}+\frac{h r_{p} \Delta \lambda}{2 f r_{o}^{2}}+\frac{m_{o} r_{p} \Delta \lambda}{2 f r_{o}^{2}}+\frac{a r_{m} \lambda^{2}}{2 r_{o}}-\frac{a f r_{m} \lambda^{2}}{2 b r_{o}}+\frac{r_{p} \lambda^{2}}{2}+\frac{b r_{p} \lambda^{2}}{2 f}+\frac{h r_{p} \lambda^{2}}{2 r_{o}}-$ $\frac{b h r_{p} \lambda^{2}}{2 f r_{o}}+\frac{m_{o} r_{p} \lambda^{2}}{2 r_{o}}-\frac{b m_{o} r_{p} \lambda^{2}}{2 f r_{o}}-\frac{\Delta \lambda^{2}}{2 b r_{o}}+\frac{\Delta \lambda^{2}}{2 f r_{o}}+\lambda^{3}=0$,

onde

$$
\Delta=\sqrt{4 b^{2}\left(-h-m_{o}\right) r_{o} r_{p}^{2}+\left(a f r_{m}-b h r_{p}-b m_{o} r_{p}-b r_{o} r_{p}\right)^{2}}
$$

Ao se inserir os valores numéricos dos parâmetros não livres na equação (40), extraem-se os termos $a_{1}, a_{2}$ e $a_{3}$ que compõe os elementos que formam a matriz de Hurwitz $\left(H_{3}\right)$, conforme citado na seção 3.2 :

$$
\begin{gathered}
a_{1}=0.55 \\
a_{2}=0.0139617+2.15692 \Delta+2.50651 h+431.527 \Delta h-56.9616 h^{2}, \\
a_{3}=0.000622405+0.0963177 \Delta+0.0991188 h+17.2911 \Delta h \\
-4.8241 h^{2}-392.947 \Delta h^{2}+51.869 h^{3},
\end{gathered}
$$

onde

$$
\Delta=\sqrt{0.00376358(-0.005-h)+(-0.00778776-0.132 h)^{2}}
$$

Segundo os critérios de Routh-Hurwitz, para garantir a estabilidade deste ponto de equilíbrio se faz necessário atender simultaneamente as seguintes condições:

$$
a_{1}>0, \quad a_{3}>0, \quad a_{1} a_{2}>a_{3} .
$$

Observe o estudo das condições para a aplicação dos critérios de Routh-Hurwitz no ponto de equilíbrio $P_{4}$ em função da evolução do parâmetro livre $h$ representados nas figuras 44 e 45 , respectivamente. 
Figura 44 - Condição $a_{3}$ para o ponto de equilíbrio $P_{4}$

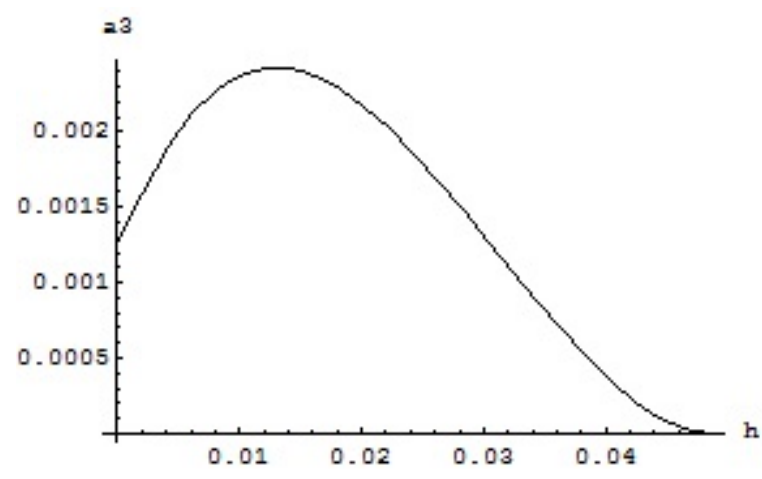

Fonte: Sergio Serino, 2016

Figura 45 - Condição $a_{1} a_{2}$ para o ponto de equilíbrio $P_{4}$

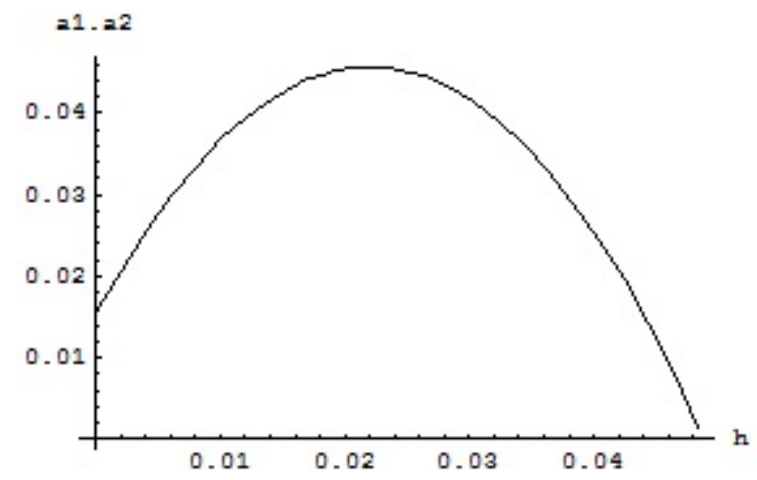

Fonte: Sergio Serino, 2016

No resumo ilustrado pela figura 46, pode-se observar o surgimento de uma região de estabilidade, na faixa de intervalo para o parâmetro livre $h$ em que $0<h<0.048$, onde estão satisfeitas todas as condições dos critérios de Routh-Hurwitz simultaneamente (V). Para valores acima de 0.048 , o comportamento das soluções para este sistema dinâmico se tornam não estáveis novamente, tal como demonstrado nos demais pontos equilíbrios já estudados. Esta transição, situada em torno do valor de 0.048 para $h$ mostra uma mudança no regime de comportamento do sistema dinâmico, um regime shift, tal como tratado na seção 1.2 , evidenciando uma transição de fase que ocorre quando o valor do parâmetro $h$ excede valor de 0.048 na vizinhança de $P_{4}$. 
Figura 46 - Estudo de sinal para os critérios de Routh-Hurwitz no ponto de equilíbrio $P_{4}$

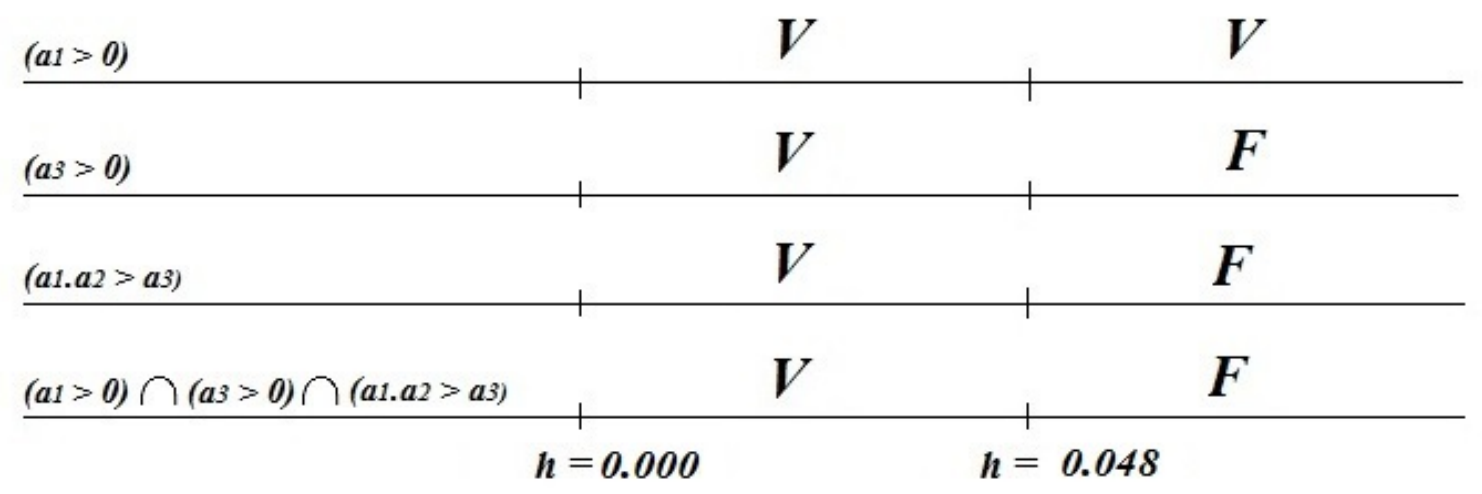

Fonte: Sergio Serino, 2016

As figuras 474849 ilustram as simulações dos comportamentos de estabilidade ao se aplicar as perturbações em torno de cada uma das variáveis na vizinhança de $P_{4}$, note que o valor da pertubação $(\delta)$ foi exagerado propositalmente para evidenciar a robustez deste sistema dinâmico em torno deste ponto de equilíbrio com estabilidade. 
Figura 47 - Soluções para o sistema dinâmico na vizinhança do ponto de equilíbrio $P_{4}$ perturbado na variável $P(t), P_{4}=\left(P^{*}-\delta, O^{*}, M^{*}\right), \delta=5 \cdot 10^{-1}, h=0.047$
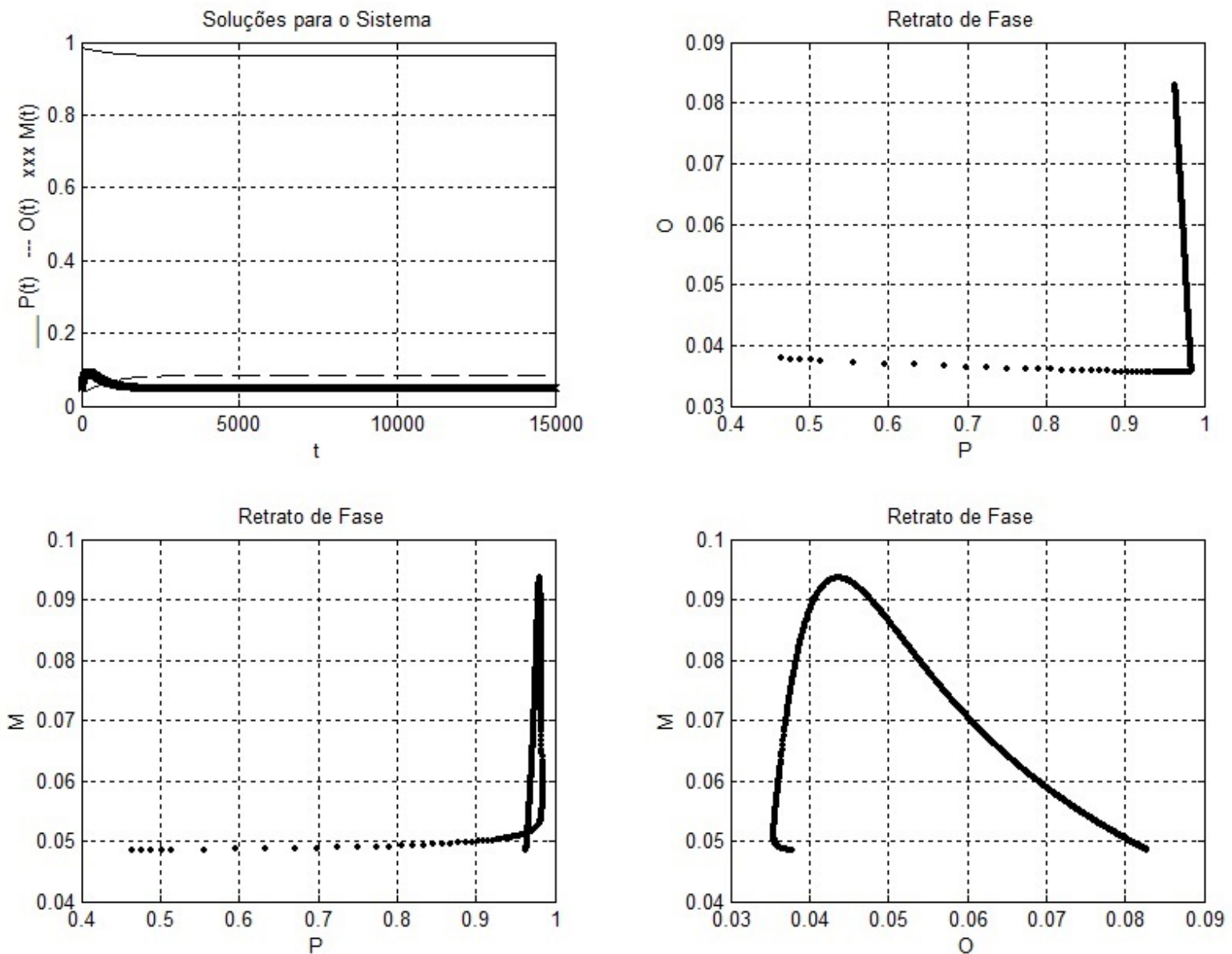

Fonte: Sergio Serino, 2016 
Figura 48 - Soluções para o sistema dinâmico na vizinhança do ponto de equilíbrio $P_{4}$ perturbado na variável $O(t), P_{4}=\left(P^{*}, O^{*}+\delta, M^{*}\right), \delta=5 \cdot 10^{-1}, h=0.047$
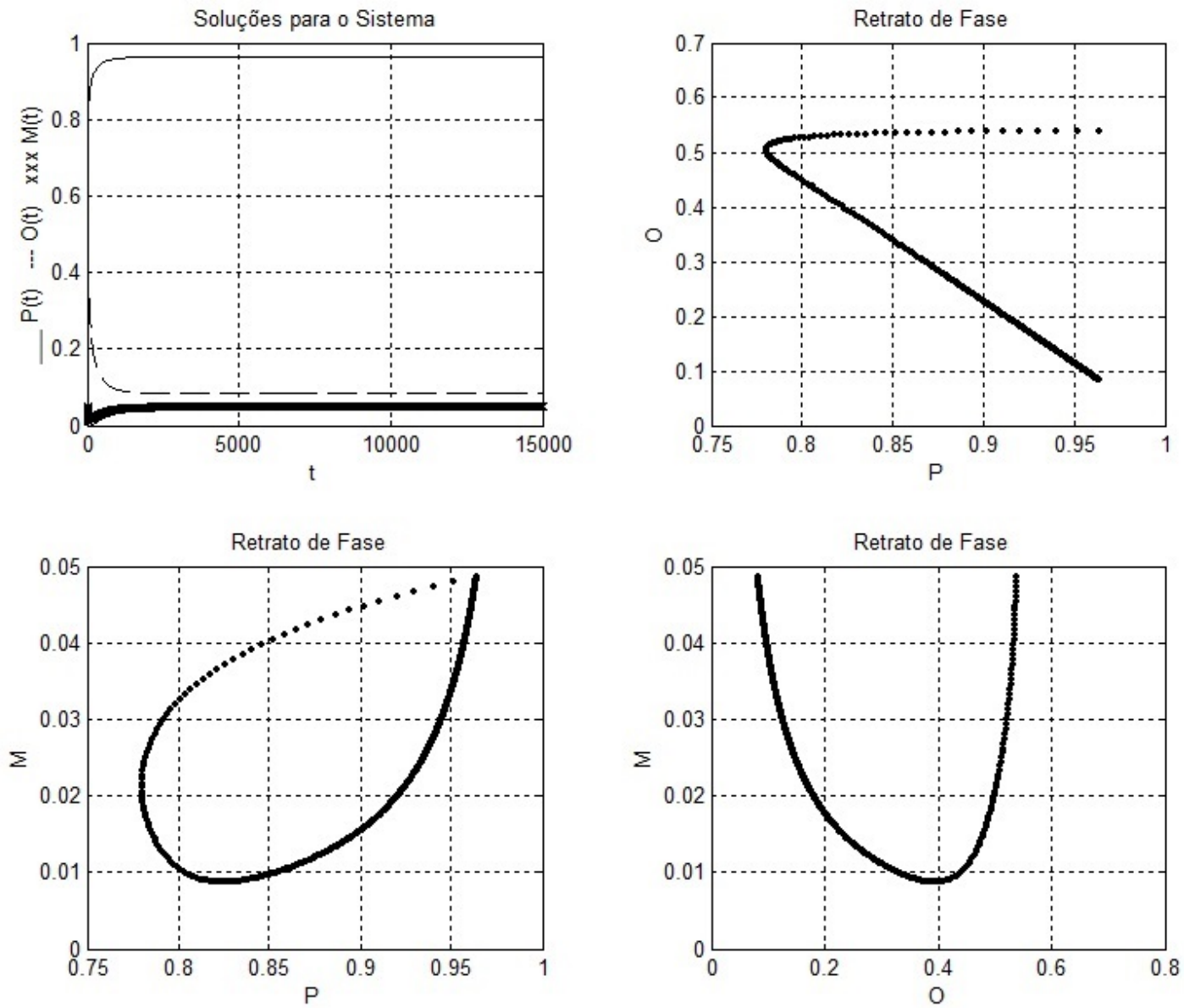

Fonte: Sergio Serino, 2016 
Figura 49 - Soluções para o sistema dinâmico na vizinhança do ponto de equilíbrio $P_{4}$ perturbado na variável $M(t), P_{4}=\left(P^{*}, O^{*}, M^{*}+\delta\right), \delta=5 \cdot 10^{-1}, h=0.047$
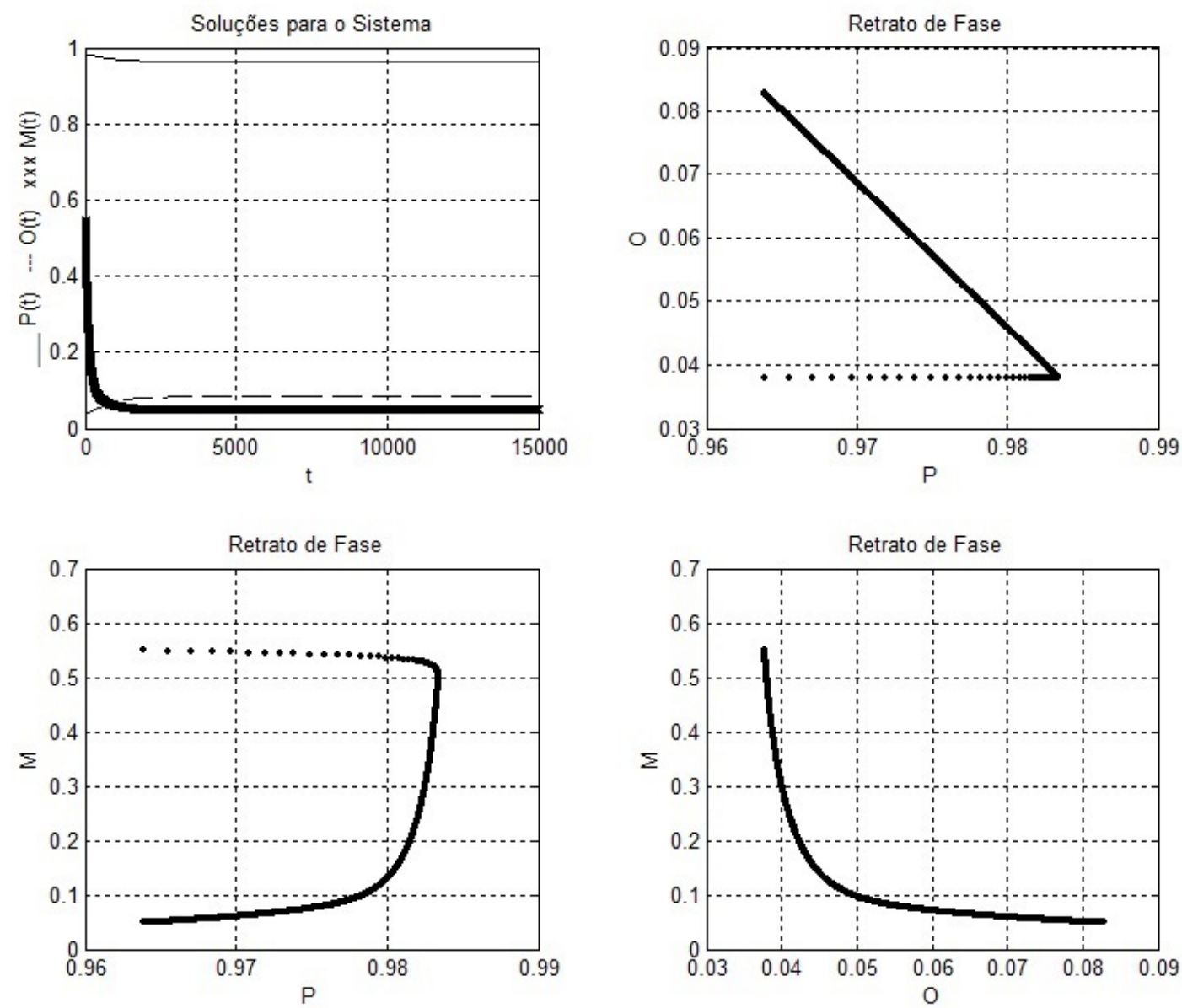

Fonte: Sergio Serino, 2016

A seguir nas figuras 50, 51 e 52 se repete a análise anterior para um valor do parâmetro livre $h$ imediatamente superior a 0.048, o que demostra a passagem do sistema dinâmico para o comportamento de não estabilidade. 
Figura 50 - Soluções para o sistema dinâmico na vizinhança do ponto de equilíbrio $P_{4}$ perturbado na variável $P(t), P_{4}=\left(P^{*}-\delta, O^{*}, M^{*}\right), \delta=1 \cdot 10^{-6}, h=0.049$
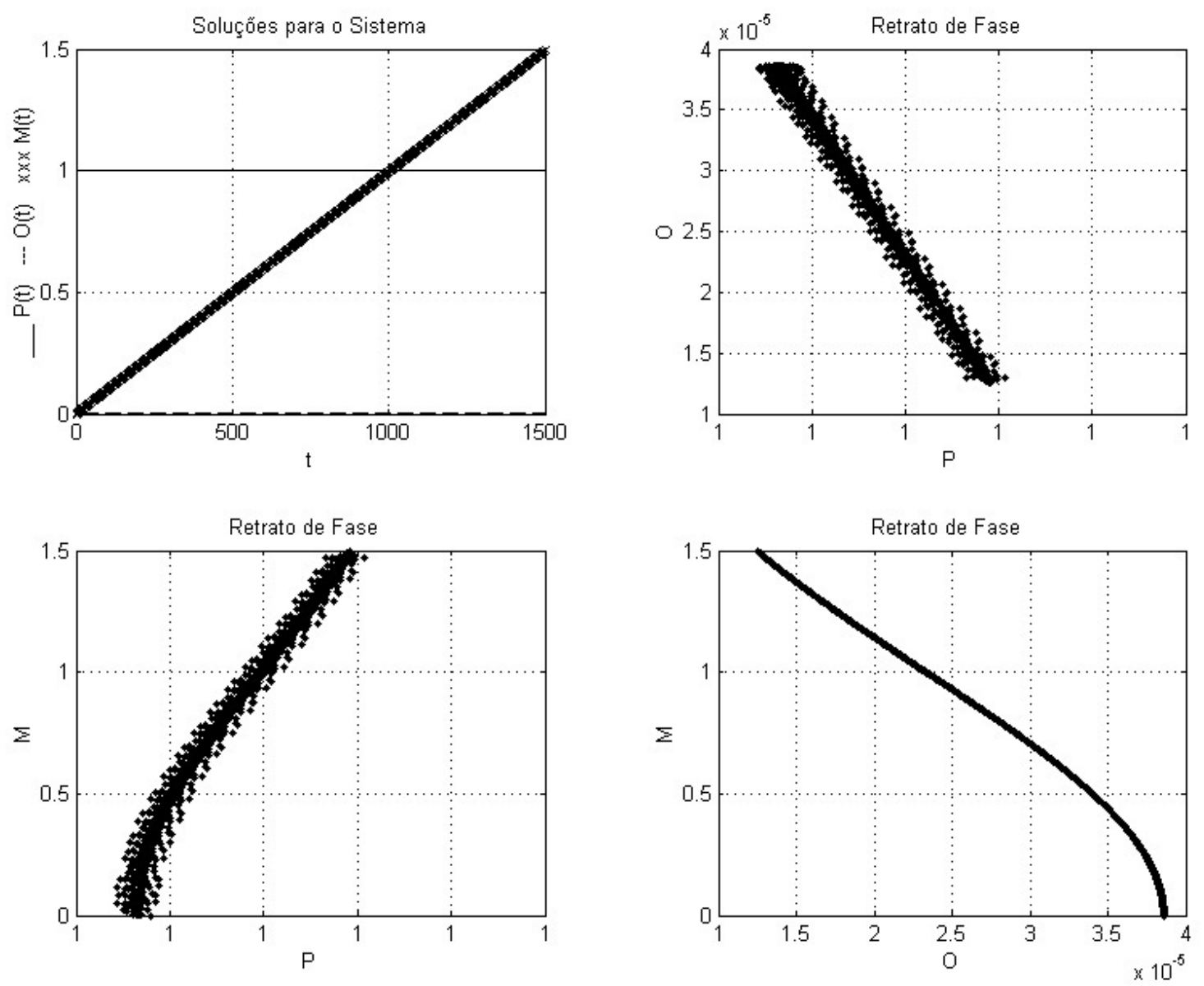

Fonte: Sergio Serino, 2016 
Figura 51 - Soluções para o sistema dinâmico na vizinhança do ponto de equilíbrio $P_{4}$ perturbado na variável $O(t), P_{4}=\left(P^{*}, O^{*}+\delta, M^{*}\right), \delta=1 \cdot 10^{-6}, h=0.049$
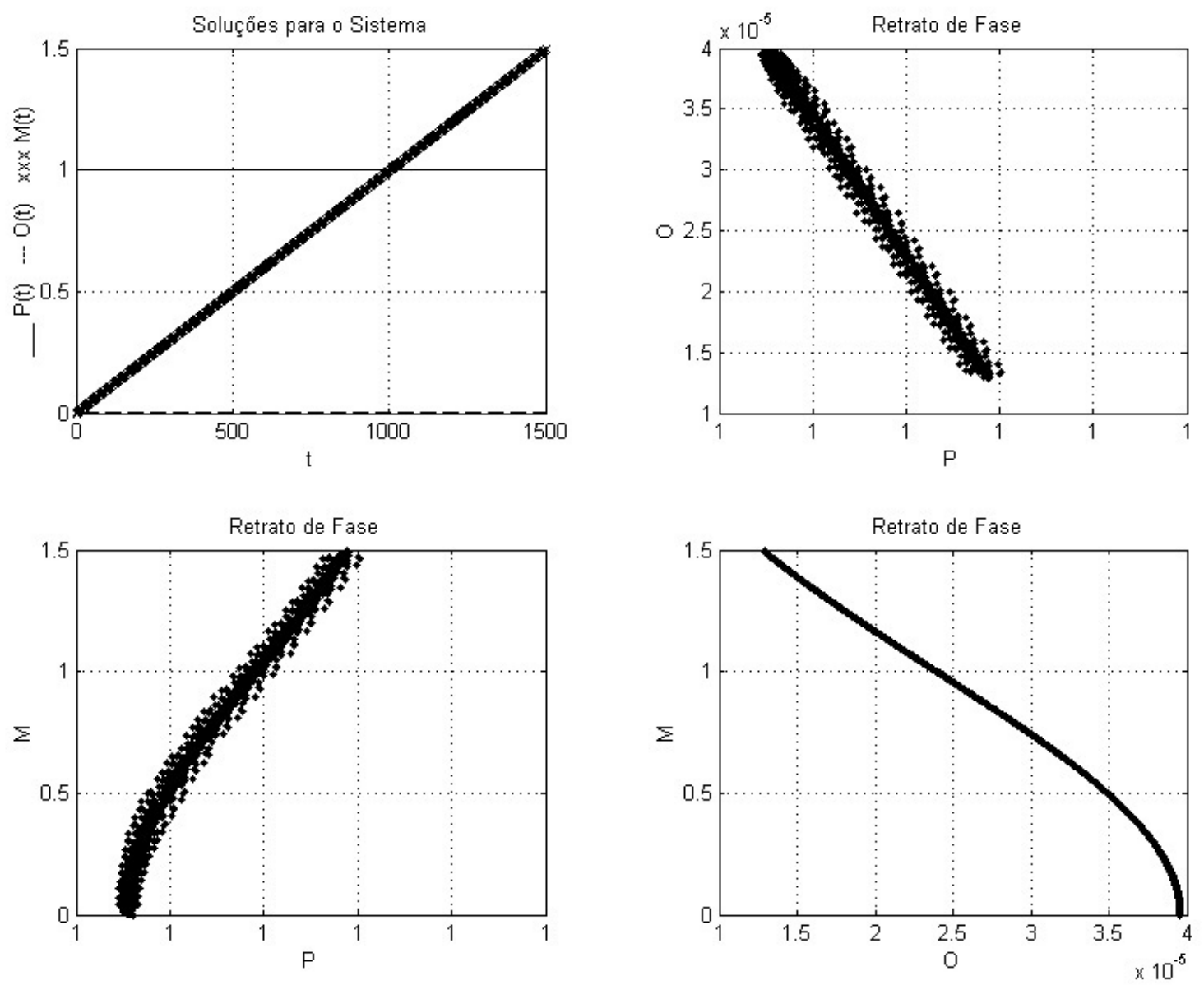

Fonte: Sergio Serino, 2016 
Figura 52 - Soluções para o sistema dinâmico na vizinhança do ponto de equilíbrio $P_{4}$ perturbado na variável $M(t), P_{4}=\left(P^{*}, O^{*}, M^{*}+\delta\right), \delta=1 \cdot 10^{-6}, h=0.049$
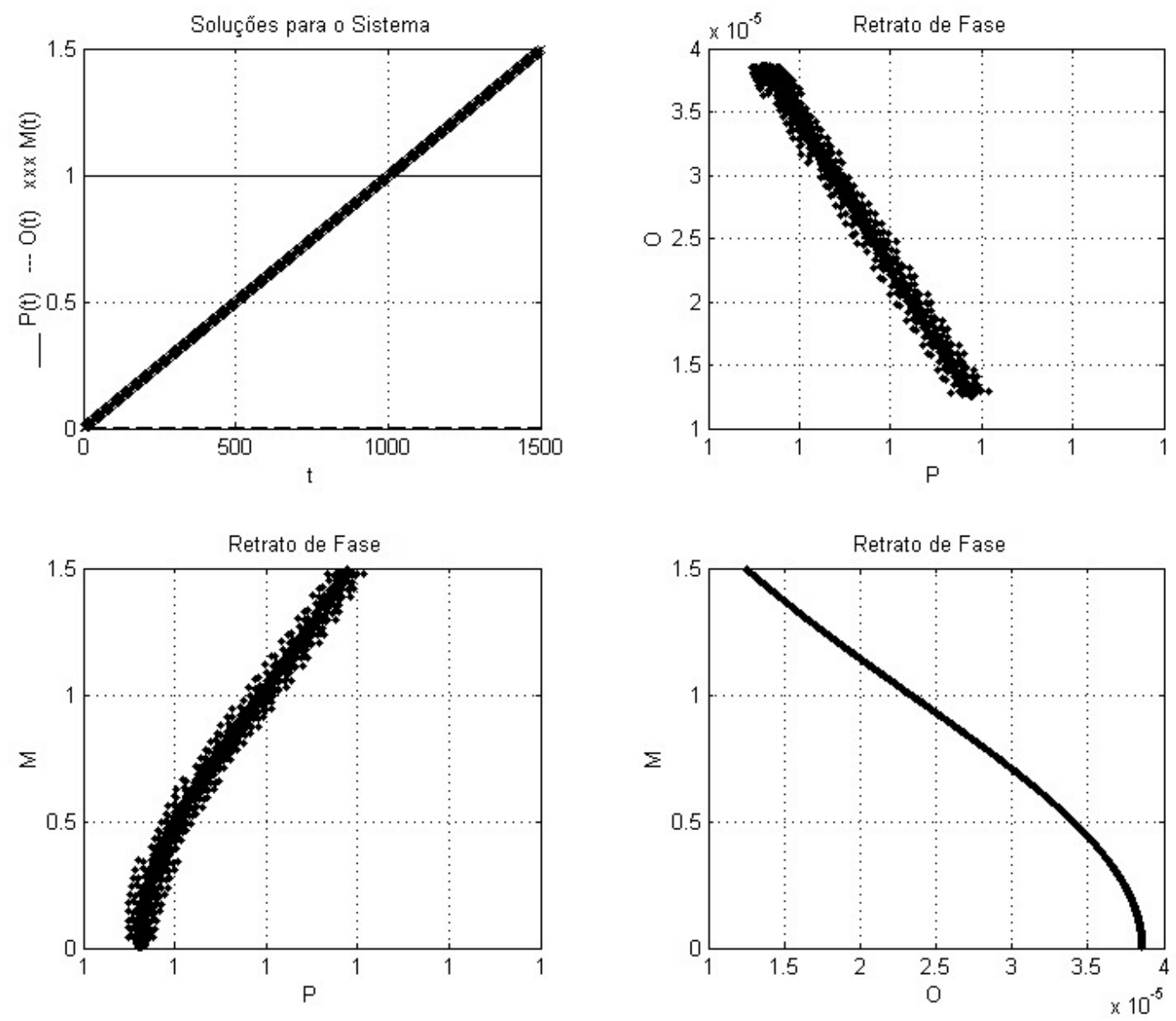

Fonte: Sergio Serino, 2016

Na figura 53 tem-se o resumo geral do resultado da aplicação das condições dos critérios de Roth-Hurwitz para cada um dos pontos de equilíbrio do sistema dinâmico em função do parâmetro $h$. 
Figura 53 - Resumo geral da classificação dos pontos de equilíbrio em função do parâmetro livre $h$

\begin{tabular}{cccc}
$P_{1}$ & não estável & não estável \\
\hline$P_{2}$ & não estável & não estável \\
\hline$P_{3}$ & não estável & não estável \\
\hline$P_{4}$ & estável & não estável \\
\hline & & $n=0.048$
\end{tabular}

Fonte: Sergio Serino, 2016

Portanto, com base neste estudo para um único parâmetro livre $(h)$, configurado conforme valores numéricos descritos na seção 3.3, pode-se concluir que a coleta de ostras para consumo humano tal como indica o parâmetro $h$, não deve exceder o valor diário de $4.8 \%$ do total de sua população, pois provocaria a desestabilização do sistema de cultura das ostras e a perda do processo de biorremediação, causando prejuízos, entre eles, danos ambientais.

\subsubsection{Estabilidade do ponto de equilíbrio $P_{4}$ com dois parâmetros livres $\left(h\right.$ e $\left.r_{p}\right)$}

A eutrofização de ambientes aquáticos é um fator externo e independente do sistema que provoca o aumento da taxa de crescimento do fitoplâncton, o que de certa maneira é um alerta do aumento da degradação ambiental em um ecossistema, para descrever esta influência, se fará a seguir, uma extensão da análise do ponto de equilíbrio $P_{4}$ para se avaliar qual a relação entre os parâmetros $h$ e $r_{p}$ que ainda mantém a estabilidade neste ponto.

Ao se inserir o valor dos parâmetros na equação (23) com exceção de $h$ e de $r_{p}$ se obtém os termos para a avaliação pelos critérios de Routh-Hurwitz:

$$
\begin{gathered}
a_{1}=r_{p} \lambda^{2} \\
a_{2}=\left(4.6124810^{-8}\right) \lambda+9.2592610^{-6} h \lambda+0.00227949 r_{p} \lambda+0.40775 h r_{p} \lambda-9.25926 h^{2} r_{p} \lambda+ \\
0.0420096 r_{p}{ }^{2} \lambda+7.54458 h r_{p}{ }^{2} \lambda-171.468 h^{2} r_{p}{ }^{2} \lambda+0.192187 \Delta \lambda+38.5802 h \Delta \lambda
\end{gathered}
$$




$$
a_{3}=2.1090510^{-11}+5.1440310^{-10} h-5.128610^{-7} r_{p}-5.1440310^{-6} h r_{p}-0.000514403 h^{2} r_{p}+
$$

$0.00205847 r_{p}{ }^{2}+0.327675 h r_{p}{ }^{2}-15.9465 h^{2} r_{p}{ }^{2}+171.468 h^{3} r_{p}{ }^{2}+0.0000457247 \Delta+0.0014289 h \Delta-$ $\frac{7.1444910^{-10} \Delta}{r_{p}}+0.17504 r_{p} \Delta+31.4358 h r_{p} \Delta-714.449 h^{2} r_{p} \Delta$

onde

$$
\Delta=\sqrt{0.0124416(-0.005-h) r_{p}^{2}+\left(2.410^{-7}-0.01416 r_{p}-0.24 h r_{p}\right)^{2}}
$$

O próximo passo é garantir as condições necessárias que indiquem a manutenção da condição de estabilidade na vizinhança do ponto de equilíbrio $P_{4}$. Essas condições estão representadas nas regiões escuras dos gráficos ilustrados nas figuras 54, 55, 56 e 57.

Teste da condição $a_{1}>0$ :

Figura 54 - Condição $a_{1}$ para o ponto de equilíbrio $P_{4}$ com os parâmetros $h$ e $r_{p}$ livres

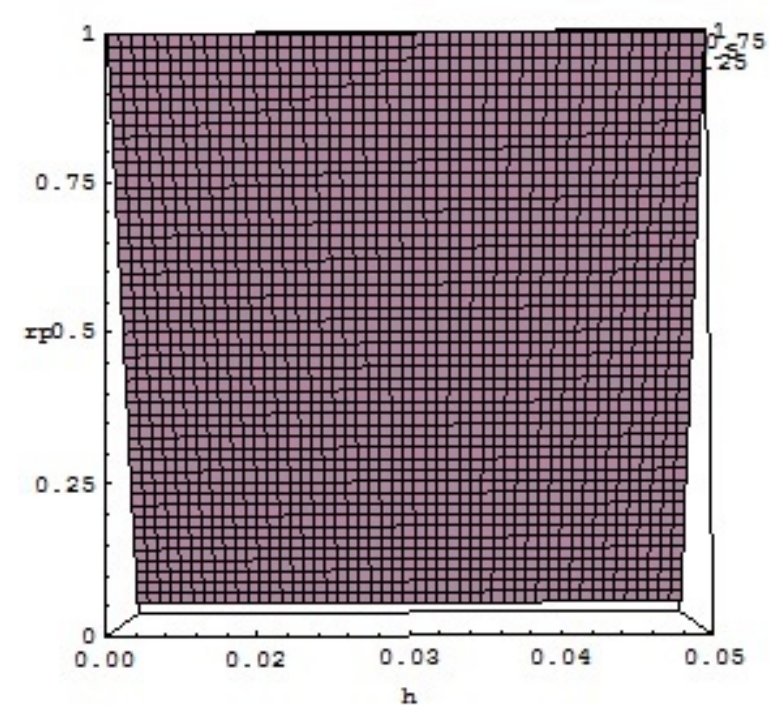

Fonte: Sergio Serino, 2016

Teste da condição $a_{3}>0$ : 
Figura 55 - Condição $a_{3}$ para o ponto de equilíbrio $P_{4}$ com os parâmetros $h$ e $r_{p}$ livres

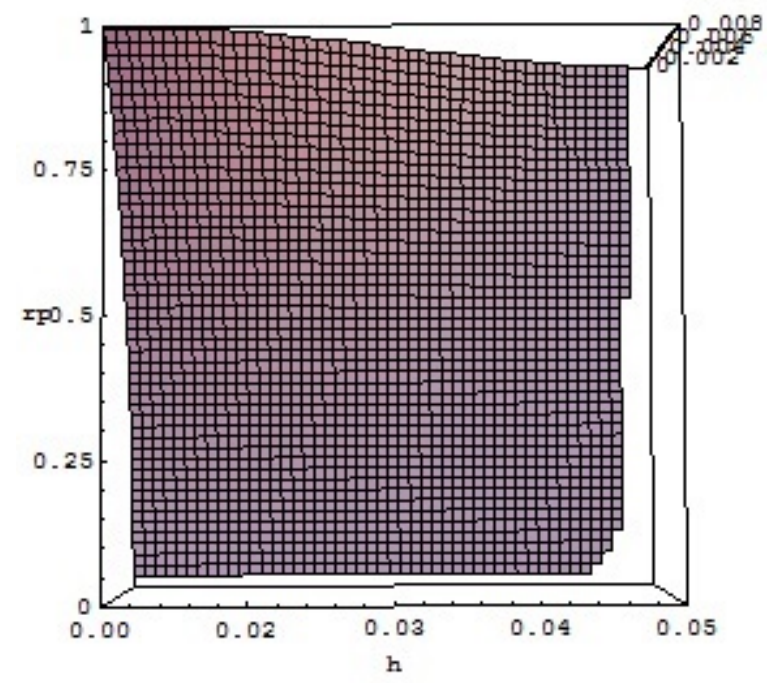

Fonte: Sergio Serino, 2016

Teste da condição $a_{1} a_{2}>a_{3}$ :

Figura 56 - Condição $a_{1} a_{2}$ para o ponto de equilíbrio $P_{4}$ com os parâmetros $h$ e $r_{p}$ livres

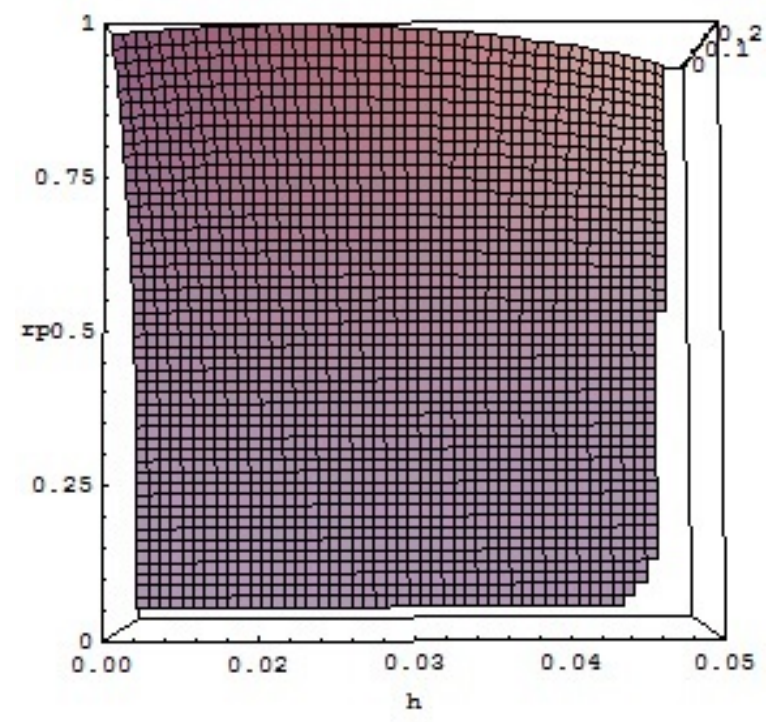

Fonte: Sergio Serino, 2016

Por fim, se vê abaixo uma parte da região onde todas as condições anteriores são atendidas $\left(\left(a_{1}>0\right) \cap\left(a_{3}>0\right) \cap\left(a_{1} a_{2}>a_{3}\right):\right.$ 
Figura 57 - Estudo de sinal para os critérios de Routh-Hurwitz no ponto de equilíbrio $P_{4}$ com os parâmetros $h$ e $r_{p}$ livres

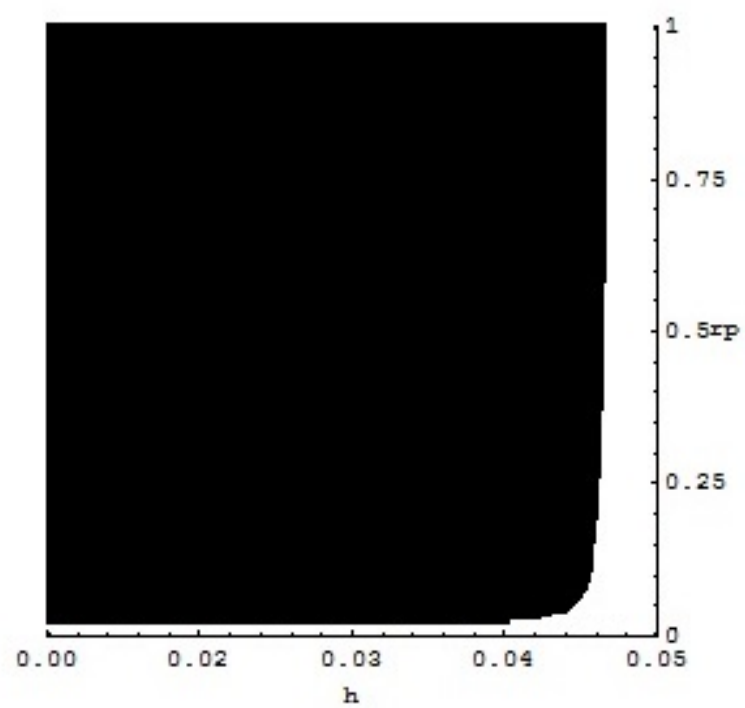

Fonte: Sergio Serino, 2016

$\mathrm{Na}$ figura 57, tem-se que cada ponto contido no interior da região escura representa um valor do parâmetro $h$ tomado no eixo horizontal e outro valor de $r_{p}$ tomado no eixo vertical que ainda mantém o sistema dinâmico em estudo com estabilidade na vizinhança do ponto de equilíbrio $P_{4}$. Note ainda, na parte clara localizada no inferior da figura, que o valor de $r_{p}$ pode começar com valores muito pequenos, porém diferentes de zero, pois em toda a região clara da figura o sistema não é estável. O formato da região escura ilustra também que a relação do parâmetro $r_{p}$ com $h$ não é linear e que há um valor máximo para $h$ situado no intervalo $(0.04<h<0.05)$. Para valores inferiores a este intervalo o sistema dinâmico praticamente não sofre influência de $r_{p}$ capaz de mudar a sua condição de estabilidade.

\subsection{Diagramas de fase em função do parâmetro livre $h$}

Nesta seção se construirá gráficos, conhecidos como diagramas de fase, para representar a condição de estabilidade das soluções do sistema proposto em relação a variação de um único parâmero livre, $h$, feito separadamente para cada variável do sistema (MONTEIRO, 2011). Os diagramas a seguir ilustram regiões de estabilidade, em que o comportamento de uma determinada variável do sistema, após um determinado tempo, se estabiliza em algum ponto do espaço de fase, região representada no diagrama por uma linha contínua, e regiões de não 
estabilidade, sendo estas representadas por uma linha pontilhada, em que não existe uma solução estável para a variável do sistema em estudo, não importando o valor do tempo decorrido.

A figura 58 mostra o diagrama de fase para os valores de convergência da solução do sistema dinâmico proposto para a variável $P(t)$ em função do parâmetro $h$ após decorrido um determinado valor de $t$ necessário a convergência da solução. Note, que a linha é contínua independentemente do valor de $h$. Cada ponto desta linha contínua, para um valor de $h>0$, representa um ponto no espaço de fase para o qual, em função de um determinado valor $h$, a variável $P(t)$ converge.

Figura 58 - Diagrama de fase para variável $P$ em função parâmetro $h$

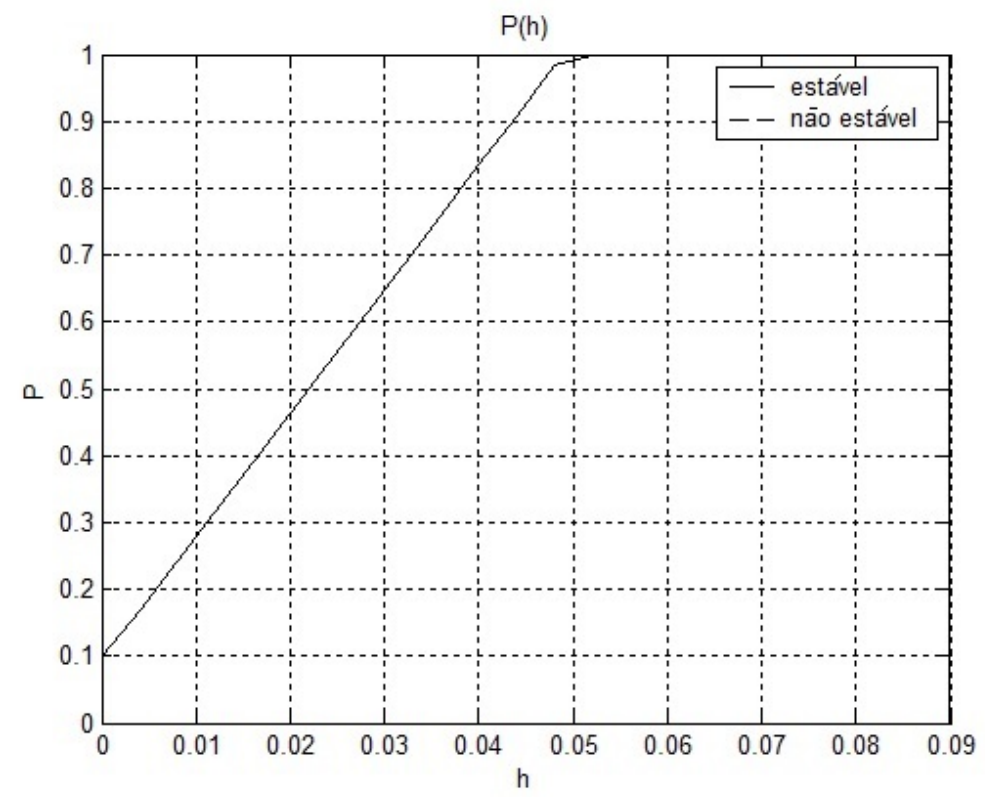

Fonte: Sergio Serino, 2016

De maneira semelhante, se apresenta na figura 59 o diagrama de fase para a variável $O(t)$. Note, que tal como o diagrama anterior, esta variável do sistema é estável independentemente do valor do parâmetro $h$. 
Figura 59 - Diagrama de fase para a variável $O$ em função parâmetro $h$

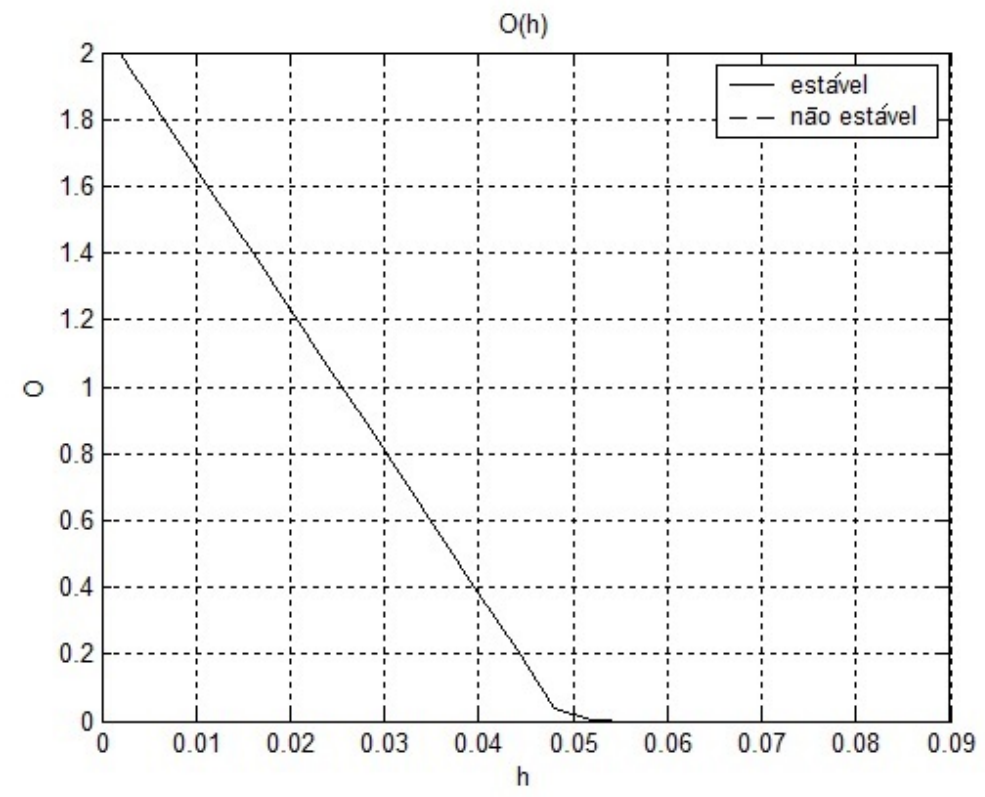

Fonte: Sergio Serino, 2016

No gráfico a seguir, ilustrado pela figura 60 , se vê o diagrama de fase da variável de sistema $M(t)$, que diferentemente das anteriores, apresenta um padrão de comportamento estável para valores de $0<h<0.048$ e não estável a partir do valor crítico de 0.048 , o que denota a ocorrência de uma mudança no padrão de comportamento das soluções para este sistema, uma vez que a variável $M(t)$ não possui mais a condição de estabilidade quando se tem $h>0.048$.

Figura 60 - Diagrama de fase para variável $M$ em função parâmetro $h$

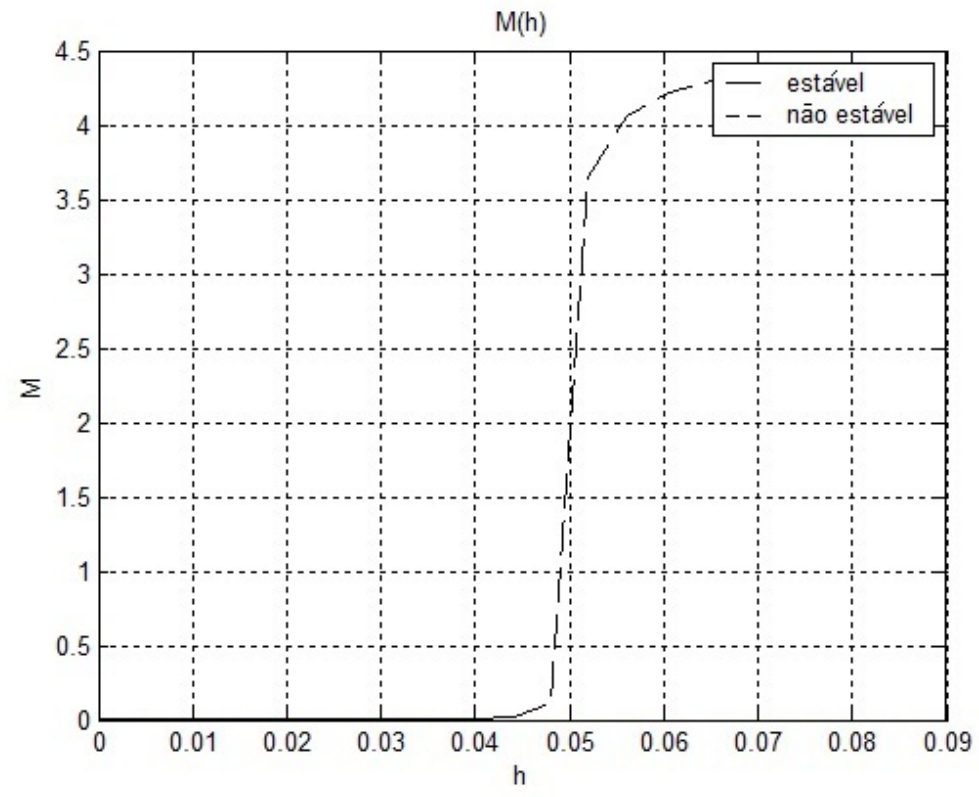

Fonte: Sergio Serino, 2016 


\section{Conclusões e perspectivas}

Construimos um sistema dinâmico capaz de representar as principais relações entre duas populações (ostras e fitoplâncton) e seu meio ambiente. $\mathrm{O}$ conjunto de equações diferenciais que modelam a interação das populações de ostras e de fitoplâncton com a matéria suspensa na água foi capaz de representar relativamente bem o comportamento de sistemas reais (conforme os artigos de cunho ecológico mencionados neste trabalho). Quanto maior a quantidade de fitoplâncton na água, maior a quantidade de matéria suspensa, diminuindo a passagem dos raios luminosos, o que impede que a vegetação localizada mais ao fundo de estuários realize fotossíntese. Isso torna a água menos oxigenada e causa o processo de anoxia, que para um determinado conjunto de parâmetros que definem o sistema pode realimentar o ecossistema até seu ponto de colapso, dizimando a população de ostras.

Este estudo localizou os pontos de equilíbrio do sistema dinâmico proposto e os classificou, encontrando um ponto com uma região de estabilidade que indicou uma quantidade relativa da população de ostras que poderia ser coletada com segurança, sem comprometer o sucesso da cultura nem a qualidade do meio ambiente.

Nesta dissertação demos ênfase à explanação e aplicação prática do método de QuirkRuppert e dos critérios de Routh-Hurwitz na classificação da estabilidade nos pontos de equilíbrio do sistema. Explorou-se o comportamento das soluções numéricas do sistema dinâmico na direção de cada variável através de simulações de suas trajetórias para investigar a estabilidade do sistema. A análise realizada com valores realísticos de parâmetros demonstrou um ponto claro de estabilidade em relação ao parâmetro $h$ que representa a coleta diária de ostras, que ficou limitado a cerca de $4.8 \%$ da sua população. A partir deste valor a análise do sistema indica que ele se torna instável. Isso demonstra que em torno desse valor há uma mudança de regime, um ponto de virada, em que o sistema transita da estabilidade para a instabilidade, ficando clara a transição de fase que o sistema tem devido à sua complexidade.

Por último, ampliou-se a análise de estabilidade para dois parâmetros livres, de modo a relacionar o parâmetro que representa a coleta de ostras, $h$, com o crescimento da população de fitoplâncton, que poderia ter por causa externa um possível processo de eutrofização, representado por um aumento parâmetro $r_{p}$. O resultado obtido desta relação é expresso na forma de um gráfico bidimensional que permite avaliar a extensão da região de estabilidade e a linha de contorno que implica na transição de fase originada pela mescla desses dois parâmetros. 
Além de seu valor didático, com a explanação detalhada da aplicação dos critérios de Quirk-Ruppert e de Routh-Hurwitz na classificação de pontos de equilíbrio em sistemas dinâmicos e o detalhadamento de passagens algébricas e exemplos de representação de soluções e classificações, a principal perspectiva deste trabalho é servir de ponto de partida para modelos mais elaborados e realísticos que representem o comportamento de populações estuarinas, seus prpocessos de anoxia e os possíveis mecanismos e impactos de processos de biorremediação. A construção desses modelos em matemática aplicada, no entanto, depende de medidas em modelos vivos tanto em laboratório quanto em situações realísticas de campo, e representa um interessante desafio. 


\section{Referências $^{1}$}

BACAËR, N. A Short History of Mathematical Population Dynamics. London: Springer, 2011. Citado na página 11.

BOCCARA, N. Modeling Complex Systems. 2. ed. New York: Wiley, 2005. Citado na página 12.

BOYCE, E.; PRIMA, R. C. Elementary Differencial Equation and Boundary Value Problems. 8. ed. Danvers: Wiley, 2005. Citado na página 14.

BRAUN, M. Differencial Equations and Their Applications: An introduction to Applied Mathemathics. 3. ed. New York: Springer-Verlag, 1983. Citado na página 14.

CAPPUCCINO, N.; PRICE, P. W. Populations Dynamics: New Approaches and Synthesis. San Diego: Academic Press, 1995. Citado na página 11.

EDELSTEIN-KESHET, L. Mathematical Models in Biology. Philadelphia, PA: SIAM, 2005. Citado 8 vezes nas páginas 13, 14, 26, 28, 30, 31, 33 e 34 .

JEFFRIES, C. Qualitative stability and digraphs in model ecosystems. Ecology, v. 55, p. 1415-1419, 1974. Citado 2 vezes nas páginas 26 e 30.

LEVINS, R. Evolution in Changing Enviroments. Princeton: Princeton University Press, 1968. Citado na página 26.

LEVINS, R. Discussion paper: The qualitative analysis of partially specified systems. Annals of the New York Academy of Sciences, Blackwell Publishing Ltd., v. 231, n. 1, p. 123-138, 1974. Citado na página 26.

MAY, R. Stability and Complexity in Model Ecosystems. Princeton: Princeton University Press, 1973. Citado 2 vezes nas páginas 26 e 34.

MMA. Gerência de Biodiversidade Aquática e Recursos Pesqueiros: Panorama da conservação dos ecossistemas costeiros e marinhos no Brasil. Brasília, 2010. Citado na página 16.

MONTEIRO, L. Sistemas Dinâmicos. 3. ed. São Paulo: Livraria da Física, 2011. Citado 3 vezes nas páginas 12,14 e 74 .

PAINTING, S. J. et al. Assessing the impact of nutrient enrichment in estuaries: Susceptibility to eutrophication. : Marine Pollution Bulletin, American Association for the Advancement of Science, n. 55, p. 74-90, 2007. Citado na página 19.

PASTOR, J. Mathematical Ecology of Populations and Ecosystems. United Kingdom: Blackwell, 2008. Citado 5 vezes nas páginas 11, 13, 14, 27 e 30.

PEREIRA, A. M. L. et al. $O$ uso de ostras na biorremediação de efluentes da aquicultura. Teresina: Embrapa Meio-Norte, 2007. Citado 3 vezes nas páginas 19, 21 e 38.

PISKUNOV, N. Differential and Integral Calculus. Moscow: Peace Publishers, 1964. Citado na página 32.

1 De acordo com a Associação Brasileira de Normas Técnicas. NBR 6023. 
PRITCHARD, D. What is an estuary: physical viewpoint. IN: Lauff $G H(E d)$, Estuaries, American Association for the Advancement of Science, p. 3-5, 1967. Citado na página 16.

SCHEFFER, M. Critical Transitions in Nature and Society. Princeton: Princeton University Press, 2009. Citado 4 vezes nas páginas 16, 17, 18 e 20.

SUN, J. et al. Top-down control of spring surface phytoplankton blooms by microzooplankton in the Central Yellow Sea, China. Deep-Sea Reasearch, Zhejiang Univ., II, n. 97, p. 51-60, 2013. Citado na página 38.

VIDAL, T. F.; NETO, J. C. Impacto da estratificação térmica na qualidade da água de reservatório do semiárido. Simpósio Brasileiro de Recursos Hídricos, ABRH, 2013. Citado na página 38.

YANG, X. et al. Mechanisms and assessment of water eutrophication. Journal of Zhejiang University Science B, Zhejiang University, v. 9, n. 3, p. 197-209, 2008. Citado na página 19. 


\section{Apêndice A - Código em Matlab para solução de EDOs.}

\section{Código para solução numérica de sistema de EDOs por Runge-Kutta 45}

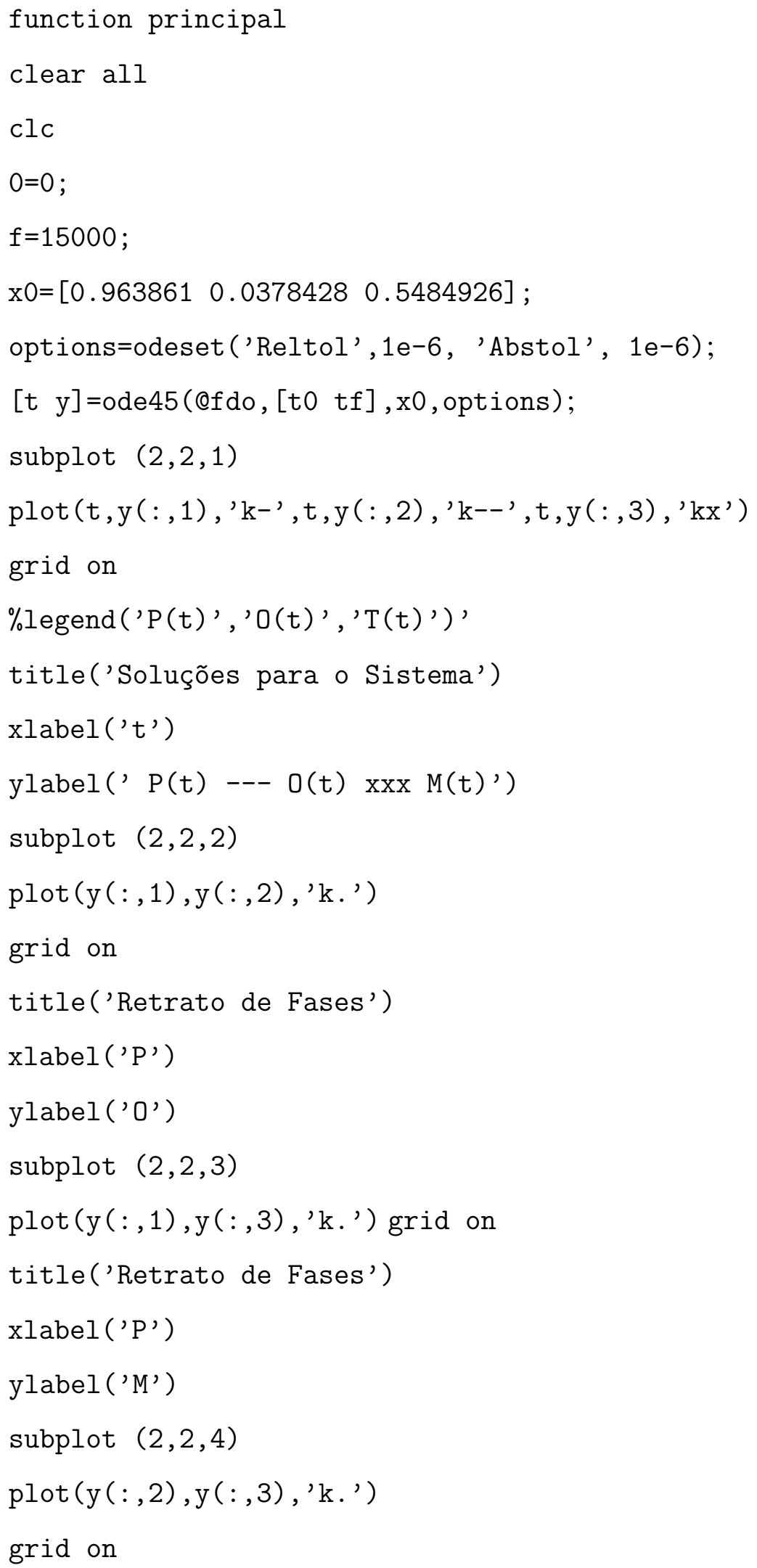


title('Retrato de Fases')

xlabel('O')

ylabel ('M')

end

function $d x=f d o(t, y)$;

$f=0.24 ; \mathrm{h}=0.047 ; \mathrm{mo}=0.005 ; \mathrm{rm}=0.001 ; \mathrm{ro}=0.054 ; \mathrm{rp}=0.55 ; \mathrm{a}=0.001 ;$

$\mathrm{b}=0.24 ; \mathrm{k}=1$;

$\mathrm{dx}=[\operatorname{rp} * \mathrm{y}(1) *(1-\mathrm{y}(1) / \mathrm{k})-\mathrm{f} * \mathrm{y}(2) * \mathrm{y}(1) ;$

$\mathrm{ro} * \mathrm{y}(1) * \mathrm{y}(2)-\mathrm{a} * \mathrm{y}(3) * \mathrm{y}(2)-\mathrm{h} * \mathrm{y}(2)-\mathrm{mo} * \mathrm{y}(2)$;

$\mathrm{rm} * \mathrm{y}(1)-\mathrm{b} * \mathrm{y}(2) * \mathrm{y}(3)]$;

end 